\title{
WestVirginiaUniversity
}

THE RESEARCH REPOSITORY @ WVU

Graduate Theses, Dissertations, and Problem Reports

2005

\section{Refinement of numerical models and parametric study of SOFC stack performance}

Andrew C. Burt

West Virginia University

Follow this and additional works at: https://researchrepository.wvu.edu/etd

\section{Recommended Citation}

Burt, Andrew C., "Refinement of numerical models and parametric study of SOFC stack performance" (2005). Graduate Theses, Dissertations, and Problem Reports. 2656.

https://researchrepository.wvu.edu/etd/2656

This Dissertation is protected by copyright and/or related rights. It has been brought to you by the The Research Repository @ WVU with permission from the rights-holder(s). You are free to use this Dissertation in any way that is permitted by the copyright and related rights legislation that applies to your use. For other uses you must obtain permission from the rights-holder(s) directly, unless additional rights are indicated by a Creative Commons license in the record and/ or on the work itself. This Dissertation has been accepted for inclusion in WVU Graduate Theses, Dissertations, and Problem Reports collection by an authorized administrator of The Research Repository @ WVU.

For more information, please contact researchrepository@mail.wvu.edu. 


\title{
REFINEMENT OF NUMERICAL MODELS AND PARAMETRIC STUDY OF SOFC STACK PERFORMANCE
}

\author{
Andrew C. Burt \\ Dissertation submitted to the \\ College of Engineering and Mineral Resources \\ at West Virginia University \\ in partial fulfillment of the requirements \\ for the degree of \\ Doctor of Philosophy \\ in \\ Mechanical Engineering \\ Ismail B. Celik, Ph.D., Chair \\ Andrei Smirnov, Ph.D., Co-Chair \\ Eric Johnson, Ph.D. \\ Gregory Thompson, Ph.D. \\ Randall Gemmen, Ph.D.
}

Department of Mechanical and Aerospace Engineering

$$
\begin{gathered}
\text { Morgantown, West Virginia } \\
2005
\end{gathered}
$$

Keywords: SOFC, solid oxide fuel cell, fuel cell stack modeling, radiation modeling, flow distribution

Copyright 2005 Andrew C. Burt 


\title{
ABSTRACT \\ REFINEMENT OF NUMERICAL MODELS AND PARAMETRIC STUDY OF SOFC STACK PERFORMANCE
}

\begin{abstract}
Andrew C. Burt
The presence of multiple air and fuel channels per fuel cell and the need to combine many cells in series result in complex steady-state temperature distributions within Solid Oxide Fuel Cell (SOFC) stacks. Flow distribution in these channels, when non-uniform, has a significant effect on cell and stack performance. Large SOFC stacks are very difficult to model using full 3-D CFD codes because of the resource requirements needed to solve for the many scales involved. Studies have shown that implementations based on Reduced Order Methods (ROM), if calibrated appropriately, can provide simulations of stacks consisting of more than 20 cells with reasonable computational effort.

A pseudo 2-D SOFC stack model capable of studying co-flow and counter-flow cell geometries was developed by solving multiple 1-D SOFC single cell models in parallel on a Beowulf cluster. In order to study cross-flow geometries a novel Multi-Component Multi-Physics (MCMP) scheme was instantiated to produce a Reduced Order 3-D Fuel Cell Model. A C++ implementation of the MCMP scheme developed in this study utilized geometry, control volume, component, and model structures allowing each physical model to be solved only for those components for which it is relevant. Channel flow dynamics were solved using a 1-D flow model to reduce computational effort.

A parametric study was conducted to study the influence of mass flow distribution, radiation, and stack size on fuel cell stack performance. Using the pseudo 2-D planar SOFC stack model with stacks of various sizes from 2 to 40 cells it was shown that, with adiabatic wall conditions, the asymmetry of the individual cell can produce a temperature distribution where high and low temperatures are found in the top and bottom cells, respectively. Heat transfer mechanisms such as radiation were found to affect the reduction of the temperature gradient near the top and bottom cell. Results from the reduced order 3-D fuel cell model showed that greater thermal gradients can be observed in the cross-flow geometry than in the co-flow geometry.
\end{abstract}




\section{ACKNOWLEDGEMENTS}

This work would not have been possible if not for the help of many. I would like to specifically mention a few names in appreciation of their significant contributions and assistance. First I would like to thank my wife Sonja for her unconditional love and emotional support. I would also like to mention the great aid she provided by working to help financially support our family and later for her willingness to become a homemaker in order to best care for our young daughter Kaylee. I would also like to thank my family and my wife's family for their support which came in so many forms during the years I spent at the University.

I am very thankful for the direction and guidance provided by my Advisor Dr. Ismail Celik without whom this work would never have come to fruit. His educated eye saw the potential in me and this work. I would also like to thank Dr. Celik for his incredible patience and council during the many times when progress was coming slowly.

I appreciate the members of my committee who took the time from their very busy schedules to assist me. I would especially like to thank Dr. Randall Gemmen who made this research possible by developing a 1-D fuel cell model which was the basis for so much of my work. There are also many at the National Energy Technology Laboratory who I might not be able to mention by name but were very instrumental in providing the financial support of this project and in allowing the use of NETL resources for this research. I would also like to thank Dr. Andrei Smirnov who gave so much assistance with the development of the Reduced Order 3-D Fuel Cell Model and the MCMP scheme. His help debugging is very much appreciated.

Last but certainly not least I would like to thank the members of the Computational Fluid Dynamics and Applied Multi-Physics Center. It was a pleasure to share work space with so many friends. Thank you all! 


\section{TABLE OF CONTENTS}

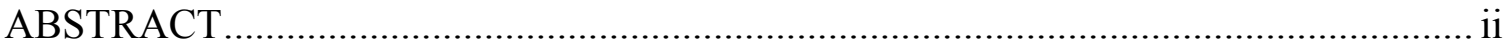

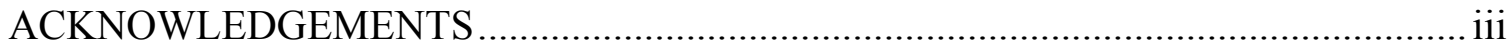

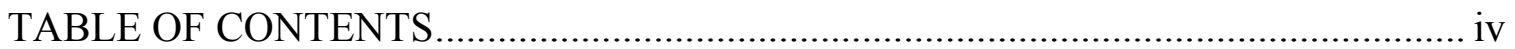

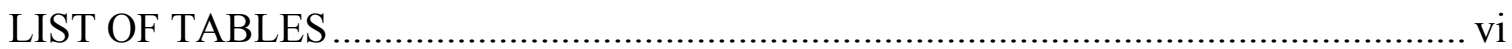

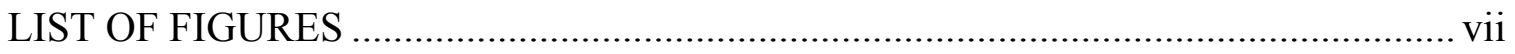

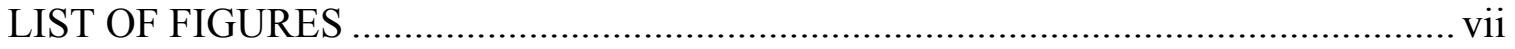

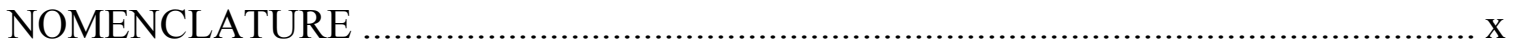

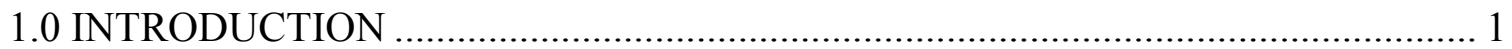

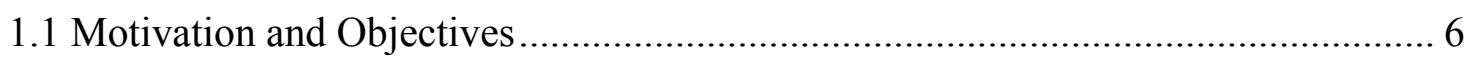

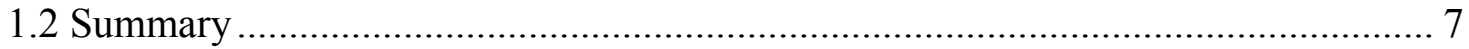

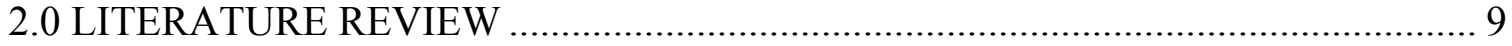

2.1 Overview of Solid Oxide Fuel Cells .............................................................. 9

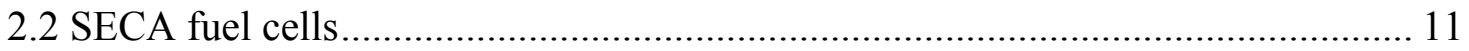

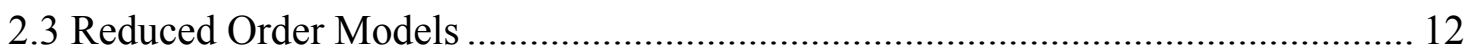

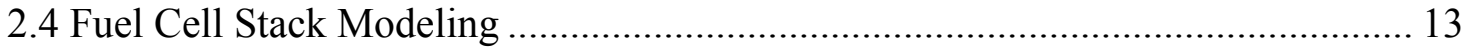

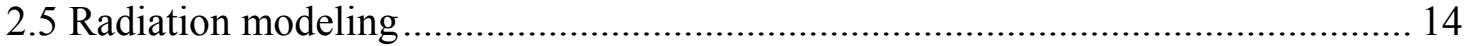

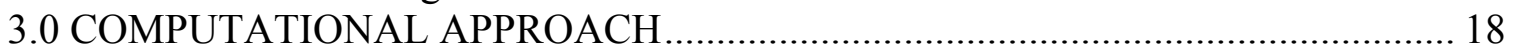

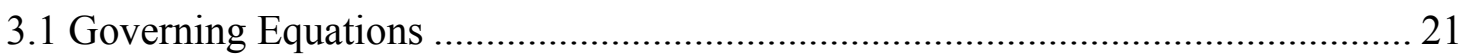

3.2 Convective and Radiative Heat Transfer ............................................................. 25

3.3 Determination of Shape Factor ………………........................................... 28

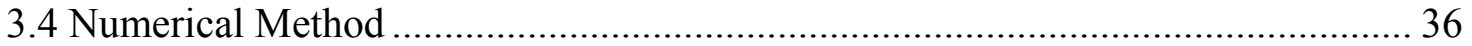

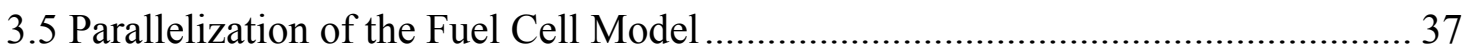

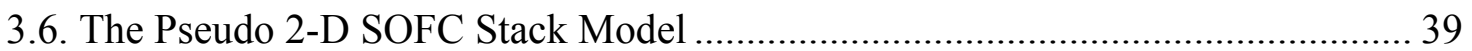

3.7 Extension to Counter-Flow Configuration............................................................ 39

3.8 Reduced Order 3-D Fuel Cell Model................................................................ 41

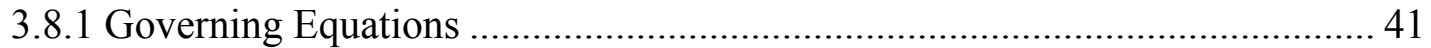

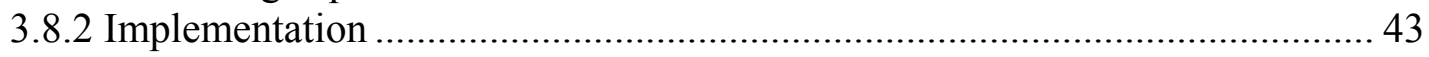

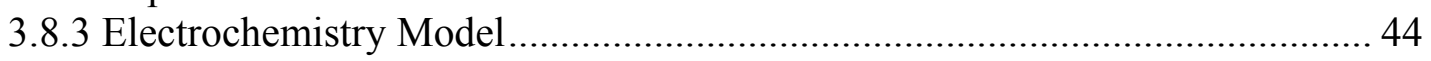

4.0 APPLICATION OF PSUEDO 2-D STACK MODEL ……….................................. 50

4.1 Verification of Fuel Cell Stack Model............................................................ 50

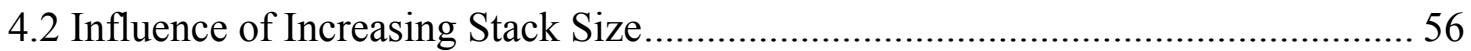

4.3 Effect of Flow Distribution on Cell-to-Cell Performance ....................................... 68

4.4 Influence of Radiative Heat Transfer on Cell-to-Cell Performance ......................... 78

5.0 APPLICATIONS WITH REDUCED ORDER 3-D FC MODEL …………................ 86

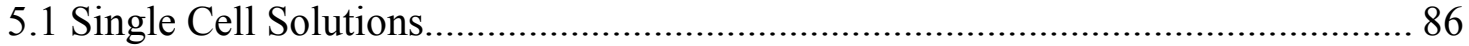

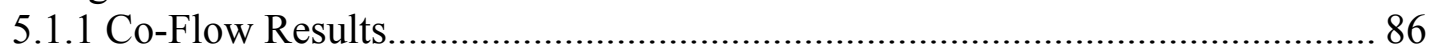

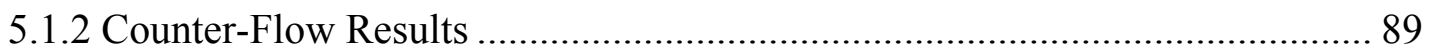

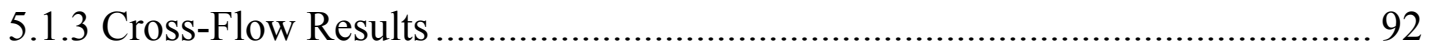

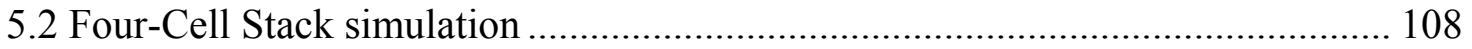

6.0 CONCLUSIONS AND FUTURE RECOMMENDATIONS................................. 114

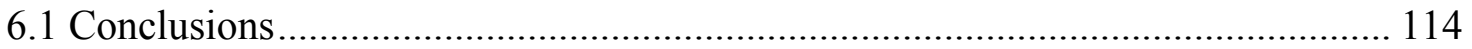

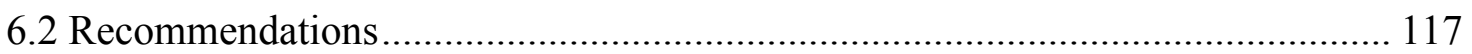

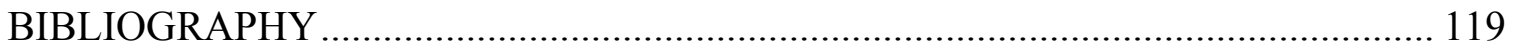

APPENDIX A: Counter-flow single-cell results .................................................... 125 
APPENDIX B: Numerical Method used for the Reduced Order 3-D Fuel Cell Model . 129

APPENDIX C: Cross-Flow Implementation based on MCMP scheme

132

APPENDIX D: User Guide for Reduced Order 3-D Fuel Cell Model.

Outline.

D.1 Introduction

D.1.2 Overview of file contents

D.2 Modifying the Code

D.2.1 Changing model parameters.

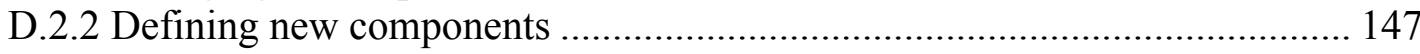

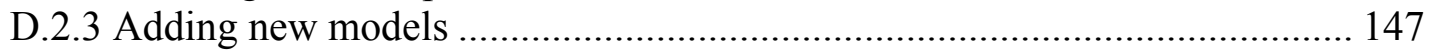

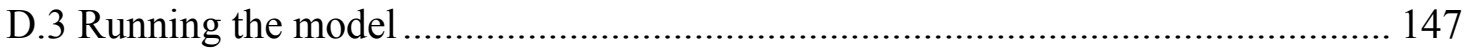

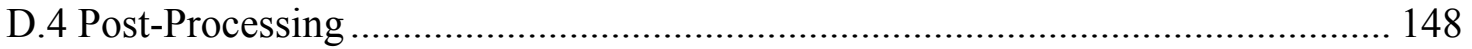




\section{LIST OF TABLES}

Table 3.3.1. View factors for 5 control volumes of equal width and height ................... 32

Table 3.8.1. Required configuration parameters for the electrochemistry model ........... 44

Table 3.8.2. Required variables for the electrochemistry model .................................. 45

Table 3.8.3. Variables returned by the electrochemistry model ................................... 45

Table 4.1.1. Fixed model parameters (1-D thermal stack model) ................................. 51

Table 4.1.2. Parameter that were varied ....................................................................... 51

Table 4.1.2. Dimensions of anode supported electrolyte fuel cell................................ 54

Table 4.1.3. Material properties and model parameters (counter-flow pseudo 2-D FC

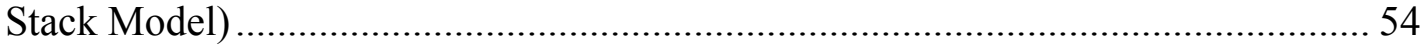

Table 4.2.1. Physical dimensions of single fuel cell with anode supported electrolyte. . 57

Table 4.2.2. Material properties and model parameters. (increasing stack size case) .....58

Table 4.2.3. Variation of temperature within the PEN for 5, 10, and 20 cell stacks operating at an average current density of $667 \mathrm{~mA} / \mathrm{cm}^{2}$ with anode and cathode inlet

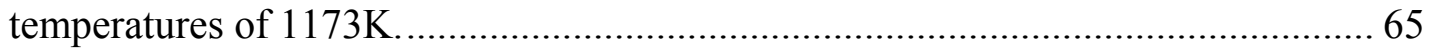

Table 4.2.4. Variation of temperature within the fuel and air gas channels in the streamwise direction for 5,10 , and 20 cell stacks operating at an average current density of $667 \mathrm{~mA} / \mathrm{cm}^{2}$ with fuel and air inlet temperatures of $1173 \mathrm{~K}$................... 65

Table 4.2.5. Cell-to-cell voltage variation for 5, 10, and 20 cell stacks operating at an average current density of $667 \mathrm{~mA} / \mathrm{cm}^{2}$ with fuel and air inlet temperatures of $1173 \mathrm{~K}$ 66

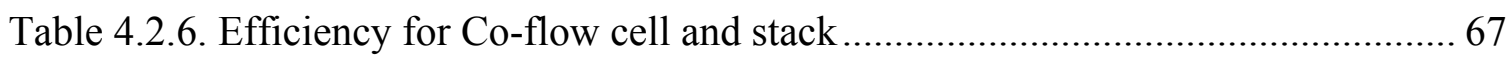

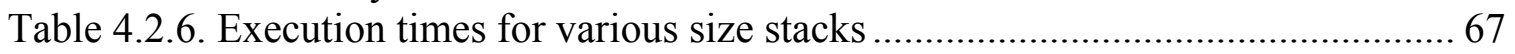

Table 4.3.1. Physical dimensions of single fuel cell (effects of flow distribution) ......... 68

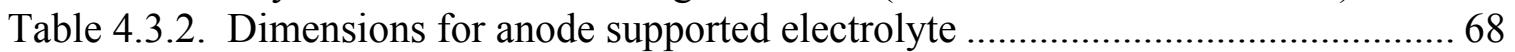

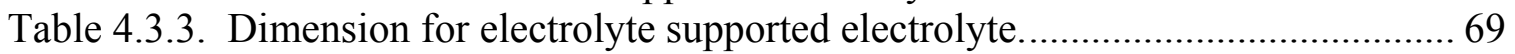

Table 4.3.4. Material properties and model parameters. (effects of flow distribution) ... 69

Table 4.3.5. Prescribed anode inlet velocity $[\mathrm{m} / \mathrm{s}]$ for the six test cases. ....................... 70

Table 4.4.1. Physical dimensions of single fuel cell with Electrolyte support (influence of

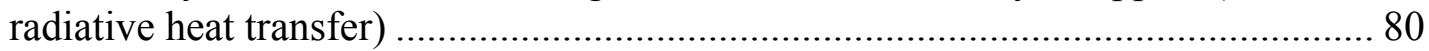

Table 4.4.2. Material properties and Model Parameters (influence of radiative heat

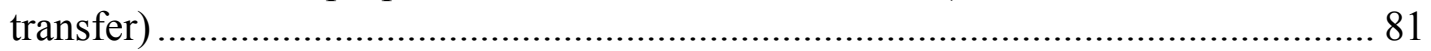

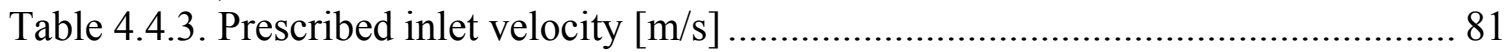

Table 5.1.1. Physical dimensions of "button" cell (co-flow cell) ................................. 87

Table 5.1.2. Material properties and model parameters (co-flow cell)........................... 87

Table 5.1.3. Physical dimensions of "button" cell (counter-flow cell)...........................90

Table 5.1.4. Material properties and model parameters (counter-flow cell) .................. 90

Table 5.1.5. Physical dimensions of "button" cell (cross-flow cell) .............................. 93

Table 5.1.6. Material properties and model parameters (cross-flow cell) ....................... 94

Table 5.2.1. Physical dimensions of "button" cell (4 cell cross-flow stack) ................ 109

Table 5.2.2. Material properties and model parameters (4 cell cross-flow stack) ......... 110

Table 5.2.3. Cell Voltage and Resistance for 4 cell stack at steady state. ..................... 110

Table D.1.2.1. files composing the Reduced Order 3-D Fuel Cell Model. .................... 145

Table D.2.1.1. lists of variables initialized in main.cc.............................................. 146 


\section{LIST OF FIGURES}

Figure 1.0.1. Diagram of operation of typical SOFC (Pakalapati, 2003) ........................ 2

Figure 1.0.2. Typical polarization curve for SOFC .................................................... 4

Figure 1.0.3. Picture of a SOFC stack (EG\&G Technical Services, Inc., 2002) ............... 5

Figure 1.0.4. Common planar fuel cell configurations ............................................... 5

Figure 3.1a. Domain decomposition for a five cell stack where each cell is treated as an individual process on a separate computer processor. ............................................ 19

Figure 3.1b. Gas channel control volume for mass conservation................................... 19

Figure 3.1c. Electrolyte control volume for energy conservation. ............................... 20

Figure 3.3.1. Simple diagram for application of Hottel's "string rule" for shape factors of

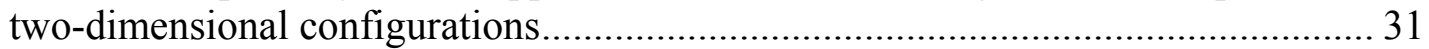

Figure 3.3.2. Determination of view factor, $F_{21}$, using Eqs 3.3.2-6 for 5 control volumes

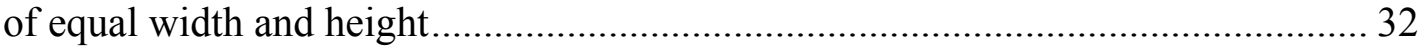

Figure 3.3.3. Semi-log plot of view factor vs. location for source at location $4(H=0.2) .34$

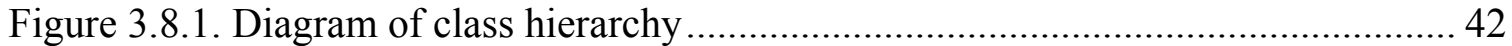

Figure 3.8.2. Relationship between element, component, and model .......................... 42

Figure 3.8.3. Cross-Flow mesh typical utilized by Gemmen and Johnson (2004) .......... 46

Figure 3.8.4. Coarse electrochemistry mesh (dashed lines) overlaid on fine channel mesh viewed from top (hash lines depict channel walls) for non-uniform fine grid ........ 47

Figure 3.8.5. Intersection of fine anode grid and coarse electrolyte grids ...................... 48

Figure 4.1.1. Temperature profile for 20 cell stack (case 1)....................................... 52

Figure 4.1.2. Temperature profile for 20 cell stack (case 2)...................................... 53

Figure 4.1.3. Temperature profile for 20 cell stack (case 3 ) ..................................... 53

Figure 4.1.4. Comparison of steady state PEN temperature profiles for 5 cell anode supported counter-flow stack at $6666 \mathrm{~A} / \mathrm{m}^{2}$ and results from Achenbach (1994).... 55

Figure 4.2.1. Geometry of unit cell with exploded view of anode supported electrolyte

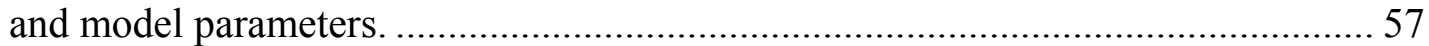

Fig. 4.2.2. Temperature contours for 20 cell stack, $1073 \mathrm{~K}$ inlet for an average current density of $667 \mathrm{~mA} / \mathrm{cm}^{2}$........................................................................ 59

Figure 4.2.3a. Temperature profile at $\mathrm{x} / \mathrm{L}=0.55$ (node 10 ) within a 5 cell stack for an average current density of $667 \mathrm{~mA} / \mathrm{cm}^{2}$.

Figure 4.2.3b. Temperature profile at $\mathrm{x} / \mathrm{L}=0.55$ (node 10 ) within a 20 cell stack for an average current density of $667 \mathrm{~mA} / \mathrm{cm}^{2}$.

Fig. 4.2.3c. Temperature profile at $\mathrm{x} / \mathrm{L}=0.55$ (node 10 ) within a 20 cell stack neglecting radiation effects for an average current density of $667 \mathrm{~mA} / \mathrm{cm}^{2}$.

Fig. 4.2.4a. Cell voltage variation within a 5 cell stack normalized with the highest cell voltage of $0.70 \mathrm{~V}$ for an average current density of $667 \mathrm{~mA} / \mathrm{cm}^{2}$.

Fig. 4.2.4b. Cell voltage variation within a 20 cell stack normalized with the highest cell voltage of $0.70 \mathrm{~V}$ for an average current density of $667 \mathrm{~mA} / \mathrm{cm}^{2}$

Fig. 4.2.4c. Cell voltage variation within a 30 cell stack (Lin et al., 2003).

Fig. 4.2.5. Cell voltage variation within a 20 cell stack due to non-uniform fuel inflow normalized with the highest cell voltage of $0.71 \mathrm{~V}$ for an average current density of $667 \mathrm{~mA} / \mathrm{cm}^{2}$

Figure 4.3.1. Utilization at different current densities ............................................... 71

Figure 4.3.2. Polarization curves for electrolyte supported five-cell stack .................... 71 
Figure 4.3.3. Influence of flow distribution on cell voltage within five-cell stack (with average current density $=6666.6 \mathrm{~A} / \mathrm{m}^{2}$ ).

Figure 4.3.4. Influence of flow distribution on cell voltage within five-cell stack (with

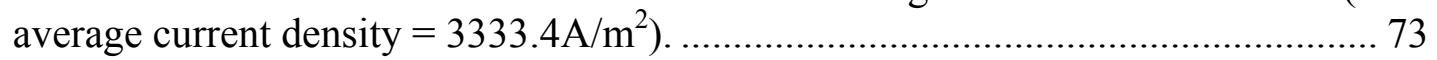

Figure 4.3.5. Temperature contours for the base case with average current density = $6666.6 \mathrm{~A} / \mathrm{m}^{2}$.

Figure 4.3.6. Influence of flow distribution on cell voltage within five-cell stack (with

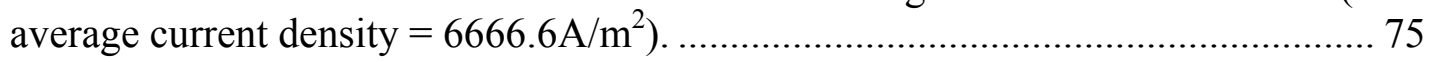

Figure 4.3.7. Influence of flow distribution on cell voltage within five-cell stack (with

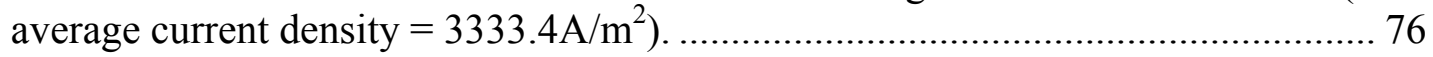

Figure 4.3.8. Change in cell voltage resulting from increasing Oxygen utilization at

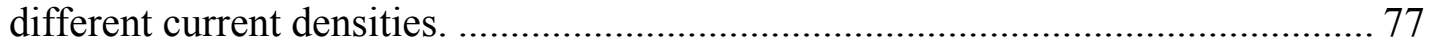

Figure 4.3.9. Electrolyte temperature for electrolyte and anode supported geometry..... 78

Figure 4.4.1. Physical geometry of a single cell ...................................................... 80

Figure 4.4.2. Temperature contours for uniform flow case (a) without radiative heat

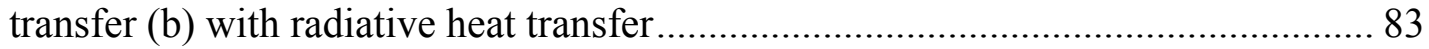

Figure 4.4.3. Variation in cell voltage for uniform flow distribution with and without radiative heat transfer; In each case the cell voltage is normalized with the highest cell voltage. 84

Figure 4.4.4. Variation in cell voltage for non-uniform flow distribution with and without radiative heat transfer; In each case the voltage is normalized with the highest voltage. 85

Figure 5.1.1. Current density versus streamwise direction calculated by ECM (square symbols) and distributed anode current (solid line)........................................... 88

Figure 5.1.2. Steady-state temperature contours in PEN of 5 channel co-flow fuel cell

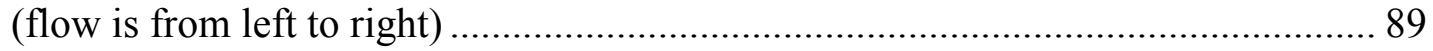

Figure 5.1.3. Current density versus streamwise direction for along center channel of counter-flow case (fuel flow is right to left)..................................................... 91

Figure 5.1.4. Variation of $\mathrm{H}_{2}$ (solid line) and $\mathrm{H}_{2} \mathrm{O}$ (dashed line) mass fraction along the center fuel channel for counter-flow case (Fuel flow is right to left) ..................... 91

Figure 5.1.5. PEN temperature contours for counter-flow case (fuel flows right to left and air flows from left to right).......................................................................... 92

Figure 5.1.6. Temperature at 3 points along line passing through center of cell.............95

Figure 5.1.7. Current density calculated by ECM (square symbols) at points where channels cross and current density distributed along fuel channel (solid line)........ 96

Figure 5.1.8. $\mathrm{H}_{2}$ (solid line) and $\mathrm{H}_{2} \mathrm{O}$ (dashed line) mass fraction along center fuel

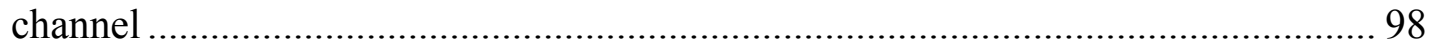

Figure 5.1.9. Density along center fuel channel .................................................. 98

Figure 5.1.10. Temperature profile along center fuel channel (solid line) with temperature of neighboring PEN (dashed line) ..................................................................... 99

Figure 5.1.11. Temperature contours in the PEN (fuel flows from left to right and air flows from bottom to top) ........................................................................ 100

Figure 5.1.12. Temperature contours for cross-flow fuel cell with internal methane reforming (Achenbach, 1994) ...................................................................... 100

Figure 5.1.13. Temperature contours in a plane passing through the center of the air gas channels (air flow from bottom to top). 101 
Figure 5.1.14. Temperature contours in a plane passing through the center of the fuel gas channels (fuel flow from left to right)

Figure 5.1.15. Current density calculated by ECM (square symbols at points where channels cross and current density distributed along fuel channel (solid line) for higher $\mathrm{H}_{2}$ utilization case.

Figure 5.1.16. Variation of $\mathrm{H}_{2}$ (solid) and $\mathrm{H}_{2} \mathrm{O}$ (dashed) mass fraction along center fuel channel for higher utilization case. 104

Figure 5.1.17. Temperature contours in the PEN (fuel flows from left to right and air flows from bottom to top) for higher utilization case. 105

Figure 5.1.18. Temperature contours for fuel channels (fuel flow is left to right) for higher utilization case 106

Figure 5.1.19. Temperature contours in air channel (air flow is bottom to top)............ 107

Figure 5.2.1. Temperature variation with time for center location of PEN in the top and bottom cell

Figure 5.2.2. Temperature profile along the center of the 4 cell cross-flow stack ........ 112

Figure 5.2.3. PEN Temperature counters for each cell in the 4 cell cross-flow stack (fuel flows left to right and air flows from bottom to top) 113

Figure A.1. Concentration of $\mathrm{H}_{2}$ in the anode gas channel vs. location for single counterflow cell descritized with 5 computational volumes.... 126

Figure A.2. Concentration of $\mathrm{O}_{2}$ in the cathode gas channel vs. location for single counter-flow cell descritized with 5 computational volumes. 126

Figure A.3. Concentration of $\mathrm{H}_{2}$ in the anode gas channel vs. location for single counterflow cell descritized with 5 computational volumes. 127

Figure A.4. Concentration of $\mathrm{O}_{2}$ in the cathode gas channel vs. location for single counter-flow cell descritized with 5 computational volumes. 128

Figure D.1.1. Three common planar fuel cell configurations. 144 


\section{NOMENCLATURE}

\begin{tabular}{|c|c|}
\hline $\mathrm{A}_{1}$ & Area of surface $1\left[\mathrm{~m}^{2}\right]$ \\
\hline Axs & Cross-sectional area $\left[\mathrm{m}^{2}\right]$ \\
\hline e & Energy per unit mass $[\mathrm{J} / \mathrm{kg}]$ \\
\hline E & Open circuit potential $[\mathrm{V}]$ \\
\hline $\mathrm{E}^{0}$ & Potential at standard state conditions [V] \\
\hline $\mathrm{E}_{\text {cor }}$ & Corrected potential [V] \\
\hline $\mathrm{F}$ & Faraday constant of $96439[\mathrm{C} / \mathrm{mol}]$ \\
\hline$F_{i j}$ & View factor from surface $i$ to surface $j[1]$ \\
\hline $\mathrm{F}_{\mathrm{i}, \text { inlet }}$ & View factor from surface $\mathrm{i}$ to inlet [1] \\
\hline$F_{i, \text { outlet }}$ & View factor from surface $i$ to outlet [1] \\
\hline$F_{12}$ & Shape factor from surface 1 to $2[1]$ \\
\hline $\mathrm{F}_{\mathrm{x}}$ & Forces in $\mathrm{x}$-(streamwise-)direction $[\mathrm{N}]$ \\
\hline G & Gibbs free energy $[\mathrm{kJ} / \mathrm{kmol}]$ \\
\hline $\mathrm{H}$ & Dimensionless height [1] \\
\hline$\Delta \mathrm{H}_{\mathrm{H}_{2} \mathrm{O}}$ & Heat of formation for $\mathrm{H}_{2} \mathrm{O}[\mathrm{kJ} / \mathrm{kgmol}]$ \\
\hline$h_{c}$ & Convective heat transfer coefficient $\left[\mathrm{W} / \mathrm{m}^{2} \mathrm{~K}\right]$ \\
\hline$i_{\text {den }}$ & Current density $\left[\mathrm{A} / \mathrm{m}^{2}\right]$ \\
\hline$i_{0}$ & Exchange current $\left[\mathrm{A} / \mathrm{m}^{2}\right]$ \\
\hline $\mathrm{k}$ & Thermal conductivity $[\mathrm{W} / \mathrm{m} \mathrm{K}]$ \\
\hline $1_{\mathrm{w}}$ & Width of control volume $[1 \mathrm{~m}]$ \\
\hline $\mathrm{L}$ & Cell length $[\mathrm{m}]$ \\
\hline$\dot{\mathrm{m}}^{\prime \prime}$ & Mass flux per area $\left[\mathrm{kg} / \mathrm{m}^{2} \mathrm{~s}\right]$ \\
\hline$\dot{\mathrm{m}}_{\text {surf }}$ & Net mass flux through surface $[\mathrm{kg} / \mathrm{s}]$ \\
\hline $\mathrm{n}$ & Number of participating electrons [1] \\
\hline $\mathrm{Nu}$ & Nusselt number [1] \\
\hline $\mathrm{P}$ & Pressure $[\mathrm{Pa}]$ \\
\hline $\mathrm{P}^{0}$ & Reference pressure $[\mathrm{Pa}]$ \\
\hline $\operatorname{Pr}$ & Prandtl number [1] \\
\hline$\dot{\mathrm{Q}}_{\text {conv }}$ & Convective heat transfer rate $[\mathrm{W}]$ \\
\hline$\dot{\mathrm{Q}}_{\mathrm{gen}}$ & Rate of heat generation [W] \\
\hline$\dot{\mathrm{Q}}_{\text {net }}$ & Net heat transfer rate $[\mathrm{W}]$ \\
\hline$\dot{\mathrm{Q}}_{\mathrm{rad}}$ & Radiative heat transfer rate $[\mathrm{W}]$ \\
\hline $\mathrm{R}$ & Resistance $\left[\Omega \mathrm{m}^{2}\right]$ \\
\hline $\operatorname{Re}$ & Reynolds number [1] \\
\hline $\mathrm{R}_{\text {net }}$ & Net resistance $\left[\Omega \mathrm{m}^{2}\right]$ \\
\hline $\mathrm{R}_{\mathrm{u}}$ & Universal gas constant \\
\hline s & Entropy per mole $[\mathrm{kJ} /(\mathrm{kmol} \mathrm{K})]$ \\
\hline $\mathrm{t}$ & Time $[\mathrm{s}]$ \\
\hline $\mathrm{T}$ & Temperature $[\mathrm{K}]$ \\
\hline $\mathrm{T}_{\text {surf }}$ & Surface temperature $[\mathrm{K}]$ \\
\hline
\end{tabular}




$\begin{array}{ll}\mathrm{T}_{\mathrm{env}} & \text { Temperature of the environment }[\mathrm{K}] \\ \mathrm{u} & \text { Velocity in } \mathrm{x} \text {-direction [m/s] } \\ \Delta \mathrm{x} & \text { Length of control volume in } \mathrm{x} \text {-direction }[\mathrm{m}] \\ \mathrm{X}_{\mathrm{k}} & \text { Mole fraction [1] } \\ \mathrm{Y}_{\mathrm{k}} & \text { Mass fraction [1] }\end{array}$

\section{Greek}

$\begin{array}{ll}\alpha & \text { Transfer coefficient [1] } \\ \varepsilon & \text { Total emittance [1] } \\ \phi & \text { General scalar variable [has units of the selected variable }] \\ \eta_{\text {act }} & \text { Activation loss [V] } \\ \eta_{\text {conc }} & \text { Concentration loss }[\mathrm{V}] \\ \eta_{\text {ohm }} & \text { Ohmic loss [V] } \\ \eta_{\text {II }} & 2^{\text {nd }} \text { law efficiency } \\ \rho & \text { Mixture density }\left[\mathrm{kg} / \mathrm{m}^{3}\right] \\ \sigma & \text { Stefan-Boltzmann constant }\left[\mathrm{W} / \mathrm{m}^{2} \mathrm{~K}\right] \\ \dot{\omega}_{k} & \left.\text { Rate of formation and destruction of specie } \mathrm{k} \text { [moles of species } \mathrm{k} / \mathrm{s} \mathrm{m}^{2}\right] \\ \forall & \\ & \text { Volume }\left[\mathrm{m}^{3}\right]\end{array}$

\section{Subscripts and Superscripts}

$\begin{array}{ll}1 & \text { Surface 1 } \\ 2 & \text { Surface 2 } \\ \mathrm{k} & \mathrm{k}^{\text {th }} \text { specie } \\ \mathrm{e} & \text { East face of control volume } \\ \text { env } & \text { Environment } \\ \mathrm{H}_{2} & \text { Hydrogen gas } \\ \mathrm{H}_{2} \mathrm{O} & \text { Water vapor } \\ \mathrm{n} & \text { North face of control volume } \\ \mathrm{O}_{2} & \text { Oxygen gas } \\ \mathrm{s} & \text { South face of control volume } \\ \text { surf } & \text { Surface of control volume } \\ \mathrm{w} & \text { West face of control volume } \\ \mathrm{xs} & \text { Cross-sectional area }\end{array}$
Abbreviations
$1-\mathrm{D}$
One Dimensional
2-D
Two Dimensional
$3-\mathrm{D}$
Three Dimensional
CFD Computational Fluid Dynamics
AFC Alkaline Fuel Cell
CTP
Core Technology Program 


$\begin{array}{ll}\text { DMFC } & \text { Direct Methanol Fuel Cell } \\ \text { DO } & \text { Discrete Ordinate method } \\ \text { GUI } & \text { Graphical User Interface } \\ \text { HPC } & \text { High Performance Computing } \\ \text { MCFC } & \text { Molten-Carbonate Fuel Cell } \\ \text { MPI } & \text { Message Passing Interface } \\ \text { NETL } & \text { National Energy Technology Laboratory } \\ \text { OCV } & \text { Open Circuit Voltage } \\ \text { PAFC } & \text { Phosphoric-Acid Fuel Cell } \\ \text { PEM } & \text { Proton Exchange Membrane } \\ \text { PEN } & \text { Positive electrode, Electrolyte, and Negative electrode assembly } \\ \text { ROM } & \text { Reduced Order Model or Method } \\ \text { SECA } & \text { Solid state Energy Conversion Alliance } \\ \text { SOFC } & \text { Solid Oxide Fuel Cell }\end{array}$




\subsection{INTRODUCTION}

During the recent years fuel cell technology has received much attention both in national news and in private and public research. Fuel cells themselves have been around for quite some time. They were used in the space program to power the space vehicles which eventually placed men on the moon. However, recently fuel cells have become more popular due to their potential as a clean alternative power source.

What is a fuel cell? A fuel cell is an electrochemical device which converts the chemical potential existing between a fuel and oxidizer into electrical power and heat. This is accomplished by first identifying an electrolyte material which allows for the conduction of ions from the anode to the cathode electrode or vice versa (depending on the type of ion which the electrolyte transports) but at the same time does not allow the conduction of electrons. This forces electrons to travel through an external circuit (see Figure 1.0.1) from the anode to cathode electrode which provides useful electric power. The ions that pass through the electrolyte are produced and consumed by half-cell reactions that occur at each electrode. These reactions produce heat which when combined with Ohmic heating account for the heating of the fuel cell. The whole process is accomplished without moving parts and thus creates no noise. Because ionic conduction is controlled by the electrolyte there exists more control over the chemical reactions that occur and thus most pollution that is traditionally resulting from combustion can be avoided. 
Fuel and oxidizer must find their way to active sites on the electrolyte known as triple phase boundaries where electrode, electrolyte, and gas phase meet. For this reason it is desirous to have porous electrodes which allow fuel and oxidizer to permeate to the electrolyte surface. Gas channels are also created to allow for transport to the electrodes.

There are several types of fuel cells. They are usually classified by the electrolyte material. In this study Solid Oxide Fuel Cell (SOFC) are considered. SOFC utilize a solid electrolyte which at higher temperatures allows for the transport of oxygen ions from the cathode electrode to the anode electrode. Because of the high temperatures (1073K1373K, Larminie and Dicks, 2003) that are required there are many thermal related issues that must be addressed when designing a SOFC.

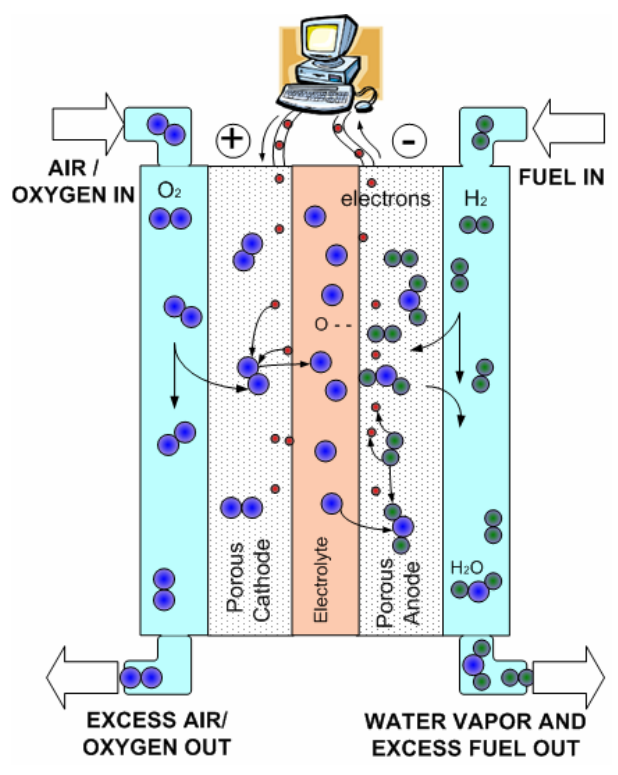

Figure 1.0.1. Diagram of operation of typical SOFC (Pakalapati, 2003) 
The electric potential across a single cell varies during cell operation and is often represented using a polarization curve or V-I curve (where cell voltage is ploted vs. current, see Figure 1.0.2). The theoretical open circuit voltage (OCV) is determined primarily by the fuel being used. The actual voltage observed across a single cell can be determined by first calculating the OCV based on the temperature, pressures, and gas compositions using the Nernst Equation. The OCV is then reduced by loses that occur due to the operation of the fuel cell. The three losses (or overpotentials) of interest are Ohmic, concentration, and activation losses. Ohmic loss results from the resistance of the materials to electronic or ionic conduction. The activation overpotential is the loss required to have the reactions occur. It can be reduced through the proper selection of catalyst and is often smaller at higher temperatures. The concentration overpotential is the loss resulting from the diffusion of a species not being able to supply the demand for that species at higher current densities. This loss is generally what limits the total current achievable by a fuel cell.

Figure 1.0.3 is a picture of a 20 cell SOFC stack. Typically a single cell produces less than a single volt. Thus stacks of cells are often used in series (just like batteries) to produce useful voltages (Figure 1.0.3). The cells in the stack are separated by a conductive material which does not allow gas transport. 


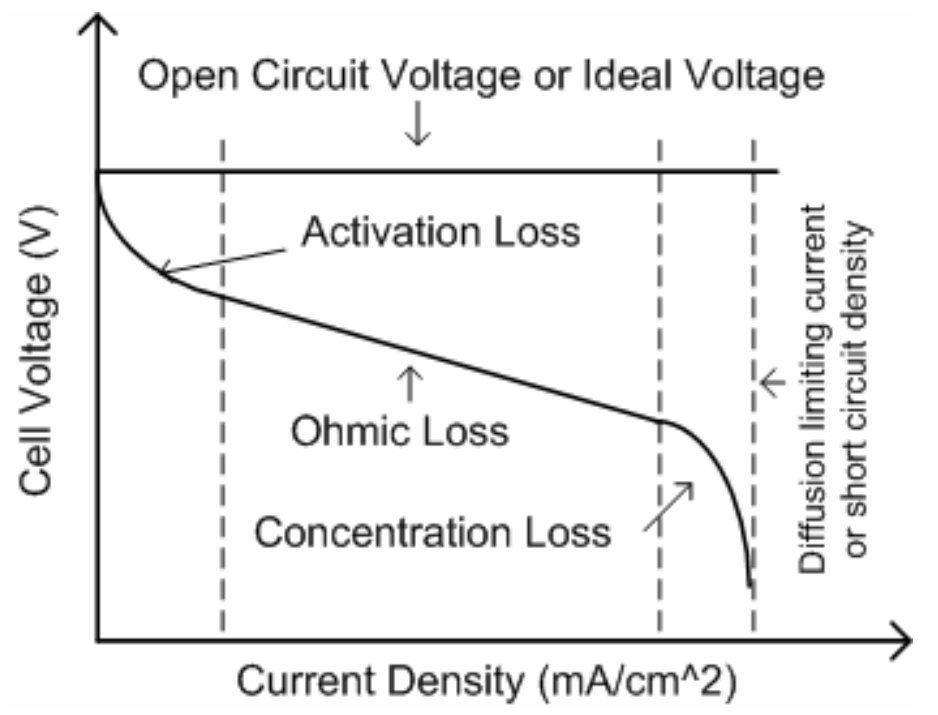

Figure 1.0.2. Typical polarization curve for SOFC.

In this research detailed models were developed to study hydrogen fed planar SOFCs and stacks. Currently fuel cells exist in more than just a planar form. For example there are tubular SOFC. Planar fuel cells, however, have the advantage of having a more compact form. They consist of layers of materials sandwiched together (Figure 1.03). This makes assembly fairly easy. Planar fuel cells require edge seals made of appropriate materials which can withstand the harsh operating conditions and thermal cycling of the fuel cell. Gas channels are normally carved into the interconnect/separator plate material which connects and divides the cells in a stack. These channels are typically cut in such a way as to have one of three common configurations; co-flow, counter-flow, and cross-flow as shown in Figure 1.0.4. 


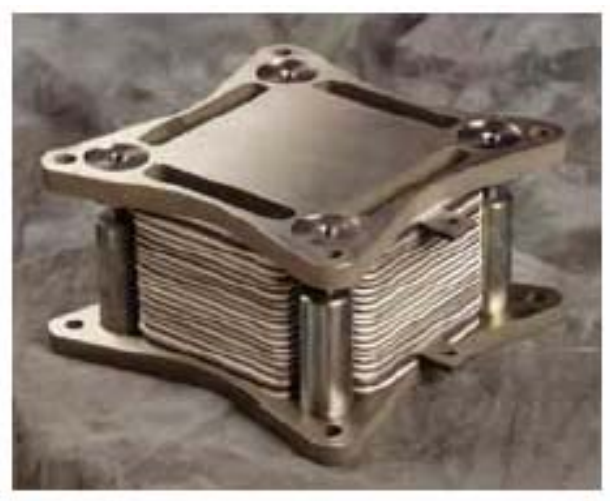

Figure 1.0.3. Picture of a SOFC stack (EG\&G Technical Services, Inc., 2002)

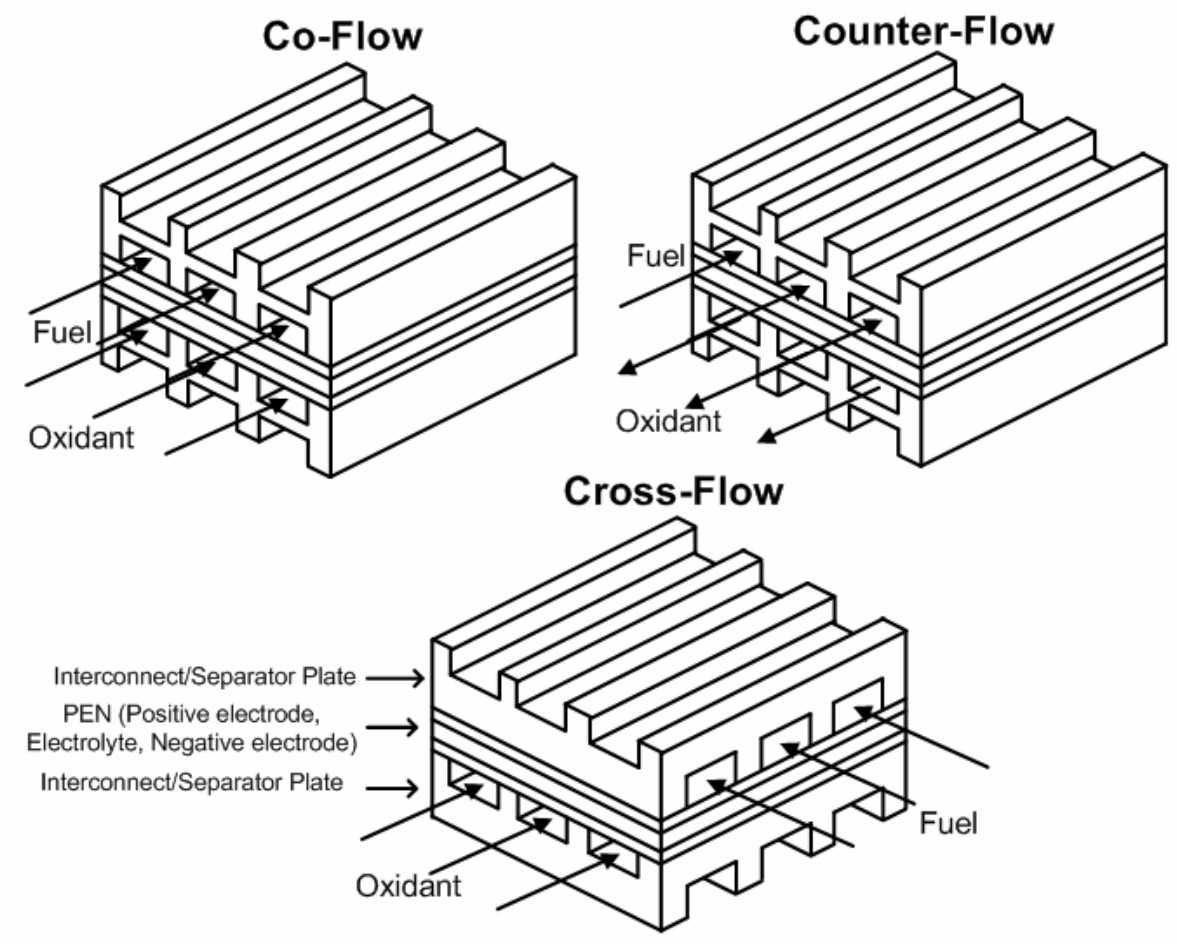

Figure 1.0.4. Common planar fuel cell configurations

Large SOFC stacks are very difficult to model using full 3-D CFD codes because of the resource requirements needed to solve for the many scales involved. Implementations 
based on Reduced Order Methods (ROM) if calibrated appropriately, can provide simulations of stacks greater than 20 cells with reasonable computational effort. ROMs use simplifying assumptions to reduce the order to which some of the models are solved. For example the gas channels might be solved using 1-D approximations. This results in a loss of detail in the gas dynamics within the channel but allows for the solution of fewer or less complex equations and thus faster computational turn around times.

\subsection{Motivation and Objectives}

The presence of multiple air and fuel channels per fuel cell and the need to combine many cells in series result in complex steady-state temperature distributions within SOFC stacks. Flow distribution in these channels, when non-uniform, has a significant effect on cell and stack performance. Large SOFC stacks are very difficult to model using full 3-D CFD codes because of the resource requirements needed to solve for the many scales involved. Therefore there is a need to develop a ROM fuel cell and stack model which can be used to simulate stacks of more than 20 cells. This model should be developed using a scheme which allows for the solution of governing equations relevant to each component in the fuel cell. Thus a multi-component multi-physics (MCMP) scheme should be developed which can be implemented in an object oriented programming language. The model implemented should take advantage of parallelization techniques such as domain decomposition in order to harness the advantages of High Performance Computing (HPC). In addition MCMP scheme should be implemented in such a way as to allow the user to easily modify or replace the sub-models which make up the fuel cell model. 
The fuel cell model should be robust enough to solve the three common planar fuel cell configurations previously described. The need to include radiation effects has not been fully addressed in the literature. However, the author believes that radiation heat transfer should be included due to the high temperatures at which SOFC operate and part of this study will address this impact on cell performance. Fuel cells having multiple air and fuel channels are susceptible to performance issues arising from poor distribution of fuel and oxidizer. The literature reviewed did not show that the impact of mal-distribution of fuel on cell performance was fully understood. This study will show that mal-distribution has the largest influence on cell performance variations within a stack. Many authors in the literature tried to reduce computational effort by simply solving a single cell and using the result multiple times to represent a fuel cell stack. This study will show the impact of increasing stack size on individual cell performance.

\subsection{Summary}

This study has the following 6 main objectives:

1. Develop a Multi-Component Multi-Physics (MCMP) scheme which defines a relationship between geometry, component, and model elements.

2. Implement a robust fuel cell model capable of studying the three common planar configurations of co-flow, counter-flow, and cross-flow. 
3. Improve the existing radiation model that was initially available in the NETL 1-D single cell model.

4. Develop fuel cell stack model which benefits from the computational resources available from clusters of computers.

5. Perform verification and validation of the developed models.

6. Perform case studies which consider the influence of stack size, flow distribution, and radiation on cell-to-cell performance within a fuel cell stack. 


\subsection{LITERATURE REVIEW}

\subsection{Overview of Solid Oxide Fuel Cells}

In recent years, emphasis has been placed on the development of affordable clean power sources. This has caused much speculation about the use of fuel cell technology in various endeavors; e.g., automobiles, stationary power generation, portable power supplies, etc. There are many fuel cell types, with the most common ones being: phosphoric-acid fuel cells (PAFC), solid-oxide fuel cells (SOFC), molten-carbonate fuel cells (MCFC), alkaline fuel cells (AFC), proton exchange membrane (PEM), and direct methanol fuel cells (DMFC). Regardless of the type of cell, stacks of cells (in electricseries) can be used to generate desired voltage output and power. The SOFC shows a high potential for being an efficient and clean solution for stationary based power generation.

At the heart of a solid oxide fuel cell is the solid electrolyte (usually made of stabilized zirconia) which at temperatures greater than $600^{\circ} \mathrm{C}$ conducts oxygen ions from the porous cathode to the porous anode. At the cathode triple interface where the electrically conducting electrode, ionically conducting electrolyte, and cathode gas phase meet, oxygen is electrochemically reduced (ionized) and enters the electrolyte to be transported across to the anode. At the anode triple interface where the anode electrode, electrolyte, 
and anode gas channel meet, the oxygen ions react with hydrogen and carbon monoxide to form water and carbon dioxide, respectively. The electrons released in the charge transfer reaction of oxygen enter the anode electrode and can then pass through an external load on their way back to the cathode and in the process release useful energy. The cathode electrode, electrolyte, and anode electrode together are called PEN. In general, the gas flow through the anode and cathode gas channels results in forced convective heat transfer, and presently it is common to see units operating at pressures close to atmospheric. In an ideal situation it is desirable to have all of the cells in a stack to perform uniformly. It has been observed experimentally that usually the cells in a stack do not operate uniformly (Gubner, et al., 2003, and Maggio et al., 1996). The cause of the variations is not well understood. Significant variations among the cells may cause long run structural problems and may eventually lead to total failure of the power generation unit. Possible causes are non-uniform fuel/air flow distribution to individual cells, non-uniform temperature and/or current distribution within the stack (Costamagna et al., 1994), and material non-uniformities. At the desired high utilization rates of fuel $(>70 \%)$ such flow non-uniformity can be limiting. However, all of these factors are interrelated hence a systematic investigation is necessary to better understand the root causes. Previous studies by Hirata and Hori (1996), Costamagna and Honegger (1998), Achenbach (1994), and Ma (2000) attempted to elucidate some of the factors but some questions such as the influence of non-symmetry and non-uniform flow distribution are left unanswered. 


\subsection{SECA fuel cells}

In order to provide meaningful research in the area of SOFC stacks it is important to consider the initiative of the U.S. Department of Energy and its sponsored Solid State Energy Conversion Alliance (SECA) Program (Strakey, 2002, and Surdoval, 2002). The goal of the SECA Program is straight forward. In order to facilitate integration of SOFC technology the cost of SOFC units must be economically competitive (less than $\$ 400$ per $\mathrm{kW}$ with production of greater then 50,000 units per year) for units capable of producing 3-10kW. To achieve this goal the SECA Program will maintain a balance between Industry Teams and development of common supporting technology by members of the Core Technology Program (CTP). The CTP brings participation from universities, National Labs, small and large businesses together to tackle important design issues. The six Industrial Teams (Acumentrics, Cummins Power Generation and SOFCo, Delphi Automotive Systems and Battelle, FuelCell Energy, General Electric Power Systems, and Siemens Westinghouse Power Corporation) are integrating the developed technology into different market applications to bring SOFCs to the consumer.

The core technologies that are being focused on can be separated into two main categories: SOFC component development, and SOFC modeling. SOFC components must be developed both in terms of material properties and manufacturing. SOFC models must be developed to model both cells and stacks under transient and steady state conditions. Appropriate system models must also be developed. This overview of the SECA program is relevant in that it is important that models developed are applicable to 
SECA compliant SOFC stacks and therefore an understanding of the objective of the program will help keep research relevant.

\subsection{Reduced Order Models}

Throughout the literature several examples (Murthy and Federov, 2003, Yuan et al., 2003, Gemmen et al., 2000, Virkar et al., 2000, and Yakabe et al., 2000, Costamagna and Honegger, 1998, Ferguson, et al., 1996, Achenbach, 1994) have been found where specialized computational models were developed for the simulation of SOFCs. Some of these models were developed to facilitate fuel cell studies in as computationally efficient manner as possible allowing short simulation times. In order to do this, some assumptions were made to reduce the order or complexity for which some governing equations or specialized models are solved. These less complex approaches result in what can be described as a reduced order method or model (ROM).

The simplest case of a ROM would be lumped models or 0-D models where the fuel cell is modeled as a single set of control volumes. One for each component air gas channel, fuel gas channel, PEN, interconnect, etc. This hides most of the detail of what occurs inside the fuel cell but allows for fast simulation times. Lumped models are appropriate for use in system modeling applications where the fuel cell interacts with other devices such as heat exchangers, combustors, turbines, etc. This kind of application needs to capture the general operating behavior of the fuel cell and requires the computation to be done quickly. 
One-Dimensional (1-D) models result from simplifying the fuel cell such that variations are accounted for along a single axial direction. The NETL 1-D single cell model (Gemmen et al., 2000) considered the variations in the streamwise direction of the cell. Thus variables such as species concentration, temperature, flow velocity, etc., were allowed to vary as a function of distance along the channel. 1-D models might also be stack models where each cell is modeled in a 0-D manner.

Following the same logic a two-dimensional (2-D) model can be developed by considering variations only within a plane thus neglecting changes in the third direction. An example of this kind of model is the Psuedo 2-D Fuel Cell Stack Model presented in this work and in Burt et al. (2004a, 2004b, 2003a, and 2003b) which was an extension of a 1-D single cell model into a stack model hence a two-dimensionality was provided. It still referred to as a pseudo 2-D model because the model does not account for 2-D variations within individual components.

\subsection{Fuel Cell Stack Modeling}

Variation in performance among cells within a stack can result from asymmetry in fuel cells. A natural asymmetry exists in Solid Oxide Fuel Cells (SOFCs) attributed mostly to a difference in the flow rates of the air and fuel gas channels. This asymmetry can cause non-uniform temperature distributions. Koh et al. (2002) found temperature variations in the upper and lower regions of a molten carbonate fuel cell stack resulted more from the influence of external heating then from the cell reaction. Such temperature variations, in 
turn, produce cell-to-cell voltage variations. Previously this cell-to-cell variation was found within a stack of five cells (Burt et al., 2004a, 2004b, 2003a, and 2003b). Costamagna et al. (1994) reported differences in voltage output because of non-uniform distribution of the feeding gas along the planar fuel cell stack. Experimental studies conducted by Gubner et al. (2003) and Maggio et al. (1996) also revealed that cells in a stack do not operate uniformly.

\subsection{Radiation modeling}

During the course of the earlier stages of this study, it was found that there were significant temperature differences within the stack as a result of natural non-symmetry that exists in a stack arranged by simply connecting cells in series. These observations lead to the investigation of the role of radiative heat transfer on the eventual temperature distribution within the stack. Solid oxide fuel cells usually operate at high temperatures in the range $\left(700-1200^{\circ} \mathrm{C}\right)$ utilizing a variety of fuels (i.e. hydrogen gas, hydrocarbons, and carbon monoxide) (Billingham et al., 2000, Yuan et al., 2003, Krotz, 2003). At these

elevated temperatures thermal radiation emitted from the solid elements of the fuel cell may constitute a noticeable portion of the heat transfer within the stack.

In the literature there are numerous studies (Hirata and Hori, 1996, Costamagna and Honegger, 1998, Achenbach, 1994, Ma, 2000, Aguiar et al., 2002, Yakabe et al., 2000) in which radiation heat transfer was treated in various ways. For example the treatment of radiation heat transfer was often neglected. Aquiar et al. (2002) developed a 2-D model 
for the internal indirect reformer, and coupled it with a 1-D model for the SOFC. The SOFC model combined the porous anode and cathode electrodes with the electrolyte as a single solid structure (PEN). A similar modeling approach was used in the present study. Aquiar et al. included radiation between the PEN and reformer using assumption of two long concentric cylinders. An emissivity of 0.9 was used for both surfaces of the solid structure and the reformer. Their results show that radiative heat transfer accounted for up to $79 \%$ of the total heat transfer between the solid structure and the reformer. Hirata and Hori (1996) consider radiative heat transfer between the PEN and the separator plate in a manner similar to the present study but for a MCFC stack. In their study an emmissivity of 0.48 and a view factor of 1 was used. The gas was considered to be nonparticipating. Costamagna and Honegger (1998) considered a planar cylindrical SOFC operating in a co-flow configuration. In their model they consider the stack to have insulated top and bottom plates this is the same as in the present study.

In Costamagna and Honeggar (1998) and Achenbach (1994) radiation was considered between the stack and the surrounding shell as part of the boundary condition for the stack, but the radiation between individual PEN and separator plate was neglected. Yakabe et al. (2000) considered a single SOFC cell in a counter-flow configuration using a 3-D model. However, no radiation model was used, because the temperature was considered to be uniform everywhere in the cell. Virkar et al. (2000), like Yakabe et al. (2000), also used a uniform temperature in their study which focused on comparison of electrolyte vs. electrode supported cell and the impact of composite electrodes. Ma (2000) neglected radiation heat transfer effects because channels were considered to be 
thin and the cells were considered to be at nearly the same temperature. The above brief literature review show that the importance and the effects of radiation heat transfer have yet to be fully realized.

Recent work by Murthy and Fedorov (2003) and VanderSteen and Pharoah (2004) show the current state of radiation modeling in single solid oxide fuel cells. Murthy and Fedorov (2003) considered radiation heat transfer in a solid oxide fuel cell with a single rectangular fuel and air channel. They found that a comparison of results with and without inclusion of radiation showed a decrease of the temperature and smaller temperature gradients in the streamwise direction. The discrete ordinate (DO) method was found to be very accurate but computational costly and memory requirements made the method not feasible. The authors then developed a simplified Rosseland/two-flux approximation resulting in a ten-fold reduction of CPU time. Agreement was good between both methods except for cases where increased optical thickness of the gas channel caused the approximations to fail.

VanderSteen and Pharoah (2004) considered radiation heat transfer with and without participating gases in a single anode gas channel. The Monte Carlo approach was used where photons introduced at a source were tracked through multiple interactions with gas and surfaces until they lost sufficient energy. In their study 2 million photon trajectories were used. The Monte Carlo approach allowed for consideration of the participation of gases like $\mathrm{CO}_{2}$ and $\mathrm{H}_{2} \mathrm{O}$ in the anode gas channel. Their study, however, found that 
radiation did significantly affect the overall temperature on the gas channel, however the participation of the gases did not have any significantly influence. 


\subsection{COMPUTATIONAL APPROACH}

In this study steady-state results were obtained for co-flow and counter-flow configurations using a Pseudo 2-D SOFC Stack Model (Burt et al., 2004, Gemmen et al., 2000) which was an extension of the NETL 1-D single cell model. The computational approach models each fuel cell using a simplified transient NETL 1-D single cell model where the variations in the stream-wise direction are accounted directly. The fuel-cell stack has been divided into computational domains using domain decomposition with each cell being treated as a separate process (see Figure 3.1a) on a distributed memory multi-processor system, such as a Beowulf cluster. Each cell was solved individually and in parallel. Communication between domains or processes was accomplished using the Message Passing Interface (MPI) library. The necessary temperatures, time step, and termination bit were communicated using MPI library calls. Results were obtained on an Intel based Beowulf cluster. 


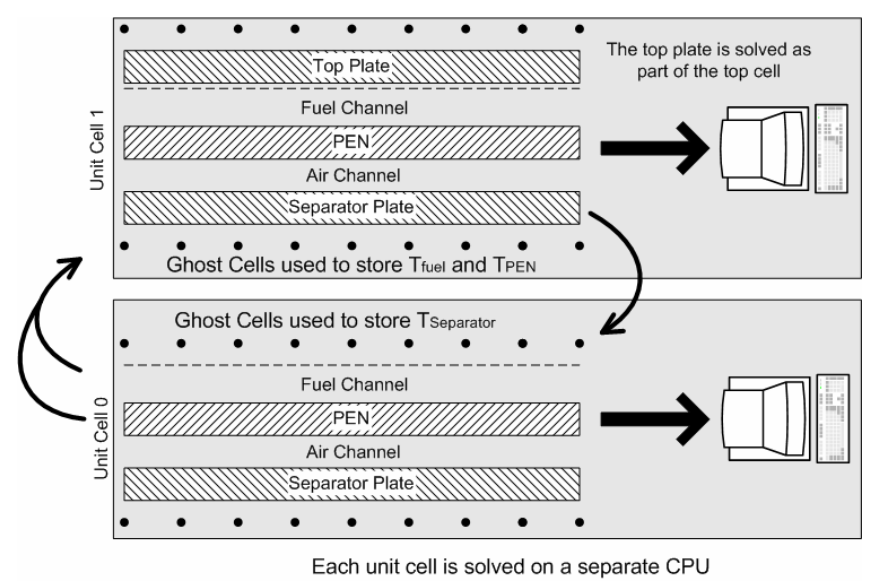

Figure 3.1a. Domain decomposition for a five cell stack where each cell is treated as an individual process on a separate computer processor.

Each cell was further divided into control volumes. Figure $3.1 \mathrm{~b}$ depicts the control volume approximation used for mass conservation and is similarly defined for the other conservation equations. Figure 3.1c shows a thermal fluxes and source terms relevant for a typical electrolyte control volume. This figure is valid for the Psuedo 2-D Stack Model and thus the fuel cell stack model where conduction through the west and east faces were neglected. The Reduced Order 3-D Fuel Cell Model that was later developed incorporated conduction through all faces of the control volume.

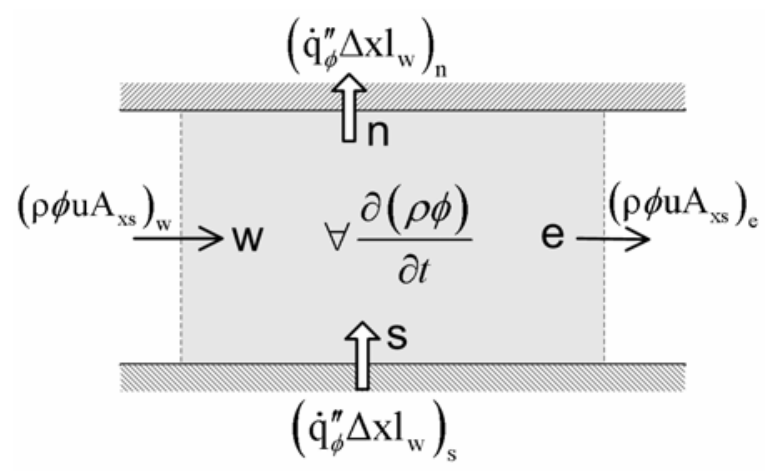

Figure 3.1b. Gas channel control volume for mass conservation. 


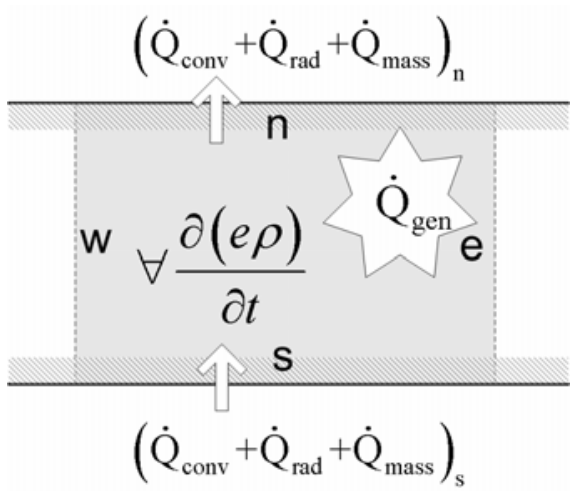

Figure 3.1c. Electrolyte control volume for energy conservation.

A one dimensional model was implemented where the variations in the streamwise (x-) direction are explicitly calculated, those in the vertical (y-) direction are accounted for via integral approximations, and those in the transverse (z-) direction are ignored. Later a Reduced Order 3-D Fuel Cell Model was developed which allowed for variations in the z- direction. This analysis was applied to the fuel cell anode gas channel, electrolyte plate, cathode gas channel, and separator plate. Each control volume of the fuel and air gas channels was required to satisfy the governing equations for mass, momentum, and energy. 


\subsection{Governing Equations}

The following governing equations for mass, momentum, and energy were solved in the air and fuel channel:

$$
\begin{aligned}
& \forall \frac{\partial \rho}{\partial t}+\left(\rho \mathrm{uA}_{\mathrm{xs}}\right)_{\mathrm{w}}-\left(\rho \mathrm{uA}_{\mathrm{xs}}\right)_{\mathrm{e}}=\dot{\mathrm{m}}_{\text {surf }} \\
& \forall \frac{\partial(\mathrm{u} \rho)}{\partial t}+\left(\mathrm{u} \rho \mathrm{uA}_{\mathrm{xs}}\right)_{\mathrm{w}}-\left(\mathrm{u} \rho \mathrm{uA}_{\mathrm{xs}}\right)_{\mathrm{e}}=\sum F_{x} \\
& \forall \frac{\mathrm{d}(e \rho)}{\mathrm{dt}}+\left(\mathrm{e} \rho \mathrm{uA}_{\mathrm{xs}}\right)_{\mathrm{w}}-\left(\mathrm{e} \rho \mathrm{uA}_{\mathrm{xs}}\right)_{\mathrm{e}}=\dot{\mathrm{Q}}_{\mathrm{conv}}
\end{aligned}
$$

where

$$
\dot{\mathrm{m}}_{\text {surf }}=\left(\dot{\mathrm{m}}^{\prime \prime} \Delta \mathrm{xl} \mathrm{w}_{\mathrm{w}}\right)_{\mathrm{s}}-\left(\dot{\mathrm{m}}^{\prime \prime} \Delta \mathrm{xl} \mathrm{w}_{\mathrm{w}}\right)_{\mathrm{n}}
$$

Specie mass conservation was satisfied using

$$
\frac{\forall \partial\left(\rho \mathrm{Y}_{\mathrm{k}}\right)}{\partial \mathrm{t}}+\left(\rho \mathrm{Y}_{\mathrm{k}} \mathrm{uA} \mathrm{A}_{\mathrm{xs}}\right)_{\mathrm{w}}-\left(\rho \mathrm{Y}_{\mathrm{k}} \mathrm{uA} \mathrm{A}_{\mathrm{xs}}\right)_{\mathrm{e}}=\dot{\omega}_{\mathrm{k}} \Delta \mathrm{xl}_{\mathrm{w}}
$$

In Eqs. (3.1.1-4) it is assumed that changes in the $\mathrm{x}$-direction are small therefore diffusion terms are neglected. The energy equation (3.1.3) is used to determine the temperature, 
and the current density is determined by an electrochemical model (Gemmen et al., 2000) using a simplified Butler-Volmer relation. Then, the current density and temperature are used to calculate appropriate fluxes which are introduced as source (or sink) terms for each of the conservation equations. The molar flux of a given species $\mathrm{k}$ is obtained from the current density using:

$$
\dot{\omega}_{k}=\frac{-i_{d e n}}{n_{k} F}
$$

where $\mathrm{n}$ is the number of electrons per mole of reactant $\mathrm{k}$.

The PEN and separator plate are considered to be made of solid material; therefore only the energy equation (that essentially reduces to the heat conduction equation) was solved in these regions which was simplified from Eq. (3.1.3) to:

$\forall \frac{\mathrm{d}(\mathrm{e} \rho)}{\mathrm{dt}}=\dot{\mathrm{Q}}_{\mathrm{net}}+\dot{\mathrm{Q}}_{\mathrm{gen}}$

The radiative and convective heat flux through the surface of the control volume, and the thermal energy transported by mass-flux, are all included in $\dot{\mathrm{Q}}_{\text {net }}$ (see Eq. 3.2.1), and the heat source, $\dot{\mathrm{Q}}_{\mathrm{gen}}$, is obtained from ohmic heating and heat associated with change of entropy resulting in the following expression: 


$$
\dot{\mathrm{Q}}_{\text {gen }}=\left(\mathrm{i}_{\text {den }}\right)^{2} \mathrm{R}+\mathrm{T} \Delta \mathrm{s} \dot{\omega}_{\mathrm{H}_{2}}
$$

The total entropy change per mole, $\Delta s$ is obtained from

$$
\Delta s=\Delta \bar{s}^{0}+R_{u} \ln \frac{r_{R}}{r_{p}}
$$

where $\Delta \bar{s}^{0}$ is the change in entropy per mole of reactant at standard conditions, and $\mathrm{r}_{\mathrm{R}}$ and $\mathrm{r}_{\mathrm{P}}$ are the reactant and product activities respectively.

Pressure, $\mathrm{P}$, is calculated from the ideal gas law:

$$
\mathrm{P}=\rho \mathrm{R}_{\mathrm{u}} \mathrm{T}
$$

The electrochemistry model is based on the assumption that the overall chemical reaction occurring in the fuel cell is:

$\mathrm{H}_{2}(\mathrm{~g})+\frac{1}{2} \mathrm{O}_{2}(\mathrm{~g}) \rightarrow \mathrm{H}_{2} \mathrm{O}(\mathrm{g})$

Calculation of the cell potential starts with the Nernst Equation which considers the mole fraction of the $\mathrm{H}_{2}, \mathrm{O}_{2}$, and $\mathrm{H}_{2} \mathrm{O}$ species: 
$\mathrm{E}=\mathrm{E}^{0}+\frac{\mathrm{R}_{\mathrm{u}} \mathrm{T}}{2 \mathrm{~F}} \ln \left[\frac{\left.\left[\mathrm{X}_{\mathrm{H}_{2}}\right]\left[\mathrm{X}_{\mathrm{O}_{2}}\right]\right]^{1 / 2}}{\left[\mathrm{X}_{\mathrm{H}_{2} \mathrm{O}}\right]}\right]+\frac{\mathrm{R}_{\mathrm{u}} \mathrm{T}}{4 \mathrm{~F}} \ln \frac{\mathrm{P}}{\mathrm{P}^{0}}$

The pressure is assumed to be the same for both the anode and cathode gas channels. The reversible potential at standard state conditions is obtained from the change in the standard Gibbs free energy.

$\mathrm{E}^{0}=-\frac{\Delta \mathrm{G}^{0}}{\mathrm{nF}}$

The corrected cell potential, $E_{\text {cor }}$, is obtained by subtracting the ohmic $\left(\eta_{\text {ohm }}\right)$, concentration $\left(\eta_{\text {conc }}\right)$, and activation $\left(\eta_{\text {act }}\right)$ losses (i.e. overpotentials) from the ideal Nernst potential, E:

$E_{\text {cor }}=E-\eta_{\text {ohm }}-\eta_{\text {conc }}-\eta_{\text {act }}$

The overpotentials are related to the current density. The activation over-potential is defined by an empirical relation represented by a limiting form of the Butler-Volmer equation.

$\eta_{\text {ohm }}=\mathrm{i}_{\text {den }} \mathrm{R}_{\text {net }}$ 


$$
\eta_{\text {conc }}=-\frac{\mathrm{R}_{\mathrm{u}} \mathrm{T}}{\mathrm{nF}} \ln \left(1-\frac{\mathrm{i}_{\mathrm{den}}}{\mathrm{i}_{\mathrm{L}}}\right)
$$

$\eta_{\text {act }}=\frac{\mathrm{R}_{\mathrm{u}} \mathrm{T}}{\mathrm{n} \alpha \mathrm{F}} \ln \left(\frac{\mathrm{i}_{\mathrm{den}}}{\mathrm{i}_{0}}\right)$

A quasi-steady gas option was used whereby the gas flow was determined from empirical steady state relations; e.g., a steady state friction coefficient equation. This allowed large time steps to be used with the time marching scheme to reach a steady state solution. More details about the mathematical model can be found in previous work (Burt et al., 2003a, 2003b, 2004a, 2004b, Gemmen et al., 2000).

\subsection{Convective and Radiative Heat Transfer}

When considering the heat flux from the PEN and separator plate, there are two main modes of heat transfer, convective heat transfer between the solid and gas phase (which includes the effect of bulk mass transport to/from the electrolyte surface), and radiative heat transfer between the solid and the neighboring solid surfaces. These are both

included in $\dot{Q}_{n e t}$, the net boundary heat flux through the top and bottom surfaces of the computational volume (see Fig1c), in Eq. (3.1.6). Thus $\dot{Q}_{n e t}$ is obtained from

$$
\begin{aligned}
\dot{\mathrm{Q}}_{\text {net }}= & \left(\dot{\mathrm{Q}}_{\text {conv }}+\dot{\mathrm{Q}}_{\mathrm{rad}}+\dot{\mathrm{Q}}_{\text {mass }}\right)_{\mathrm{s}} \\
& -\left(\dot{\mathrm{Q}}_{\text {conv }}+\dot{\mathrm{Q}}_{\mathrm{rad}}+\dot{\mathrm{Q}}_{\text {mass }}\right)_{\mathrm{n}}
\end{aligned}
$$


where $\dot{Q}_{\text {mass }}$ is the net heat transfer due to mass transport to/from the electrolyte and therefore is zero for the separator plate.

The convective heat transfer rate is given by

$$
\dot{Q}_{\text {conv }}=h_{c} A_{1}\left(T_{\text {surf }}-T_{\text {env }}\right)
$$

For the Psuedo 2-D Stack Model the Nusselt number, Nu, was found dynamically using the Re. For laminar flow $(\operatorname{Re}<1500)$ the Nu was 3.66. For turbulent flow $(\operatorname{Re}>2000)$ the following expression was used.

$$
\mathrm{Nu}=0.022 \operatorname{Re}^{0.8} \operatorname{Pr}^{0.6}
$$

A linear average of the two $\mathrm{Nu}$ values was calculated for transitional flow $(1500<\operatorname{Re}<2000)$.

The convective heat transfer coefficient, $\mathrm{h}_{\mathrm{c}}$, from

$$
\mathrm{h}_{\mathrm{c}}=\frac{\mathrm{Nuk}}{\mathrm{L}}
$$


where $\mathrm{L}$ is a characteristic length for the gas channel. For the Reduced Order 3-D Model the heat transfer coefficients were considered to be constant and calculated using a hydraulic diameter for a characteristic length. The hydraulic diameter, $\mathrm{D}_{\mathrm{h}}$, can be found from:

$\mathrm{D}_{\mathrm{h}}=\frac{4 \mathrm{~A}}{\mathrm{P}}$

Using a $\mathrm{Nu}=4, \mathrm{k}_{\text {air }}=0.0672 \mathrm{~W} / \mathrm{m}-\mathrm{K}$, and $\mathrm{k}_{\text {fuel }}=0.255 \mathrm{~W} / \mathrm{m}-\mathrm{K}$, and $\mathrm{D}_{\mathrm{h}}=0.001 \mathrm{~m}$ the convective heat transfer coefficients for air and fuel were found to be 268.8 and 1020 $\mathrm{W} / \mathrm{m}^{2}-\mathrm{K}$ respectively. The disparity in heat transfer coefficients stems from the difference in thermal conductivity of air compared to fuel. The thermal conductivity of the fuel mixture was found by taking into consideration the thermal conductivities, $\mathrm{k}_{\mathrm{H}_{2}}=0.423$ $\mathrm{W} / \mathrm{m}-\mathrm{K}$ and $\mathrm{k}_{\mathrm{H}_{2} \mathrm{O}}=0.088 \mathrm{~W} / \mathrm{m}-\mathrm{K}$ (Mills, 1995).

In general the radiative heat transfer between two surfaces 1 and 2 can be calculated from

$\dot{Q}_{\text {rad }}=A_{1} F_{12}\left(\varepsilon_{1} \sigma T_{1}^{4}-\varepsilon_{2} \sigma T_{2}^{4}\right)$

Initially, when considering the radiative heat transfer several simplifying assumptions were made (Mills, 1995). The width of the gas channels is small (on the order of $1 \mathrm{~mm}$ ) this would result in the product of partial pressure and path length also being small. When considering water vapor in the fuel gas channel a total emissivity of much less then 
0.007 was estimated (see Fig. 17-13 in Siegel and Howell, 1972). Therefore the gas medium between the surfaces is considered to be nonparticipating. The PEN and separator plate are considered to have black surfaces (having an emissivity of unity, $\varepsilon=1$ ). The view factor, $\mathrm{F}$, is assumed to be 1 . Therefore all emitted radiation is considered to be absorbed by the surface of the opposite plate. With these simplifications the radiative heat transfer rate, $\dot{Q}_{r a d}$, can be expressed as

$\dot{Q}_{\text {rad }}=A_{1} \sigma\left(T_{1}^{4}-T_{2}^{4}\right)$

It is not known what the exact radiative properties are for a generic fuel cell. Therefore in this study the results with and without radiation are compared. Equation (3.2.8) should give a maximum estimate for the heat transfer rate due to radiation. Considering heat absorbed by a participating medium (i.e., gases in the anode and cathode channels) and modeling the surfaces of the electrodes and separator plates as grey surfaces would reduce the overall influence of the radiative heat transfer.

\subsection{Determination of Shape Factor}

A simplified radiation model was implemented to determine the radiative heat transfer flux between neighboring separator plates and PEN structures. A boundary element method was used to develop a radiation model for the 1-D model. Boundary element method is more appropriate for lower dimensional problems or problems with simple geometries. Since the model of the duct is two dimensional and the geometry is straight, 
it was decided to use the boundary element method for the purpose of computing radiation transfer in this case. In multidimensional computations it is more appropriate to use a Monte Carlo method for radiation transfer (Siegel and Howell, 1972).

The method used is based on computing radiative energy exchange coefficients between surfaces of different computational cells. These coefficients are related to the so-called view factors or shape factors [Mills, 1995, Siegel and Howell, 1972]. Determination of view factors can be a difficult task for complex geometries but can be done in a relatively straightforward manner in the case of a 1-D channel.

Results obtained using the Psuedo 2-D Fuel Cell Stack Model used a view factor of 1, when considering heat transfer between opposite faces of the air and fuel channels. Radiative heat transfer to neighboring cells and to the inlet and outlet were effectively neglected. This assumption reduces somewhat the computational effort, but introduces errors, which can be large in the situations when considerable radiative heat transfer takes place due to large temperature gradients.

To compute the view factors one may consider the opposite sides of the duct as long parallel plates of equal width [Mills, 1995]. Then the following expression can be used to obtain the view factors. The view factor $F_{12}$ represents the fraction of energy leaving $\mathrm{A}_{1}$ that intersects $\mathrm{A}_{2}$.

$$
F_{12}=F_{21}=\left[1+H^{2}\right]^{1 / 2}-H
$$


where $\mathrm{H}$ is the dimensionless height obtained from

$$
H=\frac{h}{w}
$$

where $\mathrm{h}$ is the height of the channel separating the plates and $\mathrm{w}$ is the width of the plates. This ratio of height to width is a function of the number of control volumes that the fuel cell is subdivided into. The geometry described in Tables 4.4.1 and 4.4.2 had air and fuel channels which were $1.0 \mathrm{E}-03$ and $3.0 \mathrm{E}-03 \mathrm{~m}$ in height and were $1.0 \mathrm{E}-1 \mathrm{~m}$ in length. The channels where divided into 20 control volumes along the streamwise direction. The $\mathrm{H}$ values were thus found to be 0.2 and 0.6 for the fuel and air channel, respectively. Using Eq. 3.3.1 these $\mathrm{H}$ values result in view factors of 0.82 and 0.57 for the fuel and air channel. This suggests that the approximation of one previously used, although computationally less expensive, can result in significant error.

The shape factor, $F_{12}$, from surface 1 to 2 can be determined using Hottel's "string rule" as follows:

$$
F_{12}=\frac{1}{2 L 1}[A D+B C-A C-B D]
$$

where $\mathrm{L} 1$ is the length of the segment $\mathrm{AB}$ and segments $\mathrm{AD}, \mathrm{BC}, \mathrm{AC}$, and $\mathrm{BD}$ are identified in Fig. 3.3.1. 


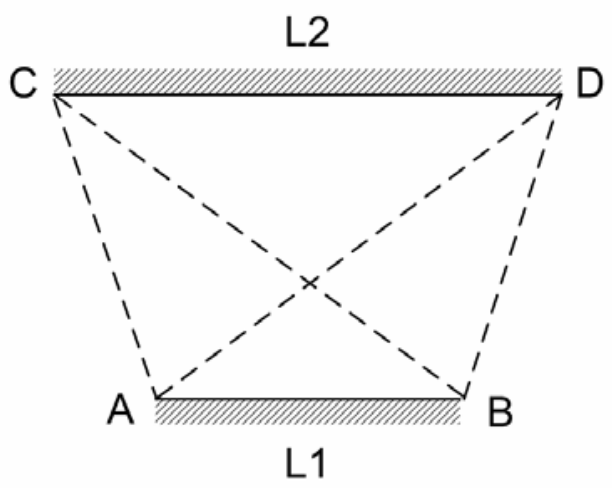

Figure 3.3.1. Simple diagram for application of Hottel's "string rule” for shape factors of two-dimensional configurations

For 1-D fuel cell model where each control volume is defined by a uniform height and width Eq 3.3.1 can be simplified into the following

$F_{i j}=\frac{a_{i j}+b_{i j}}{2}-c_{i j}$

$a_{i j}=\sqrt{(|i-j|+1)^{2}+H^{2}}$

$b_{i j}=\sqrt{(|i-j|-1)^{2}+H^{2}}$

$c_{i j}=\sqrt{(i-j)^{2}+H^{2}}$

where the dimensionless height, $\mathrm{H}$, is found from Eq. 3.3.2. 
A sample control volume is shown in Fig. 3.3.2 where the factors given in Eqs. 3.3.5-7 are indicated for the view factor $\mathrm{F}_{21}$. Table 3.3.1 presents the view factors calculated for $\mathrm{F}_{20}$ through $\mathrm{F}_{24}$.

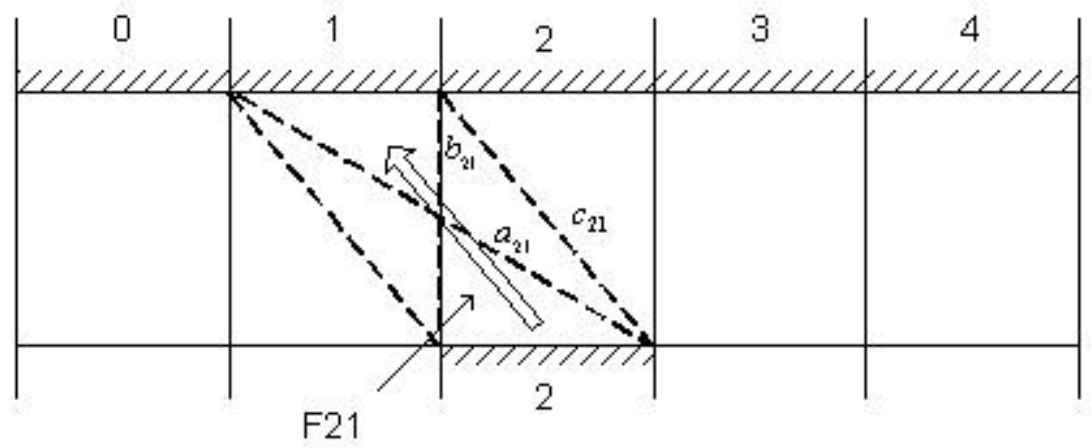

Figure 3.3.2. Determination of view factor, $F_{21}$, using Eqs 3.3.2-6 for 5 control volumes of equal width and height

Table 3.3.1. View factors for 5 control volumes of equal width and height

\begin{tabular}{|c|c|c|c|c|c|}
\hline $\mathrm{F}_{20}$ & $\mathrm{~F}_{21}$ & $\mathrm{~F}_{22}$ & $\mathrm{~F}_{23}$ & $\mathrm{~F}_{24}$ & SUM \\
\hline 0.000208 & 0.024063 & 0.951249 & 0.024063 & 0.000208 & 0.999792 \\
\hline
\end{tabular}

Using Eq 3.3.1 for long parallel plates of equal width the same value for $F_{22}$ was obtained as that from Eq. 3.3.4.

Fig. 3.3.3 presents a plot of view factors for 20 control volumes obtained using Eqs. 3.3.4-7 with $\mathrm{H}=0.2$ corresponding to the fuel channel in the 1-D SOFC model. As can be seen the view factor $\mathrm{F}_{44}$ which is from one side of the channel to the directly opposite 
side in this case is 0.82 . The view factors are symmetric in this case because each control volume has the same width. Therefore the view factor to the first neighbor control volume to the left or right is $\mathrm{F}_{43}=\mathrm{F}_{45}=0.085$. The view factor for the outlet is equal to 0.5 minus half the view factor to the opposing surface and the sum of all the view factors of the neighboring control volumes from the originating control volume to the outlet. A similar expression can be written for the view factor of the inlet, resulting in the following expressions:

$F_{i, \text { nlet }}=0.5-\frac{1}{2} F_{i i}-\sum_{j=0}^{i-1} F_{i j}$

$F_{i, \text { outlet }}=0.5-\frac{1}{2} F_{i i}-\sum_{j=i+1}^{n} F_{i j}$

In Fig 3.3.3 the view factor of the inlet and outlet, $\mathrm{F}_{4-1}$ and $\mathrm{F}_{4-20}$ have slightly higher values then the view factors of the opposing surface. Thus in the plot there is a slight upward turn at either end of the plot. These view factors capture the fraction of energy that would hit an opposing surface if the channel were infinitely long. 


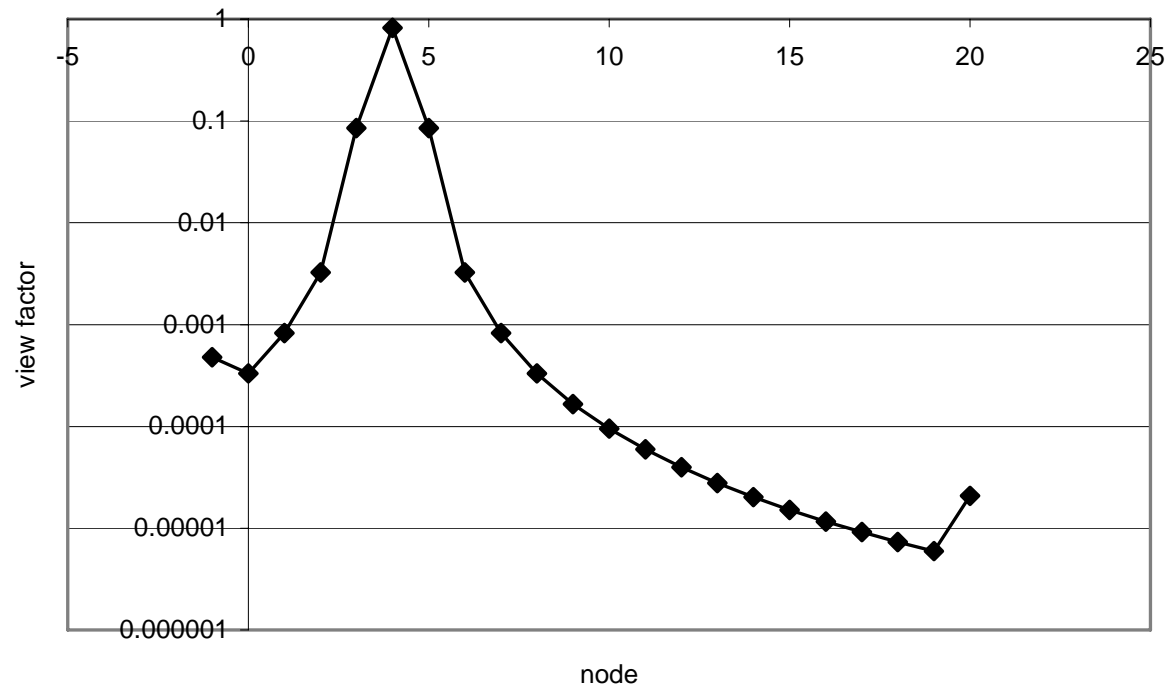

Figure 3.3.3. Semi-log plot of view factor vs. location for source at location $4(\mathrm{H}=\mathbf{0 . 2})$

A radiation model based on a boundary element method was implemented into the single cell SOFC model. The view factors are determined using Hottel's "string rule" as described above. Once the geometry has been specified the height to width ratio (Eq. 3.3.2) is determined. Equations 3.3.4-7 are then used to calculate the view factors between each surface of the PEN and interconnect. The view factors are then stored in a two-dimensional array where the indices represent the source and destination surfaces. The view factor from the top surface of the $i^{\text {th }}$ control volume of the PEN to the inlet or outlet is then calculated from Eqs. 3.3.8 and 3.3.9.

In each iteration the radiative heat flux is calculated before solving the energy equation for the PEN. The net radiative heat flux from the top surface of the $\mathrm{i}^{\text {th }}$ control volume of the PEN to the bottom surface of the $\mathrm{j}^{\text {th }}$ control volume of the interconnect is determined from the following expression. 
$\dot{Q}_{i j}=A_{i} F_{i j} \sigma\left(T_{i}^{4}-T_{j}^{4}\right)$

The total radiative heat flux from the top surface of the $\mathrm{i}^{\text {th }}$ control volume of the PEN is then determined by summing the net radiative heat fluxes. This is expressed in Eq. 3.3 .11

$\dot{Q}_{i}=\sum_{j=0}^{n} \dot{Q}_{i j}+\dot{Q}_{i, \text { inlet }}+\dot{Q}_{i, \text { outlet }}$

For the purposes of calculating the radiative heat flux the inlet and outlet are defined to have the same temperature as the first and last control volume of the interconnect, respectively. This represents the interconnect surrounding the manifold which distributes and collects the air and fuel to and from the fuel cell. This procedure is repeated for the bottom surface of the PEN. In order to reduce the computational effort the total radiative flux for the interconnect is calculated simultaneously with the PEN, and later used when solving the energy equation for the interconnect.

Computational efficiency is of concern because the previous radiation model required only the solution of Eq. 3.3.10 with an $\mathrm{F}_{\mathrm{ij}}$ of 1 which gave a fast approximation of the radiative heat flux. This new approach requires several more calculations to be made per iteration. Two approaches for determining $\mathrm{T}^{4}$ were tested. It was found that the "pow" function in math.h is on average 23 times slower then simply multiplying $\mathrm{T}^{*} \mathrm{~T}^{*} \mathrm{~T} * \mathrm{~T}$. By 
storing the temperature raised to the power 4 in an array the number of calculations was reduced from $O(n * n)$ to $O(n)$. The thermal response time of the solid PEN and interconnect is relatively long compared to other response times in the fuel cell system. Hence it may be possible to reuse a single solution for several iterations thus greatly reducing the computational effort.

\subsection{Numerical Method}

As previously noted the computational domain was divided into control volumes along the streamwise direction. A staggered grid is used where the velocity is stored at the control volume east and west face and the pressure is stored at the control volume center. The solution was obtained by solving the conservation equations (Eqs. 3.1.1-4, \& 6) explicitly using a finite volume approach in conjunction with backward Euler method in time. The approach marches in time using a time step determined by a limiting change in temperature for the energy equation. First the boundary conditions are updated by simultaneously calculating the quasi-steady gas phase solution and the distribution of current density over the cell. Then the minimum time step is calculated. The time step, heat flux, and surface temperatures are then communicated between neighboring cells in the stack. The transient fuel cell temperature is then analyzed by solving the top plate, anode gas channel, cathode gas channel, PEN, and separator plate equations. Analysis is conducted starting from the first control volume and proceeds in the streamwise direction. 
A grid convergence analysis was performed for the Psuedo 2-D Fuel Cell Stack Model on a 2 cell stack using $5,8,10,15$, and 20 nodes in the streamwise direction. Beyond 15 nodes the differences in steady state solutions were negligible. The results presented were obtained using 20 computational cells in the $\mathrm{x}$-direction.

For the Reduced Order 3-D Fuel Cell Model a grid convergence study was not done due to limitations of the current implementation. The current model requires each gas channel be defined by a single control volume. The gas channels must be separated by a single control volume. Thus the grid can not be easily refined without programming changes. Eliminating this restriction is included in recommendations for future work.

\subsection{Parallelization of the Fuel Cell Model}

The simulation approach exploits the modular structure of a fuel-cell stack, which enables a straightforward application of the domain decomposition technique for parallel implementation of the code. This is done by simulating each cell with a separate process in a multi-processor computing environment. Since the processes inside each fuel cell are relatively independent from other cells and are coupled only through the well defined fluxes (i.e. heat, mass, current), and the given boundary conditions (voltage, temperature, pressure, etc.), it is possible to arrange a stable and time accurate parallel iteration procedure for a coupled solution of cell properties in the stack without excessive communication overhead. In this implementation, temperature, thermal fluxes 
(convective and radiative), time step, and termination bit are communicated between processes using MPI (Message Passing Interface) to simulate the stack. This parallel solver can be run on a distributed memory computer platform, such as a Beowulf cluster.

A stack of cells can be modeled using several instances of individual cells. MPI library calls are used to communicate variable data between neighboring cells. Each cell in a stack is considered to be in series; therefore, the same total current is maintained by all cells. The smallest time step is used by all cells, because all equations for the stack of cells must be solved using the same time stepping.

Because the separator plate is not porous only thermal transfer must be considered between neighboring cells. The temperature of the separator plate of each cell is communicated with the neighboring cell below it. The convective and radiative heat fluxes are then calculated using the received temperature from the neighbor. These fluxes are then shared between cells and are used when calculating the temperature of the separator plate, anode gas channel, and electrolyte plate at the new time level.

Each cell process is executed independently, therefore it is important for a break signal to be communicated to all cells. In this way if one cell must stop execution all cells will also stop. Through careful communication, it is therefore possible to model a stack of cells using individual processes. The limited number of variables that must be communicated makes decomposition of a fuel cell stack a prime candidate for parallel programming. 


\subsection{The Pseudo 2-D SOFC Stack Model}

As described above, the individual components of the fuel cell are considered using onedimensional layers e.g. fuel channel (layer 1), PEN (layer 2), air channel (layer 3) etc. Communication of fluxes and current density, between layers (as explained above) allows for what may be called a pseudo 2-D solution to be obtained. This approach used in the single cell model is expanded to include multiple cells in a stack with temperature, heat flux, and total current communicated between neighboring cells. Thus, the model has effectively become two-dimensional via layering and stacking. This allowed extracting two-dimensional temperature contours (e.g., see Figs. 4.2.2), albeit the numerical grid in the transverse direction (y-direction normal to the flow direction) is coarse due to the nature of the model.

\subsection{Extension to Counter-Flow Configuration}

The 1-D fuel cell model developed at NETL which was the basis of the Pseudo 2-D SOFC Stack Model was extended to be applicable to counter-flow configurations. The counter-flow configuration would allow the user to solve stacks where the air and fuel flow in opposite directions. Careful management of indices in the computer code allows the solver to remain mostly unchanged. The approach implemented maintains the same numerical approach (upwinding) for solving the flow in the gas channels but electrochemistry and heat transfer are handled using a new index which specifies the 
neighboring control volume of the cathode gas channel. This approach eliminated the problems encountered with "negative" velocities.

The counter-flow configuration was first developed and tested with the original single coflow fuel cell model. Appendix A has some results obtained from simulating a single counter-flow fuel cell. These results from the single cell counter-flow model had the trends typical of a counter-flow fuel cell. The counter-flow model was then implemented into the parallel stack model and the results are presented in Section 4.1.

The extension to counter-flow configuration marks the pinnacle achievement of the Psuedo 2-D SOFC Stack Model. It is now able to solve both co-flow and counter-flow stacks of 40 or more cells. It was decided that the extension to cross-flow configuration be made as part of the development of a new code, the Reduced Order 3-D Fuel Cell Model. This new code will retain several features from the NETL 1-D Single Cell Model namely, the Electrochemistry Model and 1-D channel flow. This will be introduced in detail in the next section. 


\subsection{Reduced Order 3-D Fuel Cell Model}

\subsubsection{Governing Equations}

A model was developed to consider 3D heat transfer and 1D channel flow within a fuel cell which will be applicable to cross-flow fuel cells. The model implementation couples a pseudo-steady state incompressible 1-D flow solver with a 3D heat transfer solver. The Reduced Order 3-D Fuel Cell Model was based on the 1D fuel cell model developed at NETL thus solves the same governing equations described in Section 3.1 and 3.2.

Figures 3.8.1 and 3.8.2 show the class hierarchy and relationship between the elements, components, and models defined by the Multi-Component Multi-Physics (MCMP) scheme. The MCMP scheme allows for the domain to be defined geometrically by its constituent components. These components are made up of elements. Each element type was then associated with a component type and the necessary solvers was simulated using models for each relevant physical process. The figure shows how there are two main branches to the scheme; the solver/model branch and the element/geometry branch. Both of these branches come together at the component level. With this scheme in place, individual models were developed for each of the mass, momentum, energy, and species conservation equations. The governing equations and the approaches used were the same as in the NETL 1-D Single Cell Model. In order to solve cross-flow configurations a 3-D energy equation was solved. The details of the numerical methods used to solve the system of equations are described in more detail in Appendix B. 


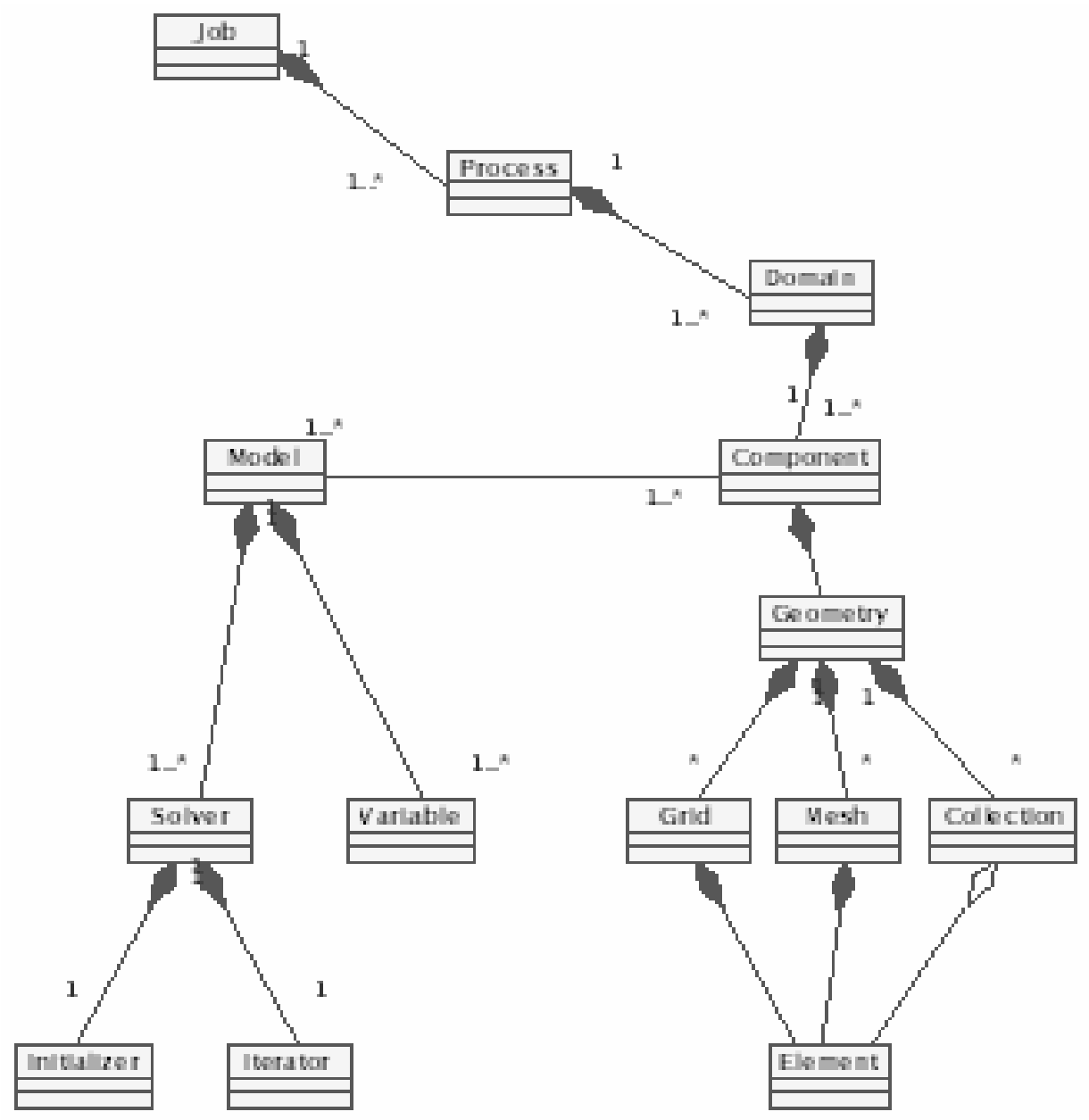

Figure 3.8.1. Diagram of class hierarchy

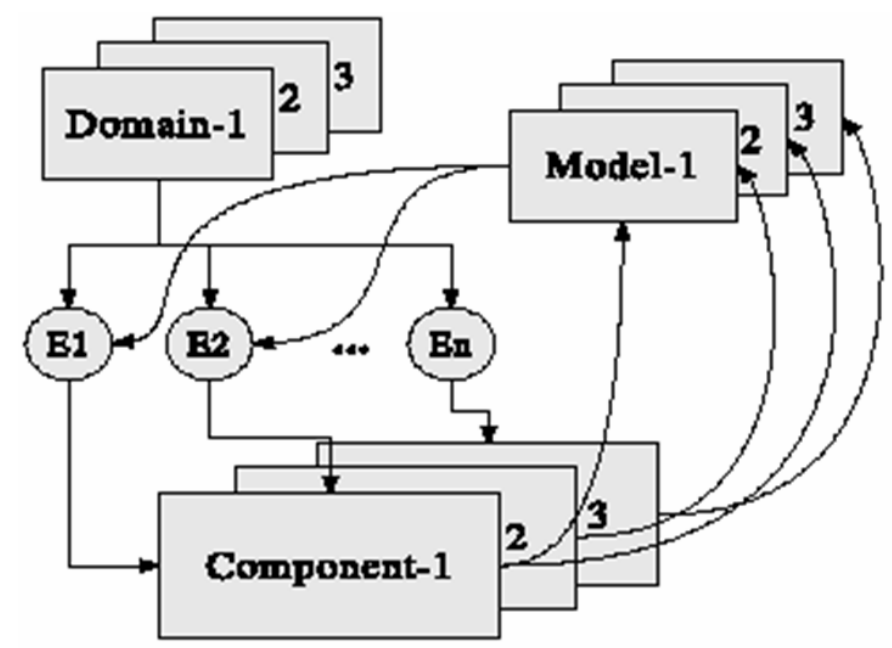

Figure 3.8.2. Relationship between element, component, and model 


\subsubsection{Implementation}

In order to study cross-flow geometries a novel Multi-Component Multi-Physics (MCMP) scheme was instantiated to produce a Reduced Order 3-D Fuel Cell Model. A $\mathrm{C}++$ implementation of the MCMP scheme developed in this study utilized geometry, control volume, component, and model structures allowing each physical model to be solved only for components for which it is relevant. Channel flow dynamics were solved using a 1-D flow model to reduce computational effort.

The development of the cross-flow model proceeded in the direction of micro and macromodeling. A macro-modeling approach serves for a quick analysis of balances in the system based on coarse grained subdivision of the domain into control volumes. The difference from a traditional control-volume approach in CFD is that each controlvolume can implement different physical model, with different variables and numerical solution methods. Thus, a simple engineering approximation for duct fluid flow can be used for the air/fuel channel sub-models, and a more sophisticated electro-chemistry model can be used for the PEN sub-model. The possibility of introducing different empirical models, not necessarily based on PDE, enables a quick solution of a complex system on a collection of relatively large control-volumes.

The alternative approach is to perform a traditional discretization of the domain on a regular grid, and perform the integration, using standard control-volume, finitedifference, or finite-element methods. The second approach, referred to as micro- 
modeling, is more accurate but requires longer processing time and is more difficult to implement for multi-physics systems. For more details see Appendix C.

\subsubsection{Electrochemistry Model}

It was decided that the electrochemistry model from the NETL 1-D Single Cell Model could be used with some modifications in the Reduced Order 3-D Fuel Cell Model. The basic idea is to adapt the electrochemistry model using a black box approach where required input is provided and the solved electrochemistry can then be used to determine the state of the fuel cell for the next time level. Table 3.8.1 lists the physical parameters that are required by the electrochemistry model. Table 3.8.2 lists the variables that change from time level to time level and are required for the solver. Table 3.8.3 lists the variables that are returned by the electrochemistry model. The electrochemistry model calculates the total current and cell voltage with a fixed load resistance. To be applicable to stacks of cells it became necessary to modify the model so that the total current is fixed.

\section{Table 3.8.1. Required configuration parameters for the electrochemistry model} PEN Surface Area

Cathode Cross-sectional Area

Cathode Thickness

Anode Thickness

Electrolyte Thickness

Separator Plate Thickness 


\section{Table 3.8.2. Required variables for the electrochemistry model}

PEN Temperature

Separator Plate Temperature

Air Gas Channel Pressure

Air Gas Channel Velocity

Air Gas Channel Density

Air Gas Channel Oxygen Mole Fraction

Air Gas Channel Nitrogen Mole Fraction

Fuel Gas Channel Pressure

Fuel Gas Channel Hydrogen Mole Fraction

Fuel Gas Channel Water Mole Fraction

Separator Temperature

Load Resistance

Table 3.8.3. Variables returned by the electrochemistry model

Load Voltage

Total Current

Current Density

Entropy Heat Generation

One goal of the Reduced Order 3-D Fuel Cell Model was to expand the NETL 1-D Single Cell Model to make it applicable to cross-flow geometries. In the process the Reduced Order 3-D Fuel Cell Model transitioned from a 1-D cell, pseudo 2-D stack model into a 3-D transient model with 1-D transient gas channel model. Gemmen and Johnson (2004) previously expanded the NETL 1-D Single Cell Model to a cross-flow geometry using an approach illustrated in Figure 3.8.3. Fluid flow in the air and fuel gas channels is indicated with arrows. In their approach the walls of the channel are considered to be thin. And are represented in the code trough the use of contact resistances and increased interconnect mass. This approach allows the electrolyte to be solved as though the entire surface is adjacent to both air and fuel gas channels. Table 3.8.1 shows that it is necessary 
to input data from neighboring air and fuel gas channels in order for the electrochemistry model to have sufficient boundary conditions.

Figure 3.8.4 shows how the cross-flow geometry is subdivided into control volumes in the Reduced Order 3-D Fuel Cell Model. The control volumes are separated with solid lines. The grid shown is for the non-uniform case where the channels are wider then the channel walls. The channel walls are indicated by hashed regions. Double hashed areas indicate locations where channel wall intersects channel wall. These intersection areas are believed to have the least electrochemistry. Dashed lines are overlaid to show how the same approach used by Gemmen and Johnson (2004) might be applied. The dashed lines divide the geometry with a coarse grid similar to Figure 3.8.3.

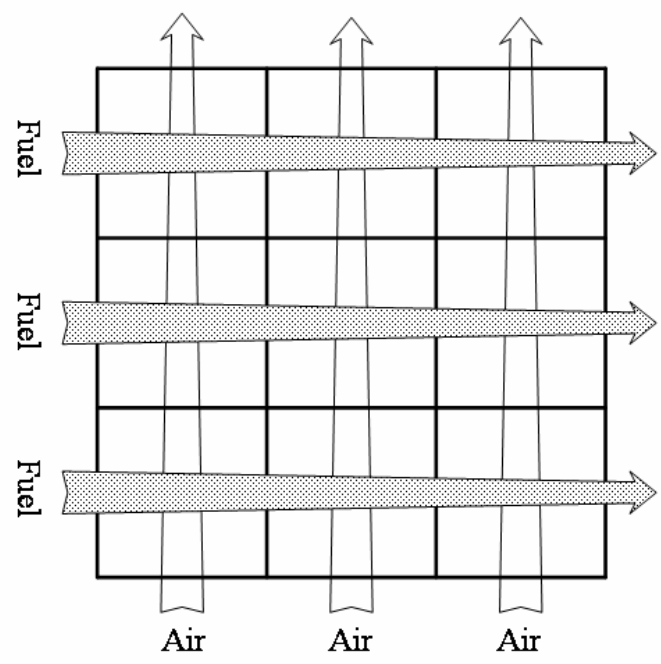

Figure 3.8.3. Cross-Flow mesh typical utilized by Gemmen and Johnson (2004) 


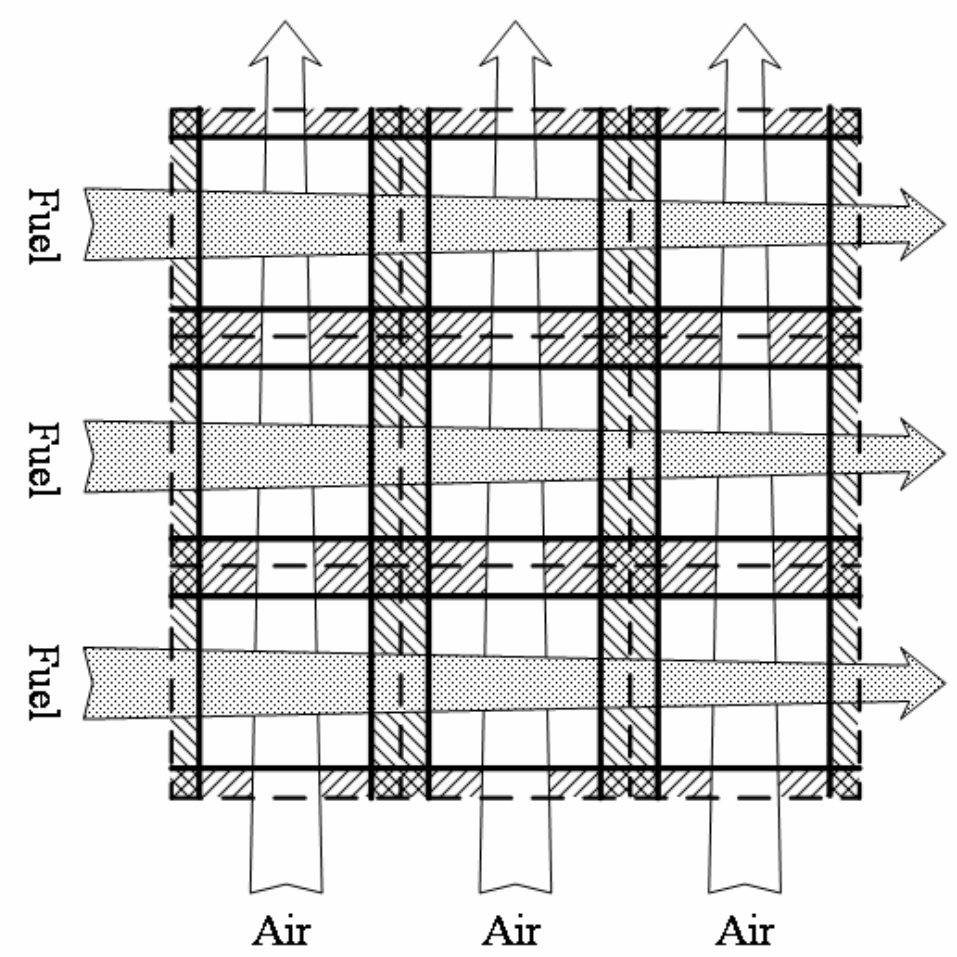

Figure 3.8.4. Coarse electrochemistry mesh (dashed lines) overlaid on fine channel mesh viewed from top (hash lines depict channel walls) for non-uniform fine grid

It is suggested that the required transient variables listed in Table 3.8.2 be obtained from the fine grid air and fuel gas channels. The electrochemistry model can then determine the variables listed in Table 3.8.3 for the coarse grid. An algebraic relation can then be used to transfer the current density and entropy heat generation to the fine grid.

Assuming that the components of the current in the PEN assembly that are not perpendicular to the electrolyte surface can be neglected, then the total current must be the same for the electrolyte as it is for the anode and cathode electrodes. The total electrolyte current can be found from: 
$I_{e}=i_{e} A_{e, \text { coarse }}$

where the total current passing through the electrolyte, $I_{e}$, is obtained from the current density for that control volume, $i_{e}$, and the area of the electrolyte on the coarse grid, $A_{e, \text { coarse }}$.

For this study current distribution within the coarse grid is considered to be uniform within each coarse grid control volume. Therefore the current is redistributed based on area ratio which accounts for the coincidental area that is part of both the fine and coarse grid. This is shown for the case of the anode in Figure 3.8.5.

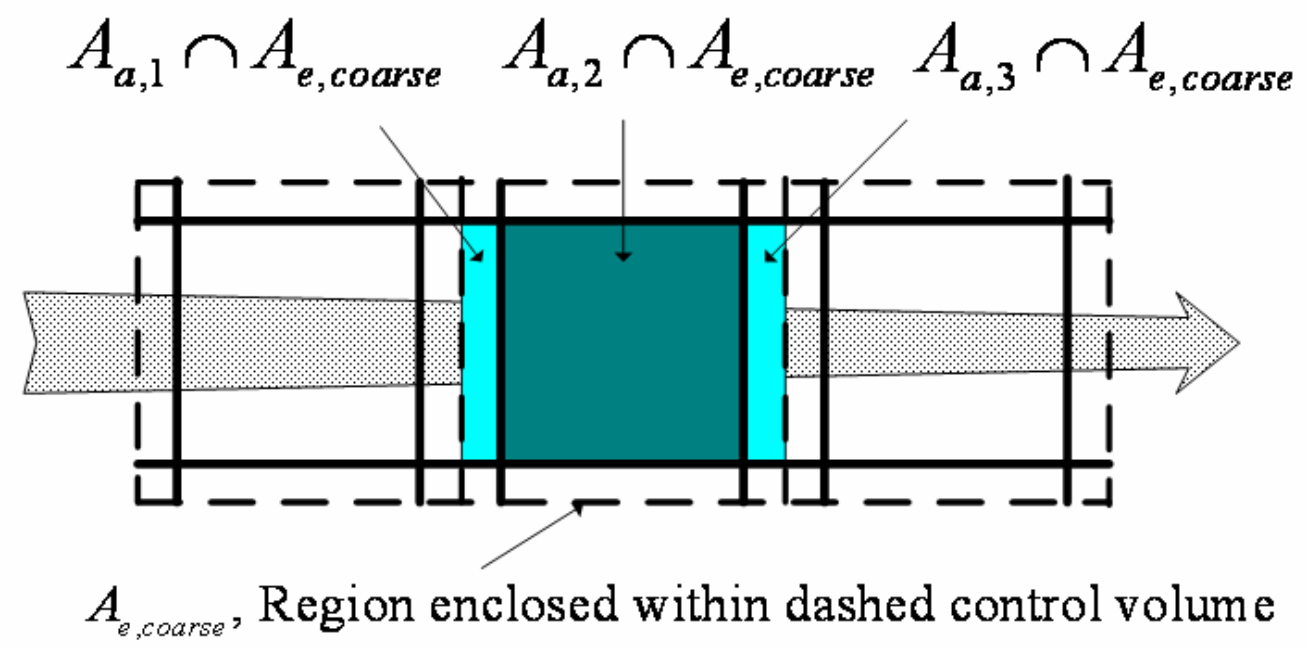

Figure 3.8.5. Intersection of fine anode grid and coarse electrolyte grids

In Figure 3.8.5 $A_{a, 1} \cap A_{e, \text { caarse }}, A_{a, 2} \cap A_{e, \text { coarse }}, A_{a, 3} \cap A_{e, \text { coarse }}$ denote the area of the anode which intersects with the area of the electrolyte on the coarse grid. An area ratio is then 
calculated by considering the ratio of this intersected area to the sum of the intersected areas. Using this approach the anode current and cathode current can then be found from:

$$
\begin{gathered}
I_{a, 1}=I_{e} \frac{A_{a, 1} \cap A_{e, \text { coarse }}}{\sum_{n=1}^{N} A_{a, n} \cap A_{e, \text { coarse }}} \\
I_{c, 1}=I_{e} \frac{A_{c, 1} \cap A_{e, \text { coarse }}}{\sum_{n=1}^{N} A_{c, n} \cap A_{e, \text { coarse }}}
\end{gathered}
$$

Once the current density has been determined then the depletion or creation of species due to electrochemistry in the air and fuel gas channels can be calculated from the appropriate electrode. 


\subsection{APPLICATION OF PSUEDO 2-D STACK MODEL}

\subsection{Verification of Fuel Cell Stack Model}

\section{Independent 1-D Thermal Stack Model}

An independent verification of the Pseudo 2-D Fuel Cell Stack Model was conducted by developing an 1-D Thermal Stack Model and studying various temperature profiles that exist for a 20 cell stack. The Pseudo 2-D Fuel Cell Stack Model produced temperature profiles near the center line of the stack which had an "S" shape (see Figure 4.2.3b and Figure 4.2.3c). By developing a simple model which solved a 1-D energy equation for a 20 cell stack it was possible to see the influence of the various heat fluxes on the temperature of the stack. Results from this study showed that the " $\mathrm{S}$ " shape temperature profile can be reproduced using an independent model.

The 20 cell stack was discretized such that each unit cell was represented by four control volumes (each representing the complete fuel channel, PEN, air channel, and separator). Table 4.1.1 gives the dimensions and other model parameters used for all three cases. The inlet mass flow rate and heat transfer coefficients for the air and fuel channel are given in Table 4.1.2 for the three cases. For this study there was no mass transfer through the electrolyte. Thus the outlet mass flow rate was the same as the inlet. Wall heat fluxes 
were calculated based on the prescribed heat transfer coefficients. Total heat generation (representative of both Ohmic heating and from electrochemical reactions) for each cell was $350 \mathrm{~J} / \mathrm{s}$ and was divided between the interconnect/separator plate at a ratio of 0.15 .

Table 4.1.1. Fixed model parameters (1-D thermal stack model)

\begin{tabular}{|c|c|}
\hline Width of Stack, $\Delta \mathrm{x}[\mathrm{m}]$ & 0.09 \\
\hline Depth of Stack, $\Delta \mathrm{z}[\mathrm{m}]$ & 1.0 \\
\hline Fuel Channel Height, $\Delta \mathrm{y}[\mathrm{m}]$ & 0.001 \\
\hline PEN Height, $\Delta \mathrm{y}[\mathrm{m}]$ & 0.001035 \\
\hline Separator Height, $\Delta \mathrm{y}[\mathrm{m}]$ & 0.0075 \\
\hline Air Channel Height, $\Delta \mathrm{y}[\mathrm{m}]$ & 0.003 \\
\hline Specific Heat for Fuel $[\mathrm{J} / / \mathrm{kg}-\mathrm{K}]$ & 14760 \\
\hline Specific Heat for Air $[\mathrm{J} / \mathrm{kg}-\mathrm{K}]$ & 1130 \\
\hline Specific Heat for PEN $[\mathrm{J} / \mathrm{kg}-\mathrm{K}]$ & 800 \\
\hline Specific Hear for Separator Plate $[\mathrm{J} / \mathrm{kg}-\mathrm{K}]$ & 400 \\
\hline Total Heat Generation for each Cell $[\mathrm{J} / \mathrm{s}]$ & 350 \\
\hline Heat Generation in Separator Plate/ & 0.15 \\
\hline Total Heat Generation & 1073 \\
\hline Inlet Temperature of Fuel $[\mathrm{K}]$ & 1073 \\
\hline Inlet Temperature of Air $[\mathrm{K}]$ & 1200 \\
\hline Initial Temperature of Stack $[\mathrm{K}]$ &
\end{tabular}

Table 4.1.2 gives the parameters that were varied between the three cases shown. All three cases had the same fuel mass flow rate. For case 2 and 3 the air mass flow rate was increased from $3 \mathrm{e}-3$ to $2 \mathrm{~kg} / \mathrm{s}$ and the heat transfer coefficient was decreased from 50 to 8 $\mathrm{J} / \mathrm{s}-\mathrm{m}^{2}-\mathrm{K}$ for the air channel. The difference between Case 2 and 3 was the decrease in the heat transfer coefficient from 300 to $78 \mathrm{~J} / \mathrm{s}-\mathrm{m}^{2}-\mathrm{K}$ for the fuel channels.

Table 4.1.2. Parameter that were varied

\begin{tabular}{|c|c|c|c|}
\hline & Case 1 & Case 2 & Case 3 \\
\hline Fuel Mass Flow Rate $[\mathrm{kg} / \mathrm{s}]$ & $1 \mathrm{e}-6$ & $1 \mathrm{e}-6$ & $1 \mathrm{e}-6$ \\
\hline Air Mass Flow Rate $[\mathrm{kg} / \mathrm{s}]$ & $3 \mathrm{e}-3$ & 2 & 2 \\
\hline Fuel Heat Transfer Coefficient $\left[\mathrm{J} / \mathrm{s}-\mathrm{m}^{2}-\mathrm{K}\right]$ & 300 & 300 & 78 \\
\hline Air Heat Transfer Coefficient $\left[\mathrm{J} / \mathrm{s}-\mathrm{m}^{2}-\mathrm{K}\right]$ & 50 & 8 & 8 \\
\hline
\end{tabular}


Figures 4.1.1-3 show the temperature profiles obtained with the 1-D Thermal Stack Model for a stack of 20 fuel cells for the three cases described in Table 4.1.2. Figure 4.1.1 has the "s" shaped curve that was commonly found in the results obtained with the Pseudo 2-D Stack Model (see Figure 4.2.3b and Figure 4.2.3c).

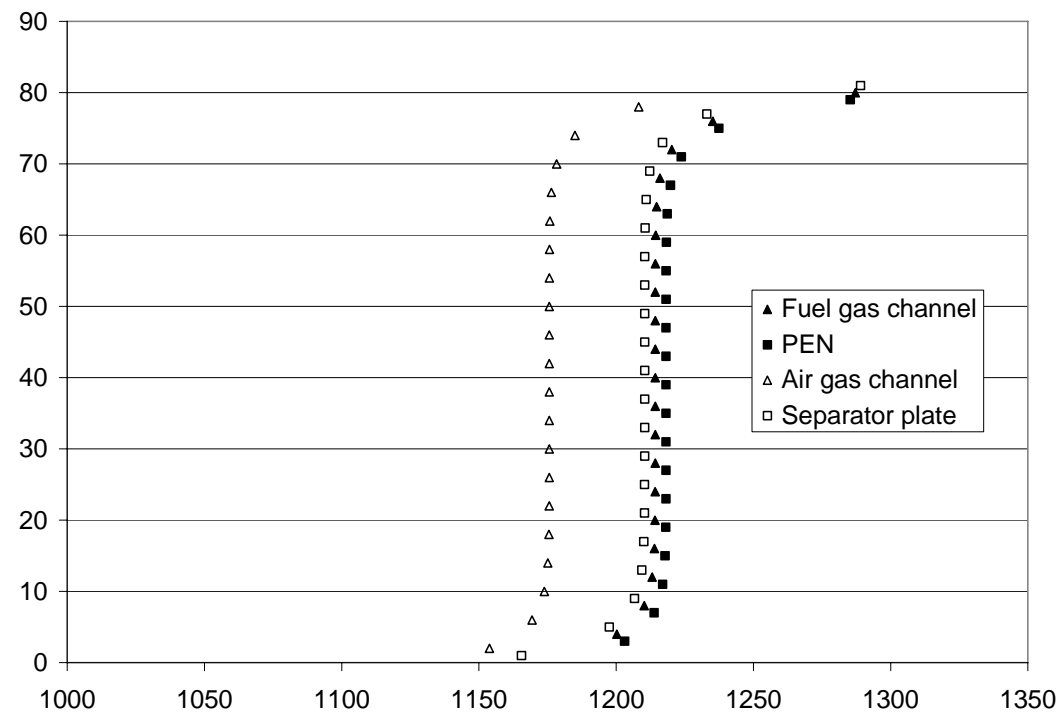

Figure 4.1.1. Temperature profile for 20 cell stack (case 1)

Figures 4.1.2 and 4.1.3 show the influence of the heat transfer coefficient in the fuel channel on the temperature profile. Both Figures 4.1.2 and 4.1.3 show cases where the air channel is significantly cooler than the PEN, separator plate, and fuel channel due to the increased air mass flow rate of $2 \mathrm{~kg} / \mathrm{s}$. The fuel channel can have nearly the same temperature as the PEN and separator ( Figure 4.1.2) in cases where the heat transfer coefficient is large enough that a high wall heat flux exists when compared to the difference in energy transported into and out of the channel control volume. In other 
words, if the fuel channel mass flow rate is relatively small and the wall heat flux is large enough, the mass in the fuel channel control volume can be heated to a temperature close to that of the neighboring fuel cell components.

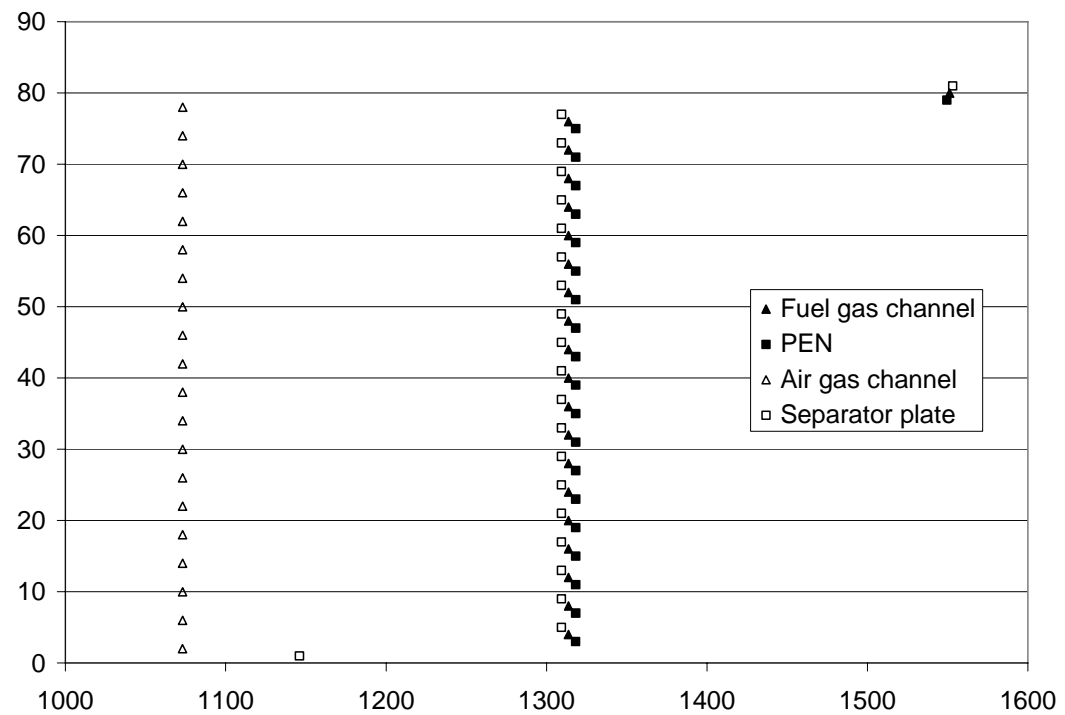

Figure 4.1.2. Temperature profile for 20 cell stack (case 2)

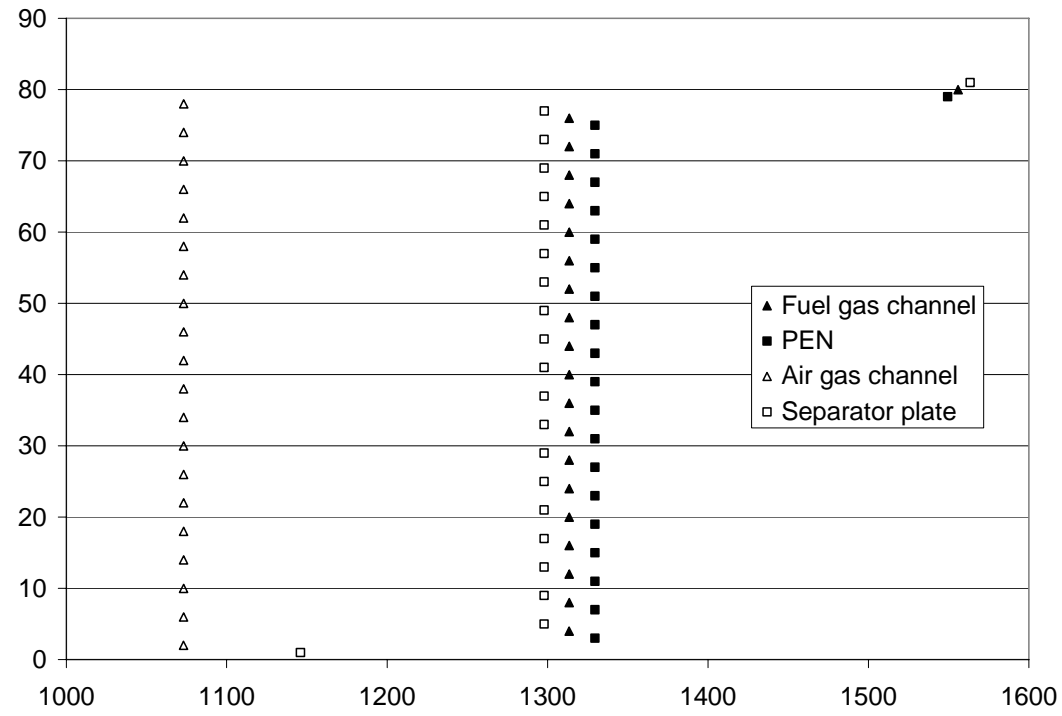

Figure 4.1.3. Temperature profile for 20 cell stack (case 3) 


\section{Counter-flow using Pseudo 2-D Fuel Cell Stack Model}

The Pseudo 2-D Fuel Cell Stack Model was used to simulate a 5 cell counter-flow anode supported SOFC stack. The trends observed in the temperature were found to be consistent with results published by Achenbach (1994). Each cell was defined by the dimensions listed in Table 4.1.2 and the model parameters are listed in Table 4.1.3.

Table 4.1.2. Dimensions of anode supported electrolyte fuel cell.

\begin{tabular}{|c|c|}
\hline SOFC Component & [m] \\
\hline Cell Length & $1.0 \mathrm{E}-01$ \\
\hline Grid Length, $\Delta \mathrm{x}$ & $5.0 \mathrm{E}-02$ \\
\hline Cell Width, $\Delta \mathrm{z}$ & $1.0 \mathrm{E}-00$ \\
\hline Fuel Gas Channel Height, $\Delta \mathrm{y}$ & $1.0 \mathrm{E}-03$ \\
\hline Air Gas Channel Height, $\Delta \mathrm{y}$ & $3.0 \mathrm{E}-03$ \\
\hline Electrolyte Thickness, $\Delta \mathrm{y}$ & $1.0 \mathrm{E}-05$ \\
\hline Anode Electrode Thickness, $\Delta \mathrm{y}$ & $1.0 \mathrm{E}-03$ \\
\hline Cathode Electrode Thickness, $\Delta \mathrm{y}$ & $2.5 \mathrm{E}-05$ \\
\hline Separator Thickness, $\Delta \mathrm{y}$ & $7.5 \mathrm{E}-04$ \\
\hline
\end{tabular}

Table 4.1.3. Material properties and model parameters (counter-flow pseudo 2-D FC Stack Model)

\begin{tabular}{|c|c|}
\hline Cell Heat Capacity $[\mathrm{J} / \mathrm{kg}-\mathrm{K}]$ & $8.00 \mathrm{E}+02$ \\
\hline Cell Density $\left[\mathrm{kg} / \mathrm{m}^{3}\right]$ & $1.50 \mathrm{E}+03$ \\
\hline Separator Heat Capacity $[\mathrm{J} / \mathrm{kg}-\mathrm{K}]$ & $4.00 \mathrm{E}+02$ \\
\hline Separator Density $\left[\mathrm{kg} / \mathrm{m}^{3}\right]$ & $8.00 \mathrm{E}+03$ \\
\hline No. Axial Nodes & 20 \\
\hline Anode Inlet Temperature $[\mathrm{K}]$ & 1173 \\
\hline Anode Inlet Pressure $[\mathrm{Pa}]$ & $1.01 \mathrm{E}+05$ \\
\hline $\mathrm{H}_{2}$ Anode Inlet Mole Fraction & $9.70 \mathrm{E}-01$ \\
\hline $\mathrm{H}_{2} \mathrm{O}$ Anode Inlet Mole Fraction & $3.00 \mathrm{E}-02$ \\
\hline Cathode Inlet Temperature $[\mathrm{K}]$ & 1173 \\
\hline Cathode Inlet Pressure $[\mathrm{Pa}]$ & $1.01 \mathrm{E}+05$ \\
\hline $\mathrm{O}_{2}$ Cathode Inlet Mole Fraction & $2.10 \mathrm{E}-01$ \\
\hline $\mathrm{N}_{2}$ Cathode Inlet Mole Fraction & $7.90 \mathrm{E}-01$ \\
\hline Contact + Separator Resistance $\left[\Omega / \mathrm{cm}^{2}\right]$ & $1.0 \mathrm{E}-01$ \\
\hline Limiting Current Density $\left[\mathrm{A} / \mathrm{m}^{2}\right]$ & $4.0 \mathrm{E}+03$ \\
\hline Exchange Current Density[$\left[\mathrm{A} / \mathrm{m}^{2}\right]$ & $5.5 \mathrm{E}+03$ \\
\hline
\end{tabular}


Figure 4.1.4 presents the steady state PEN temperature for a 5 cell counter-flow anode supported SOFC stack operating at $6666 \mathrm{~A} / \mathrm{m}^{2}$. Similar results were presented by Achenbach (1994) using a 3D numerical model. Data points along the centerline of temperature contour plot presented by Achenbach for the cross-flow case were plotted in Figure 4.1.4 for comparison. However, direct comparison with the results from Achenbach cannot be performed due to many differences between these cases. Achenbach's solution was obtained with internal reforming of methane, and with different stoichiometry, total current, and fuel gas compositions, thus lower temperatures were observed. However a qualitative comparison in Figure 4.1.4 shows that the same trend can be observed in the temperature profile, with the maximum temperature occurring at approximately the same location in both counter-flow examples.

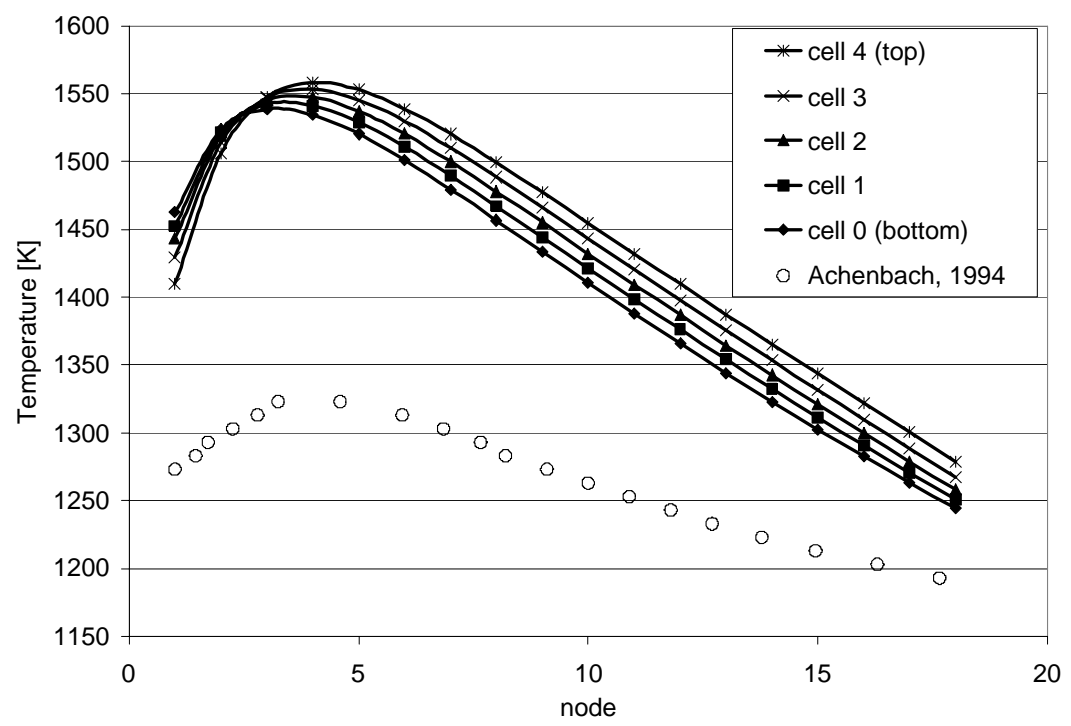

Figure 4.1.4. Comparison of steady state PEN temperature profiles for 5 cell anode supported counter-flow stack at $6666 \mathrm{~A} / \mathrm{m}^{2}$ and results from Achenbach (1994). 


\subsection{Influence of Increasing Stack Size}

The present computational model was applied to stacks of 5, 10, and 20 cells. Uniform flow distribution was prescribed to both the fuel and air gas channels. Results were obtained with two different inlet temperatures $1073 \mathrm{~K}$ and $1173 \mathrm{~K}$. For all cases studied, the applied current loading was $667 \mathrm{~mA} / \mathrm{cm}^{2}$. Adiabatic boundary conditions were imposed at the top and bottom of the stack. Therefore heat transport to and from the stack is limited to convection from the air and fuel gas channels.

Figure 4.2.1 represents the unit cell geometry. The stream-wise direction is from left to right. The 1-D model assumes a depth of unit length $(1 \mathrm{~m})$. The fuel and air gas channels extend $0.5 \mathrm{~cm}$ up and downstream of the active area of the fuel cell. The cell is divided into 20 control volumes of $0.5 \mathrm{~cm}$ width in the stream-wise direction. 


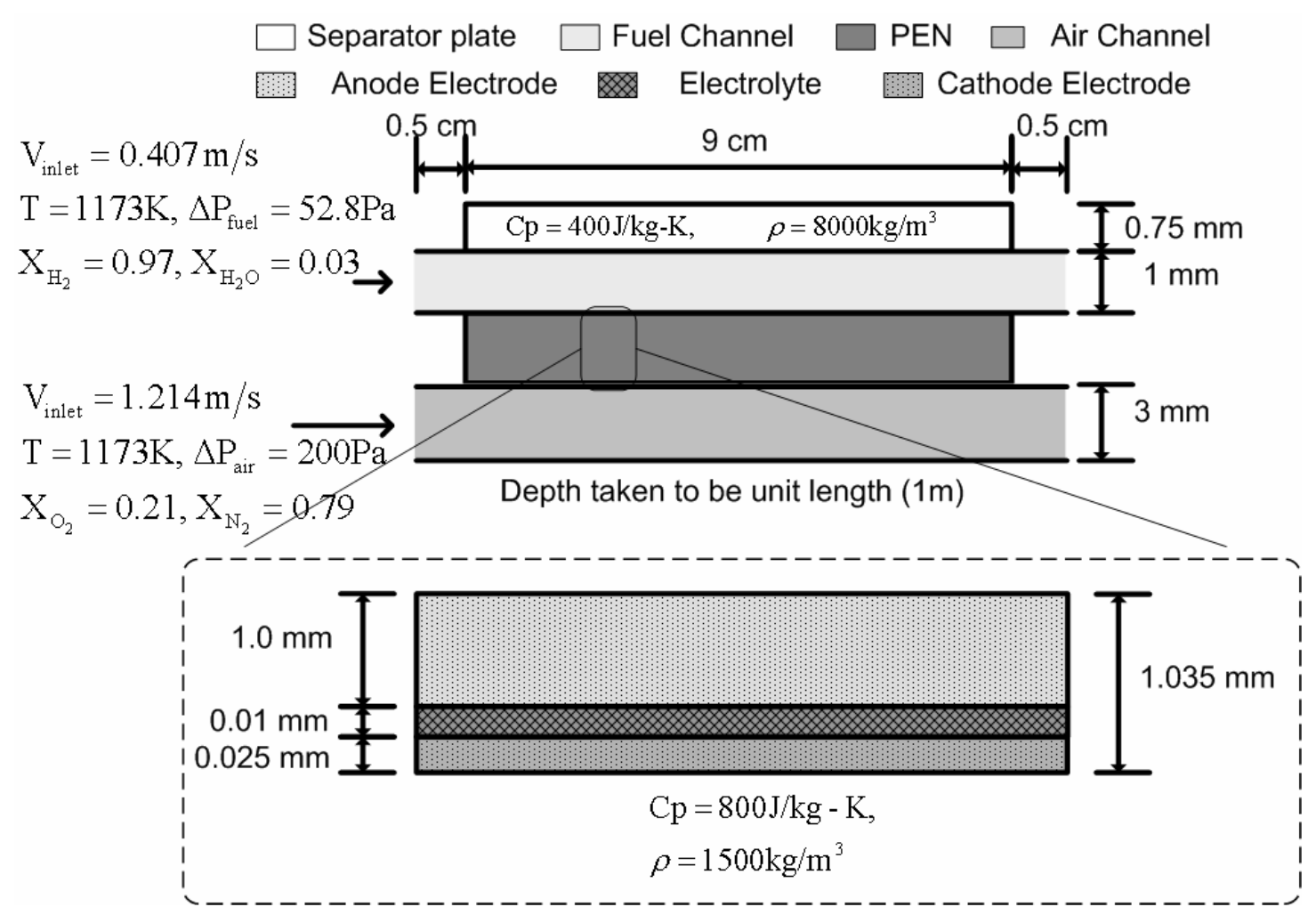

Figure 4.2.1. Geometry of unit cell with exploded view of anode supported

electrolyte and model parameters.

Table 4.2.1 and 4.2.2 list the physical dimensions, material properties and model parameters used. The geometry is defined by the cell length, gas channel heights, and component thicknesses.

Table 4.2.1. Physical dimensions of single fuel cell with anode supported electrolyte.

\begin{tabular}{|c|c|}
\hline SOFC Component & [m] \\
\hline Cell Length & $1.0 \mathrm{E}-01$ \\
\hline Grid Length, $\Delta \mathrm{x}$ & $5.0 \mathrm{E}-02$ \\
\hline Fuel Gas Channel Height, $\Delta \mathrm{y}$ & $1.0 \mathrm{E}-03$ \\
\hline Air Gas Channel Height, $\Delta \mathrm{y}$ & $3.0 \mathrm{E}-03$ \\
\hline Electrolyte Thickness, $\Delta \mathrm{y}$ & $1.0 \mathrm{E}-05$ \\
\hline Anode Electrode Thickness, $\Delta \mathrm{y}$ & $1.0 \mathrm{E}-03$ \\
\hline Cathode Electrode Thickness, $\Delta \mathrm{y}$ & $2.5 \mathrm{E}-05$ \\
\hline Separator Thickness, $\Delta \mathrm{y}$ & $7.5 \mathrm{E}-04$ \\
\hline
\end{tabular}


Table 4.2.2. Material properties and model parameters. (increasing stack size case)

\begin{tabular}{|c|c|}
\hline Cell Heat Capacity $[\mathrm{J} / \mathrm{kg}-\mathrm{K}]$ & $8.00 \mathrm{E}+02$ \\
\hline Cell Density $\left[\mathrm{kg} / \mathrm{m}^{3}\right]$ & $1.50 \mathrm{E}+03$ \\
\hline Separator Heat Capacity $[\mathrm{J} / \mathrm{kg}-\mathrm{K}]$ & $4.00 \mathrm{E}+02$ \\
\hline Separator Density $\left[\mathrm{kg} / \mathrm{m}^{3}\right]$ & $8.00 \mathrm{E}+03$ \\
\hline No. Axial Nodes & 20 \\
\hline Anode Inlet Temperature $[\mathrm{K}](2$ cases $)$ & 1073 \\
& 1173 \\
\hline Anode Inlet Pressure $[\mathrm{Pa}]$ & $1.01 \mathrm{E}+05$ \\
\hline $\mathrm{H}_{2}$ Anode Inlet Mole Fraction & $9.70 \mathrm{E}-01$ \\
\hline $\mathrm{H}_{2}$ O Anode Inlet Mole Fraction & $3.00 \mathrm{E}-02$ \\
\hline Cathode Inlet Temperature $[\mathrm{K}](2$ cases $)$ & 1073 \\
& 1173 \\
\hline Cathode Inlet Pressure $[\mathrm{Pa}]$ & $1.01 \mathrm{E}+05$ \\
\hline $\mathrm{O}_{2}$ Cathode Inlet Mole Fraction & $2.10 \mathrm{E}-01$ \\
\hline $\mathrm{N}_{2}$ Cathode Inlet Mole Fraction & $7.90 \mathrm{E}-01$ \\
\hline Contact + Separator Resistance $\left[\Omega / \mathrm{cm}^{2}\right]$ & $1.0 \mathrm{E}-01$ \\
\hline Limiting Current Density $\left[\mathrm{A} / \mathrm{m}^{2}\right]$ & $4.0 \mathrm{E}+03$ \\
\hline Exchange Current Density $\left[\mathrm{A} / \mathrm{m}^{2}\right]$ & $5.5 \mathrm{E}+03$ \\
\hline
\end{tabular}

The resistivities of the anode electrode, electrolyte, cathode electrode, and separator plate are functions of temperature. These empirical functions are obtained by curve fitting to experimental data and were obtained from Gemmen etal. (2000).

Results are first presented for the cases where a $1073 \mathrm{~K}$ inlet temperature was prescribed for the anode and cathode gas channels. The influence of stack size on cell voltage and temperature is investigated and results are presented in detail. Tabulated results from other cases are presented for brevity.

Figure 4.2.2 depicts the temperature contours observed for a stack of 20 planar solid oxide fuel cells. Predominant features are the cool air channels entering from the left at 
$1073 \mathrm{~K}$ and exiting to the right at an average temperature of $1300 \mathrm{~K}$. It is observed that cell temperatures increase from bottom to top.

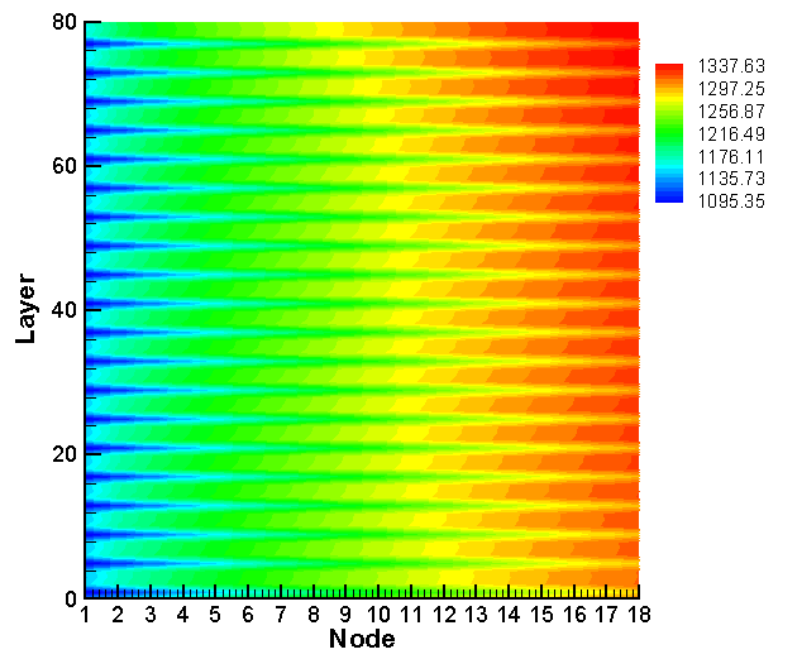

Fig. 4.2.2. Temperature contours for 20 cell stack, $1073 \mathrm{~K}$ inlet for an average current density of $667 \mathrm{~mA} / \mathrm{cm}^{2}$.

Figure 4.2.3a-c depict temperature profiles in the vertical direction near the middle of the streamwise direction (at $\mathrm{x} / \mathrm{L}=0.55$, i.e. node 10 ) for a 5 and 20 cell stack. Temperature profiles are nearly linear for small 5 cell stacks; however, for the larger 20 cell stack, interior cells appear to have nearly uniform temperature with cells towards the top and bottom being influenced by the top and bottom cells. 


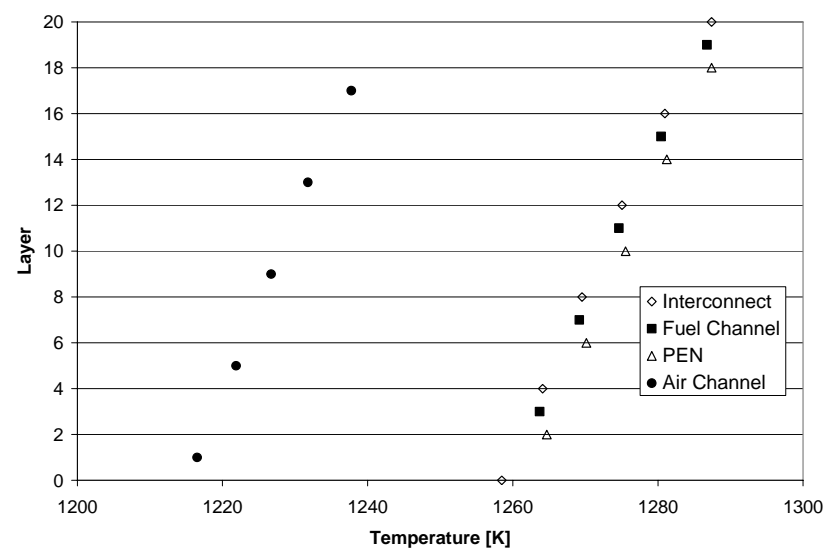

Figure 4.2.3a. Temperature profile at $\mathrm{x} / \mathrm{L}=0.55$ (node 10$)$ within a 5 cell stack for an average current density of $667 \mathrm{~mA} / \mathrm{cm}^{2}$.

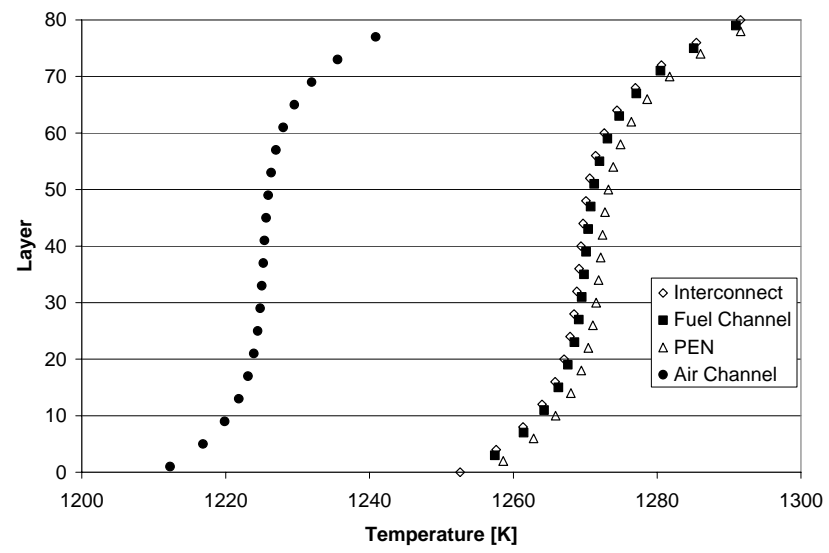

Figure 4.2.3b. Temperature profile at $\mathrm{x} / \mathrm{L}=\mathbf{0 . 5 5}$ (node 10) within a 20 cell stack for an average current density of $667 \mathrm{~mA} / \mathrm{cm}^{2}$.

Figure $4.2 .3 \mathrm{c}$ shows the steeper temperature gradients at the top and bottom observed with the radiation model turned off resulting in a more sharp " $\mathrm{S}$ " shaped profile. This observation supports results presented in Section 4.4 which indicated the importance of radiative heat transfer for SOFCs. Variations in temperature, like those observed near the 
top and bottom of the stack in Figure 4.2.3b and 4.2.3c, can cause significant thermal stresses. The impact of these variations was considered in a study conducted by Valluru (2005). In this case neglecting radiation might greatly over-exaggerate the thermal stresses.

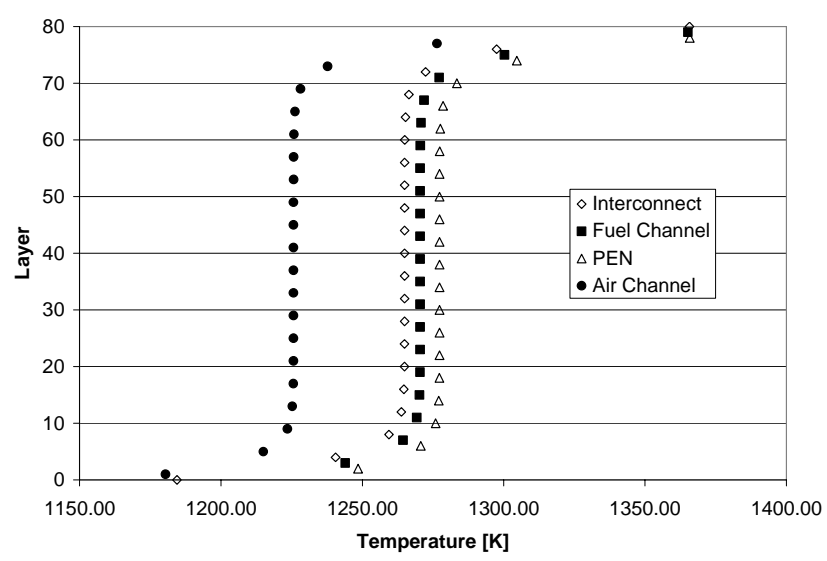

Fig. 4.2.3c. Temperature profile at $\mathrm{x} / \mathrm{L}=\mathbf{0 . 5 5}$ (node 10) within a 20 cell stack neglecting radiation effects for an average current density of $667 \mathrm{~mA} / \mathrm{cm}^{2}$.

Figures 4.2.4a and 4.2.4b depict the cell voltage variation for 5 cell and 20 cell stacks. Similar trends are observed in the cell voltages as was seen in the temperature profiles. A relatively small cell-to-cell voltage variation of $0.7 \%$ and $1.1 \%$ was observed for the 5 cell and 20 cell stacks, respectively. Of interest, however, is the nearly linear variation observed for the 5 cell stack whereas for the larger 20 cell stack an asymmetric profile was obtained where the cell voltage was influenced by the top and bottom cells. This trend was also observed by Lin et al. (2003). Figure 4.2.4c shows cell voltage variations in a 30 cell stack. They also noted similar behavior in 8 and 15 cell stacks. 
It is normally assumed that interior cells will have nearly uniform performance which is an appropriate assumption for this case given the relatively small variation observed in cell voltage.

Figure 4.2.5 depicts cell to cell voltage variations observed in a 20 cell stack with nonuniform fuel flow distribution. A 7\% variation in cell voltage was observed when $20 \%$ of the fuel flow was taken from the bottom cell (cell 0) and added to the neighboring cell (cell 1). This non-uniform distribution of fuel flow resulted in negligible changes in the temperature profile.

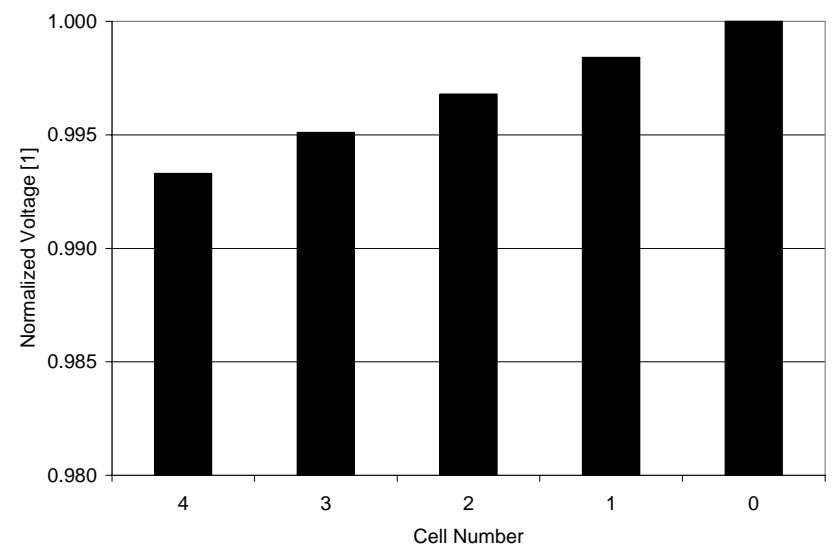

Fig. 4.2.4a. Cell voltage variation within a 5 cell stack normalized with the highest cell voltage of $0.70 \mathrm{~V}$ for an average current density of $667 \mathrm{~mA} / \mathrm{cm}^{2}$. 


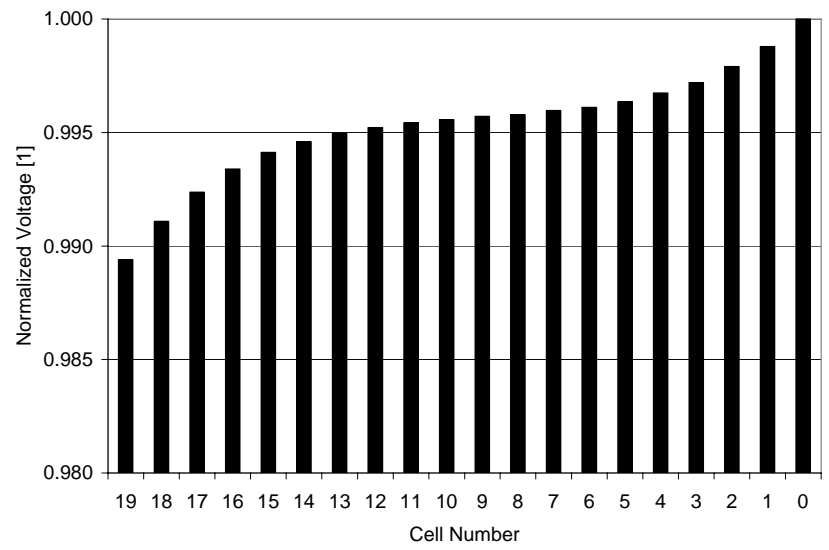

Fig. 4.2.4b. Cell voltage variation within a 20 cell stack normalized with the highest cell voltage of $0.70 \mathrm{~V}$ for an average current density of $667 \mathrm{~mA} / \mathrm{cm}^{2}$.

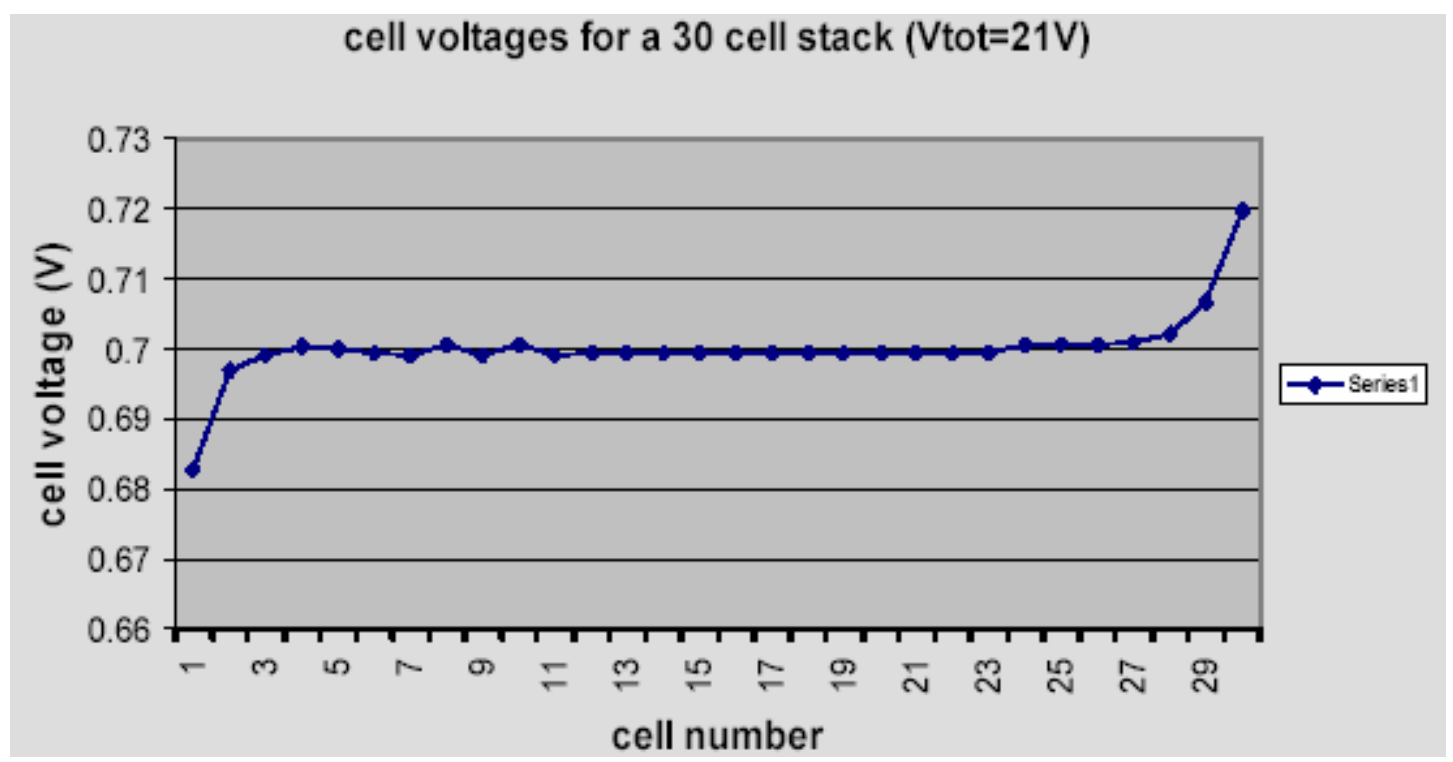

Fig. 4.2.4c. Cell voltage variation within a 30 cell stack (Lin et al., 2003). 


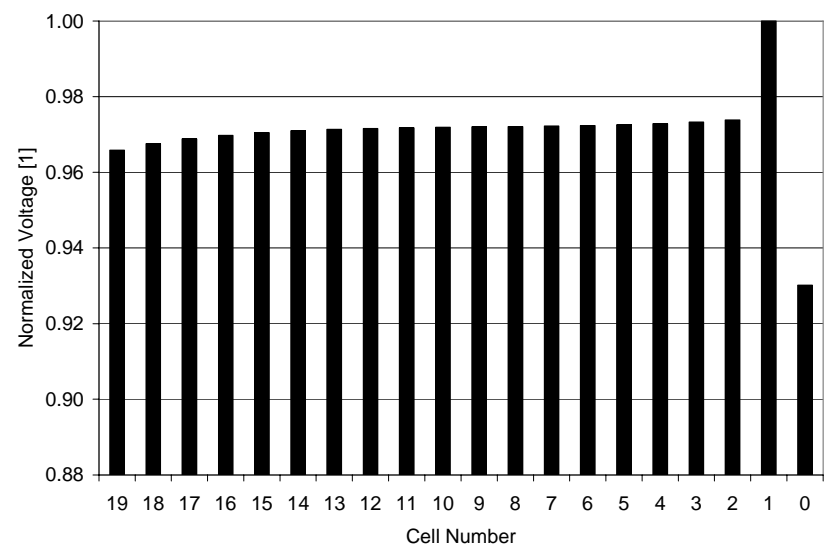

Fig. 4.2.5. Cell voltage variation within a 20 cell stack due to non-uniform fuel inflow normalized with the highest cell voltage of $0.71 \mathrm{~V}$ for an average current density of $667 \mathrm{~mA} / \mathrm{cm}^{2}$.

Tables 4.2.3 and 4.2.4 show temperature changes observed for cases of different stack sizes. An $1173 \mathrm{~K}$ inlet temperature was prescribed for both the fuel and air channels. Increasing the stack size only contributed to small changes in the temperature distribution. It was observed that as stack size increased the average temperature of the PEN decreased slightly. Also temperature variation in the PEN increases in a non-linear manner with stack size. The results indicate that as stack sizes increase beyond 20 cells, more of the center cells will operate near the average cell temperature. Thus for very large stacks it may be possible to represent the majority of the stack using a single cell approximation assuming that the flow distribution is uniform. 
Table 4.2.3. Variation of temperature within the PEN for 5, 10, and 20 cell stacks operating at an average current density of $667 \mathrm{~mA} / \mathrm{cm}^{2}$ with anode and cathode inlet temperatures of 1173K.

\begin{tabular}{|c|c|c|}
\hline & $\left.\Delta T_{P E N}\right|_{x / L=0.55}[\mathrm{~K}]$ & $\left.T_{P E N, A V E}\right|_{x / L=0.55}[\mathrm{~K}]$ \\
\hline 5 cell & 19.91 & 1409.52 \\
\hline 10 cell & 31.20 & 1407.88 \\
\hline 20 cell & 33.63 & 1406.8 \\
\hline
\end{tabular}

Table 4.2.4 presents the maximum difference between the inlet and outlet temperature for both the fuel and air gas channel. The maximum difference was found to be in the top cell of the stack. Thus it was observed that with increasing stack sizes larger temperature gradients may be observed in the top cell. However it should be noted that the average outlet temperature went down with increasing stack size following the same trend shown in Table 4.2.3 for the average PEN temperature.

Table 4.2.4. Variation of temperature within the fuel and air gas channels in the streamwise direction for 5,10 , and 20 cell stacks operating at an average current density of $667 \mathrm{~mA} / \mathrm{cm}^{2}$ with fuel and air inlet temperatures of $1173 \mathrm{~K}$.

\begin{tabular}{|c|c|c|}
\hline & $\Delta T_{\text {Fuel }}[\mathrm{K}]$ & $\Delta T_{\text {Air }}[\mathrm{K}]$ \\
\hline 5cell & 298.16 & 277.17 \\
\hline 10cell & 303.55 & 282.41 \\
\hline 20cell & 305.47 & 284.05 \\
\hline
\end{tabular}

Table 4.2.5 presents the maximum cell-to-cell voltage variations observed for stacks of 5 , 10 , and 20 cells with fuel and air inlet temperatures of $1173 \mathrm{~K}$. A similar trend to what was previously shown in Fig. 7a and $7 \mathrm{~b}$ was observed in these cases. The cell-to-cell variation of less than $1.5 \%$ can be considered to be relatively small. 
Table 4.2.5. Cell-to-cell voltage variation for 5,10 , and 20 cell stacks operating at an average current density of $667 \mathrm{~mA} / \mathrm{cm}^{2}$ with fuel and air inlet temperatures of 1173K.

\begin{tabular}{|c|c|}
\hline & Max Cell-to-Cell voltage variation [\%] \\
\hline 5 cell & 0.79 \\
\hline 10 cell & 1.31 \\
\hline 20 cell & 1.45 \\
\hline
\end{tabular}

Significant variations in temperature have been observed in simulations of 5, 10, and 20 cell stacks. However, cell-to-cell voltage variations remain fairly small, approximately $1 \%$. Except in the case where non-uniform fuel flow distribution was prescribed a $7 \%$ cell voltage variation was observed. Increasing stack size resulted in slightly lower average temperatures across the cells but slightly larger temperature gradients in the top cell along the stream-wise direction.

\section{Efficiency for a cell and a stack}

The free-energy ( $2^{\text {nd }}$ law) efficiencies (Blomen and Mugerwa, 1993) were calculated for different size co-flow planar SOFC stacks using:

$\eta_{\mathrm{II}}=\frac{\mathrm{nFV}}{\Delta \mathrm{G}}$

where $\mathrm{n}$ is the number of participating electrons, $\mathrm{F}$ is the Faraday constant, $\mathrm{V}$ is the cell voltage, and $\Delta \mathrm{G}$ is the change in Gibbs free energy per kmol of $\mathrm{H}_{2}$ for the reaction which is a function of the inlet temperature, and species concentrations. 
Table 4.2.6 shows the calculated $2^{\text {nd }}$ law efficiencies for a single cell and for 2 different size stacks. It was observed that the efficiency remained approximately the same (around $60 \%)$. An efficiency of approximately $60 \%$ is within the range given by Blomen and Mugerwa (1993) of 50\%-80\%.

Table 4.2.6. Efficiency for Co-flow cell and stack

\begin{tabular}{|c|c|c|c|}
\hline & cell & 20 cell & 40 cell \\
\hline Efficiency & $58.98 \%$ & $59.98 \%$ & $60.36 \%$ \\
\hline
\end{tabular}

\section{Scale-up of parallel run times}

It is always of interest to see if parallel execution of a solver produces results proportional to the number of processors assigned to the job. Table 4.2.6 gives approximate times required to run given cases. It was previously noted that the parallelization approach used was to solve individual cells on separate processors. Thus the number of cells is also the number of processors used. When comparing the 5 cell to 40 cell run although the run time increased from 4 days to 11 days the size of the problem increase by a factor of 8 . The cluster was being heavily used by others during these executions. Hence, these may not be indicative of actual scale up.

Table 4.2.6. Execution times for various size stacks

\begin{tabular}{|c|c|}
\hline Case & Run time \\
\hline 5 cell stack & 4 days \\
\hline 10 cell stack & 4 days \\
\hline 20 cell stack & 6 days \\
\hline 40 cell stack & 11 days \\
\hline
\end{tabular}


It should be mentioned that all of these runs were performed on a University computer cluster which although it used a queue system did not guarantee that the nodes did not have other jobs sharing the processor time. Loads on the network switches may also have varied depending on what was being run by the multiple users of the cluster.

\subsection{Effect of Flow Distribution on Cell-to-Cell Performance}

A study of a five-cell stack was performed with various inlet velocities prescribed for the anode gas channel. The geometry of the fuel cell is given in Table 4.3.1. Two types of electrolytes were considered. The dimensions for the anode supported electrolyte and electrolyte supported electrolyte are given in Tables 4.3.2. and 4.3.3. The model parameters are given in Tables 4.3.4.

Table 4.3.1. Physical dimensions of single fuel cell (effects of flow distribution)

\begin{tabular}{|c|c|}
\hline SOFC Component & [m] \\
\hline Cell Length & $1.0 \mathrm{E}-01$ \\
\hline Grid Length, $\Delta \mathrm{x}$ & $5.0 \mathrm{E}-02$ \\
\hline Cell Width, $\Delta \mathrm{z}$ & $1.0 \mathrm{E}-00$ \\
\hline Fuel Gas Channel Height, $\Delta \mathrm{y}$ & $1.0 \mathrm{E}-03$ \\
\hline Air Gas Channel Height, $\Delta \mathrm{y}$ & $3.0 \mathrm{E}-03$ \\
\hline
\end{tabular}

Table 4.3.2. Dimensions for anode supported electrolyte

\begin{tabular}{|c|c|}
\hline SOFC Component & [m] \\
\hline Electrolyte Thickness, $\Delta \mathrm{y}$ & $1.0 \mathrm{E}-05$ \\
\hline Anode Electrode Thickness, $\Delta \mathrm{y}$ & $1.0 \mathrm{E}-03$ \\
\hline Cathode Electrode Thickness, $\Delta \mathrm{y}$ & $2.5 \mathrm{E}-05$ \\
\hline Separator Thickness, $\Delta \mathrm{y}$ & $7.5 \mathrm{E}-03$ \\
\hline
\end{tabular}


Table 4.3.3. Dimension for electrolyte supported electrolyte.

\begin{tabular}{|c|c|}
\hline SOFC Component & [m] \\
\hline Electrolyte Thickness, $\Delta \mathrm{y}$ & $1.8 \mathrm{E}-04$ \\
\hline Anode Electrode Thickness, $\Delta \mathrm{y}$ & $5.0 \mathrm{E}-05$ \\
\hline Cathode Electrode Thickness, $\Delta \mathrm{y}$ & $5.0 \mathrm{E}-05$ \\
\hline Separator Thickness, $\Delta \mathrm{y}$ & $2.0 \mathrm{E}-03$ \\
\hline
\end{tabular}

Table 4.3.4. Material properties and model parameters. (effects of flow distribution)

\begin{tabular}{|c|c|}
\hline Cell Heat Capacity [J/kg-K] & $8.00 \mathrm{E}+02$ \\
\hline Cell Density $\left[\mathrm{kg} / \mathrm{m}^{3}\right]$ & $1.50 \mathrm{E}+03$ \\
\hline Separator Heat Capacity $[\mathrm{J} / \mathrm{kg}-\mathrm{K}]$ & $4.00 \mathrm{E}+02$ \\
\hline Separator Density $\left[\mathrm{kg} / \mathrm{m}^{3}\right]$ & $8.00 \mathrm{E}+03$ \\
\hline No. Axial Nodes & 20 \\
\hline Anode Inlet Temperature $[\mathrm{K}](2$ cases $)$ & 1073 \\
& 1173 \\
\hline Anode Inlet Pressure $[\mathrm{Pa}]$ & $1.01 \mathrm{E}+05$ \\
\hline $\mathrm{H}_{2}$ Anode Inlet Mole Fraction & $9.70 \mathrm{E}-01$ \\
\hline $\mathrm{H}_{2} \mathrm{O}$ Anode Inlet Mole Fraction & $3.00 \mathrm{E}-02$ \\
\hline Cathode Inlet Temperature $[\mathrm{K}](2$ cases) & 1073 \\
& 1173 \\
\hline Cathode Inlet Pressure $[\mathrm{Pa}]$ & $1.01 \mathrm{E}+05$ \\
\hline $\mathrm{O}_{2}$ Cathode Inlet Mole Fraction & $2.10 \mathrm{E}-01$ \\
\hline $\mathrm{N}_{2}$ Cathode Inlet Mole Fraction & $7.90 \mathrm{E}-01$ \\
\hline Contact + Separator Resistance $\left[\Omega / \mathrm{cm}^{2}\right]$ & $1.0 \mathrm{E}-01$ \\
\hline Limiting Current Density $\left[\mathrm{A} / \mathrm{m}^{2}\right]$ & $4.0 \mathrm{E}+03$ \\
\hline Exchange Current Density[A $\left.0 \mathrm{~m}^{2}\right]$ & $5.5 \mathrm{E}+03$ \\
\hline
\end{tabular}

This study consisted of six cases (Cases A-F) having the same total anode flow rate, but using different flow rates on individual cells. Table 4.3.5 presents the prescribed velocities (flow rates) for the anode gas channel. For case A (referred to as the base case) uniform flow distribution was prescribed. Each of the other cases involved redistributing $20 \%$ of the flow in the anode gas channel of the bottom cell to the other cells in the stack. Redistribution of the fuel flow increased the variation in cell-to-cell voltage. The six cases were completed for different current demands ranging from 50A to $650 \mathrm{~A}$. The study was conducted with electrolyte and anode supported geometries and with high and 
low oxygen utilizations obtained by specifying inlet mass flow rates of $1.09 \times 10^{-3} \mathrm{~kg} / \mathrm{s}$ and $5.451 \times 10^{-3} \mathrm{~kg} / \mathrm{s}$ (Lmdot and Hmdot) for the cathode gas channel.

Table 4.3.5. Prescribed anode inlet velocity $[\mathrm{m} / \mathrm{s}]$ for the six test cases.

\begin{tabular}{ccccccc} 
& $\mathrm{A}$ & $\mathrm{B}$ & $\mathrm{C}$ & $\mathrm{D}$ & $\mathrm{E}$ & $\mathrm{F}$ \\
4 & 0.4070 & 0.4274 & 0.4070 & 0.4070 & 0.4070 & 0.4884 \\
3 & 0.4070 & 0.4274 & 0.4070 & 0.4070 & 0.4884 & 0.4070 \\
2 & 0.4070 & 0.4274 & 0.4070 & 0.4884 & 0.4070 & 0.4070 \\
1 & 0.4070 & 0.4274 & 0.4884 & 0.4070 & 0.4070 & 0.4070 \\
0 & 0.4070 & 0.3256 & 0.3256 & 0.3256 & 0.3256 & 0.3256 \\
\hline total & 2.0350 & 2.0350 & 2.0350 & 2.0350 & 2.0350 & 2.0350
\end{tabular}

The results are presented for the electrolyte supported geometry cases with low and high oxygen utilizations first. Then, the effect of high versus low oxygen utilization with the electrolyte supported geometry is discussed. Finally, the temperature distributions for the anode and electrolyte supported cases are compared.

Performance of the SOFC stack was obtained by holding the flow rate constant and allowing the utilization to vary. For reference, the range of overall stack hydrogen and oxygen utilization for all cases is shown in Figure 4.3.1. 


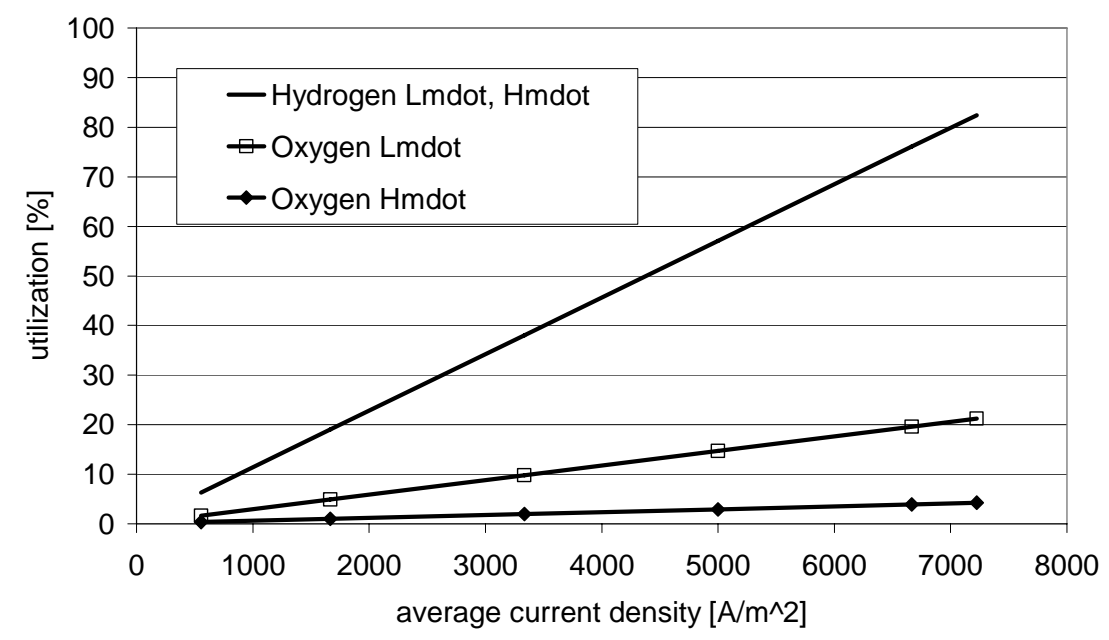

Figure 4.3.1. Utilization at different current densities

Initial results were obtained for the case of an electrolyte supported cell with low oxygen utilization. The mass flow rate at the inlet to cathode is prescribed as $\dot{\mathrm{m}}_{\text {air }}=5.451 \times 10^{-3} \mathrm{~kg} / \mathrm{s}$. The results show that the model is capable of capturing the polarization curve for a SOFC.

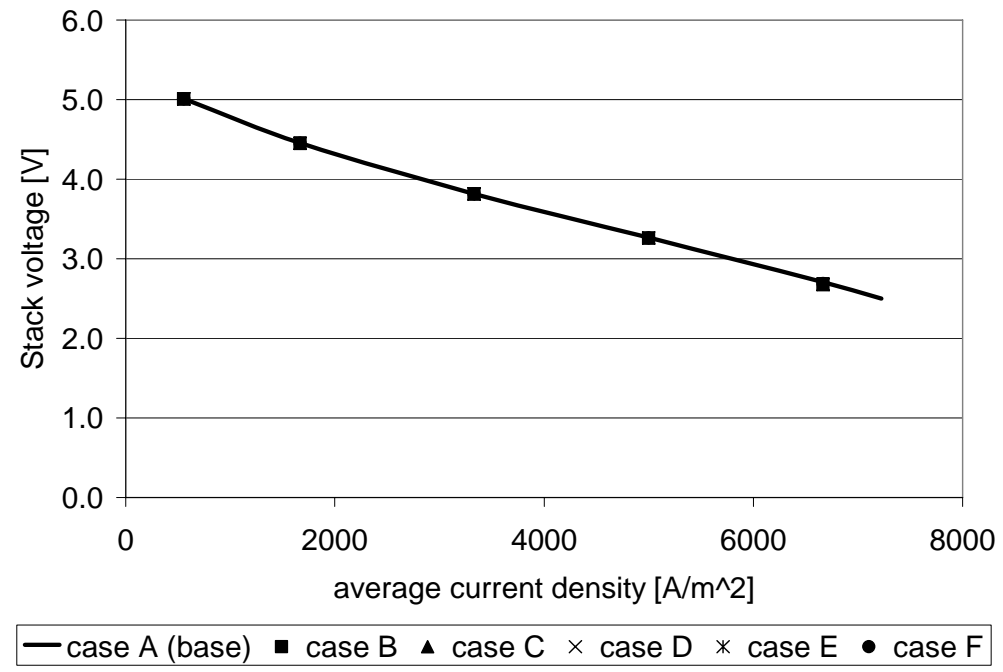

Figure 4.3.2. Polarization curves for electrolyte supported five-cell stack 
Figures 4.3.2 shows how the 5-cell stack model captures the region of the polarization curve where the ohmic loss dominates over the activation and concentration losses. Figure 4.3.2 contains the stack V-I curves for each of the six cases. The stack voltage data points from the non-uniform cases coincide very closely with the data points from the uniform case. Thus while there exists performance variations within the stack (as discussed below), the overall stack V-I performance curve changes very little.

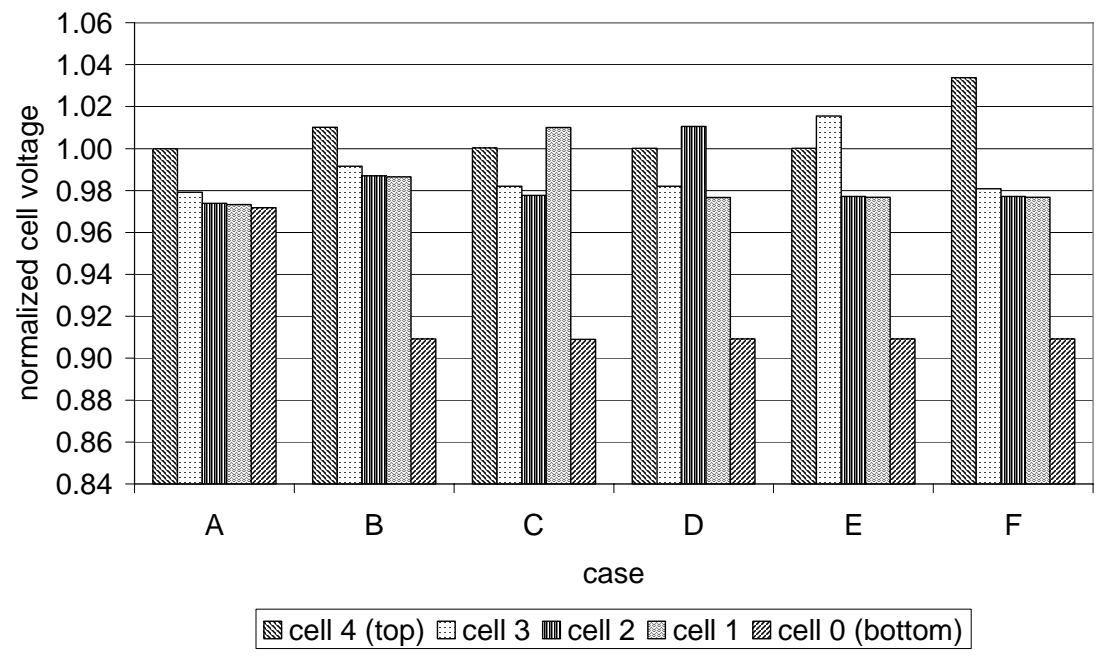

Figure 4.3.3. Influence of flow distribution on cell voltage within five-cell stack (with average current density $=6666.6 \mathrm{~A} / \mathrm{m}^{2}$ ). 


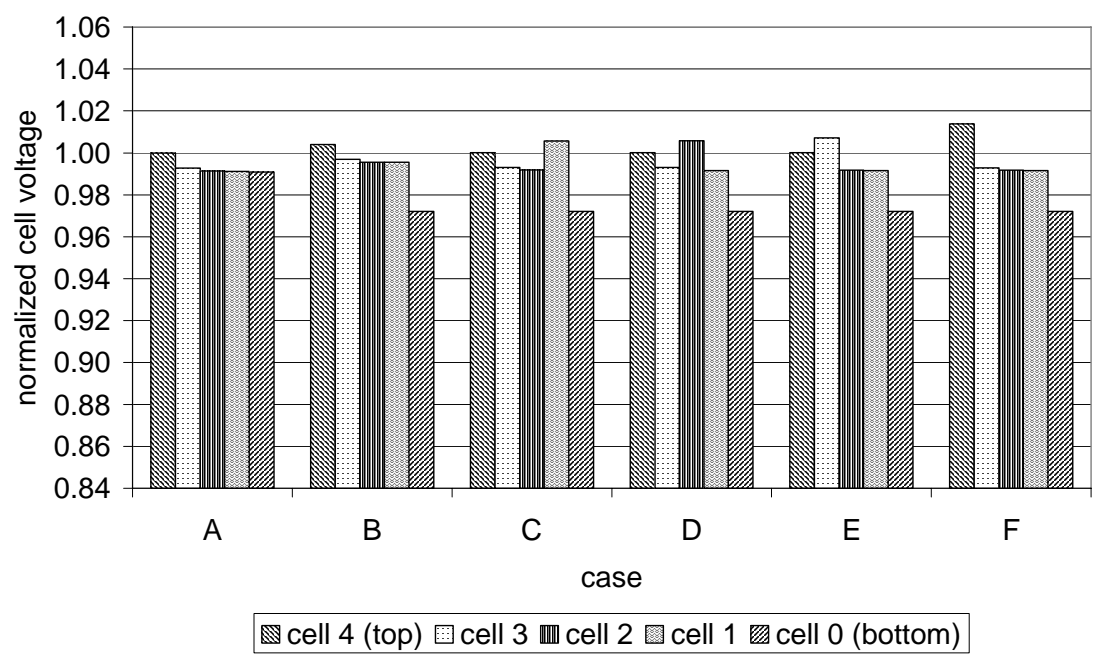

Figure 4.3.4. Influence of flow distribution on cell voltage within five-cell stack (with average current density $=3333.4 \mathrm{~A} / \mathrm{m}^{2}$ ).

Hence, the flow distribution did not have a significant impact on the total stack voltage. While the highest stack voltage was obtained from a uniform flow distribution, for each case the stack voltage differed by no more than $0.85 \%$ from the uniform case. Of greater interest, however, is the variation in cell voltage from cell to cell.

The five-cell stack with uniform flow distribution and an average current density of 6667 $\mathrm{A} / \mathrm{m}^{2}$ had cell voltages that varied by $2.8 \%$. For the case with anode supported electrolyte the cell-to-cell voltage variation was found to be $6.6 \%$ for an average current density of $6667 \mathrm{~A} / \mathrm{m}^{2}$. Variations in cell voltages are further increased by changing the supply of fuel and oxidizer to the cells in the fuel cell stack. For the cases with nonuniform flow distribution in the anode gas channel the cell voltages varied as much as 12.0\% (case $\mathrm{F}$ in Figure 4.3.3). At lower current densities the variation in cell-to-cell voltage became smaller, only 3.3\% (Compare Figure 4.3.3 with Figure 4.3.4.). 


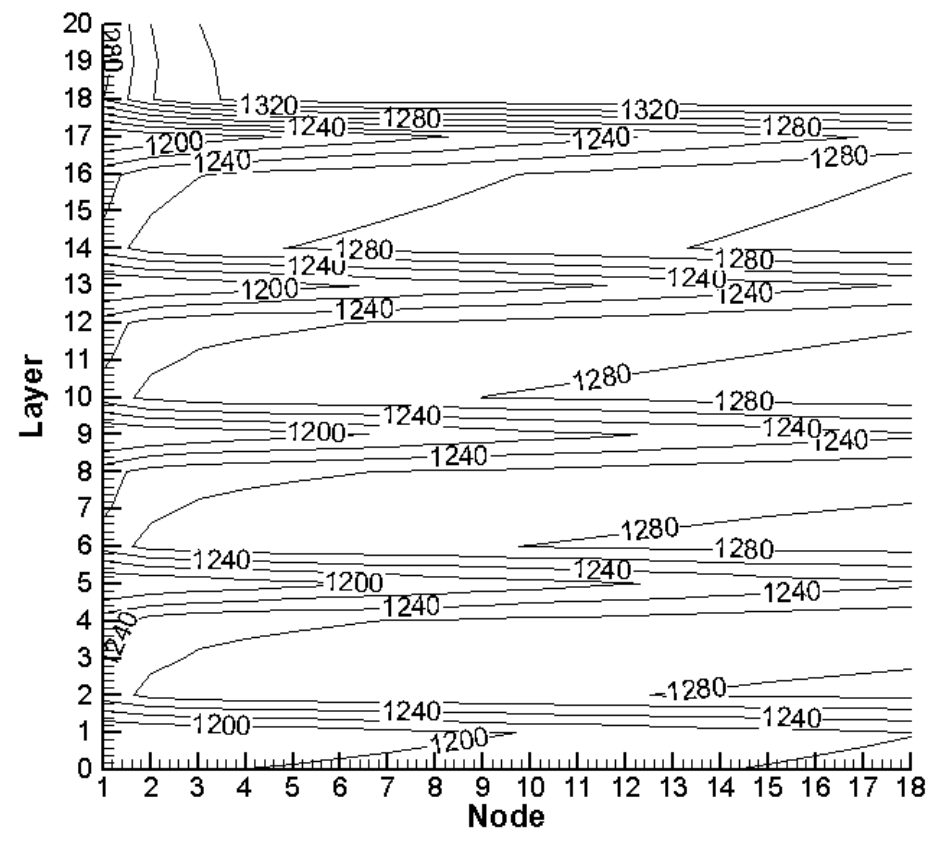

Figure 4.3.5. Temperature contours for the base case with average current density = 6666.6 A/ $\mathrm{m}^{2}$.

As mentioned previously, the fuel cell stack geometry is inherently asymmetric. The stack is operating with different cathode and anode mass flow rates causing the heat transfer coefficient to vary between gas channels. The air gas channel has the highest mass flow rate and therefore provides the most cooling. This asymmetry is the dominant cause for the asymmetry in the fuel cell stack. Hence, the top cell does not suffer from the presence of a cooling cathode gas channel that a neighboring cell would provide. Likewise, the bottom cell does not benefit from the heat that a neighboring cell would provide. The result, as shown in Figure 4.3.5, is that the top cell operates at the highest temperature and the bottom cell operates at the lowest temperature. Each layer (i.e. separator plate, cathode gas channel, electrolyte, and anode gas channel) is numbered and 
for 5 cells results in 21 layers. (In Figure 4.3.5 each layer is given a uniform thickness for presentation.) The most notable contours are the cool cathode gas channels.

Next case considered an electrolyte supported cell with high oxygen utilization. For the high oxygen utilization case the inlet mass flow rate was $\dot{m}_{\text {air }}=1.09 \times 10^{-3} \mathrm{~kg} / \mathrm{s}$. Similar results were obtained with this smaller mass flow rate prescribed at the cathode (see Figures 4.3.6 and 4.3.7). For a current density of $6666.6 \mathrm{~A} / \mathrm{m}^{2}$ there was a variation in cell voltage of 3.6\% between the top cell (cell 4) and the bottom cell (cell 0). The largest cell-to-cell voltage variation was obtained in case $\mathrm{C}$ having a $12.0 \%$ variation.

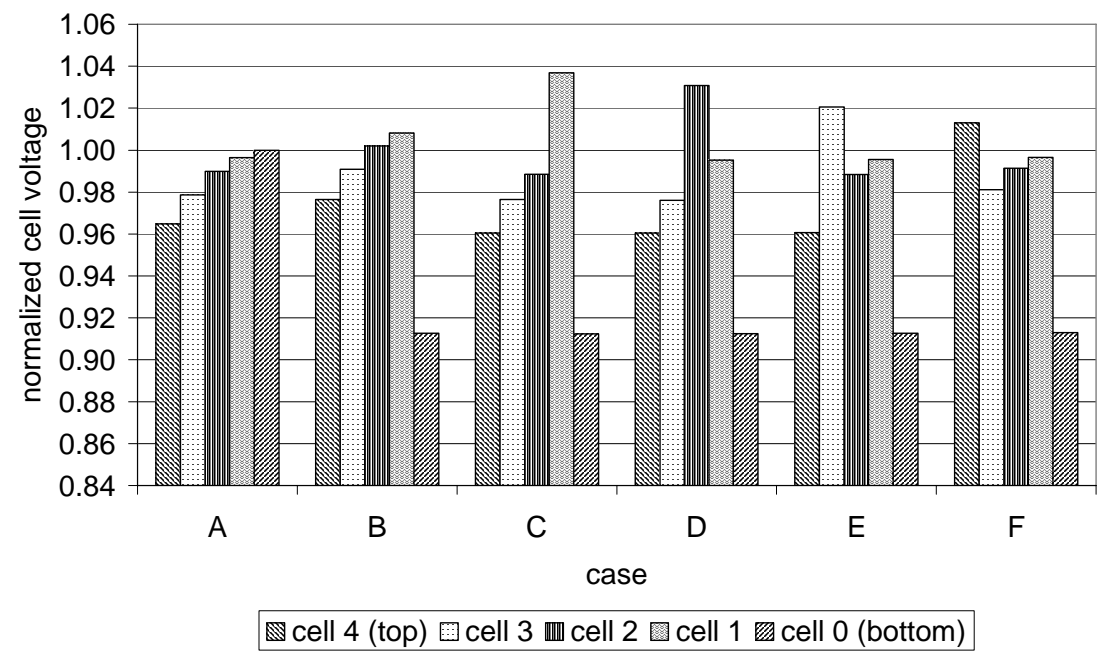

Figure 4.3.6. Influence of flow distribution on cell voltage within five-cell stack (with average current density $=6666.6 \mathrm{~A} / \mathrm{m}^{2}$ ). 


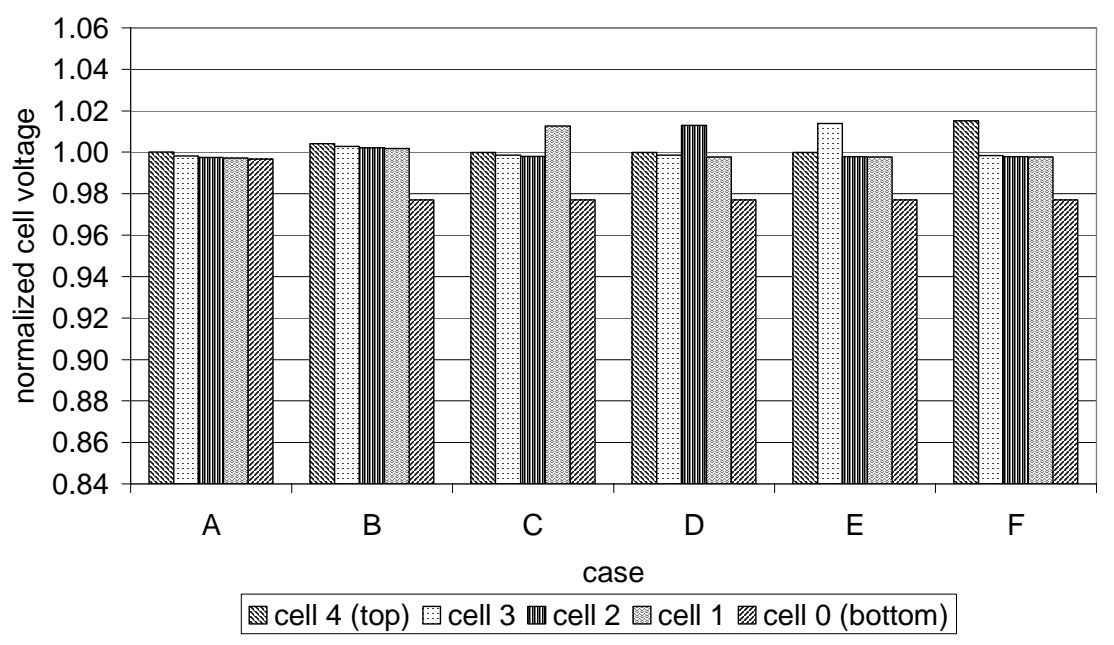

Figure 4.3.7. Influence of flow distribution on cell voltage within five-cell stack (with average current density $=3333.4 \mathrm{~A} / \mathrm{m}^{2}$ ).

Reducing the current reduced the fuel and oxidizer utilization (see Figure 4.3.1) and resulted in smaller voltage variations within the stack. For the case with average current density of $3333.3 \mathrm{~A} / \mathrm{m}^{2}$ the largest voltage variation was $3.8 \%$ in case $\mathrm{F}$.

Figure 4.3.8 shows the percent change in cell voltage for different current densities due to decreasing the air mass flow rate from $\dot{\mathrm{m}}_{\text {air }}=5.451 \times 10^{-3} \mathrm{~kg} / \mathrm{s}$ to $\dot{\mathrm{m}}_{\text {air }}=1.09 \times 10^{-3} \mathrm{~kg} / \mathrm{s}$ resulted in different cell voltages. The percent change in cell voltage shown was found from first normalizing the cell voltage for each case using the highest cell voltage from the uniform case. There is a pronounced change at higher current densities. For the base case current density of $6666.6 \mathrm{~A} / \mathrm{m}^{2}$, less than a $5.2 \%$ difference in cell voltage resulted. Thus it can be shown that the oxygen utilization can have a large influence on the voltage variation for cases with high utilization. Different overall flow rates may result in different temperature distributions hence, directly affecting the cell voltage distribution. 


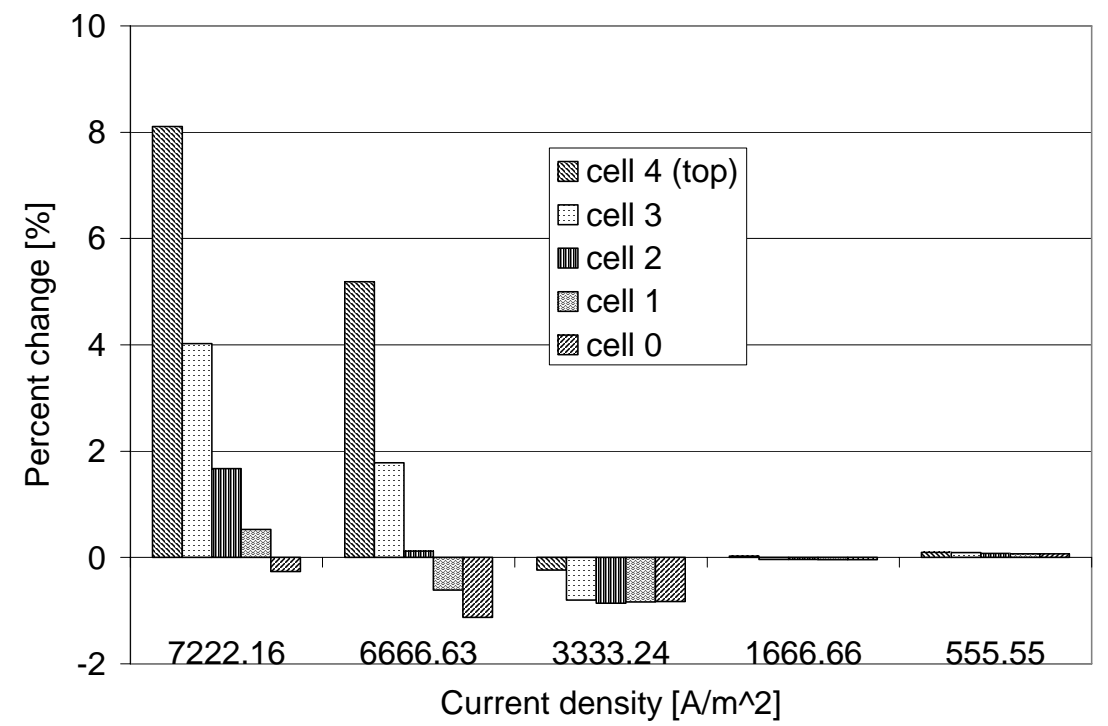

Figure 4.3.8. Change in cell voltage resulting from increasing Oxygen utilization at different current densities.

The operating temperature of the cells in the stack was greatly influenced by ohmic heating caused by the resistance of the solid parts of the fuel cell. Changing the cell geometry from electrolyte to anode supported resulted in a change in resistance and thus less ohmic heating. Thus one can see that the cell-to-cell voltage variation is the result of a non-linear coupling of flow distribution and cell geometry as well as temperature distribution. 


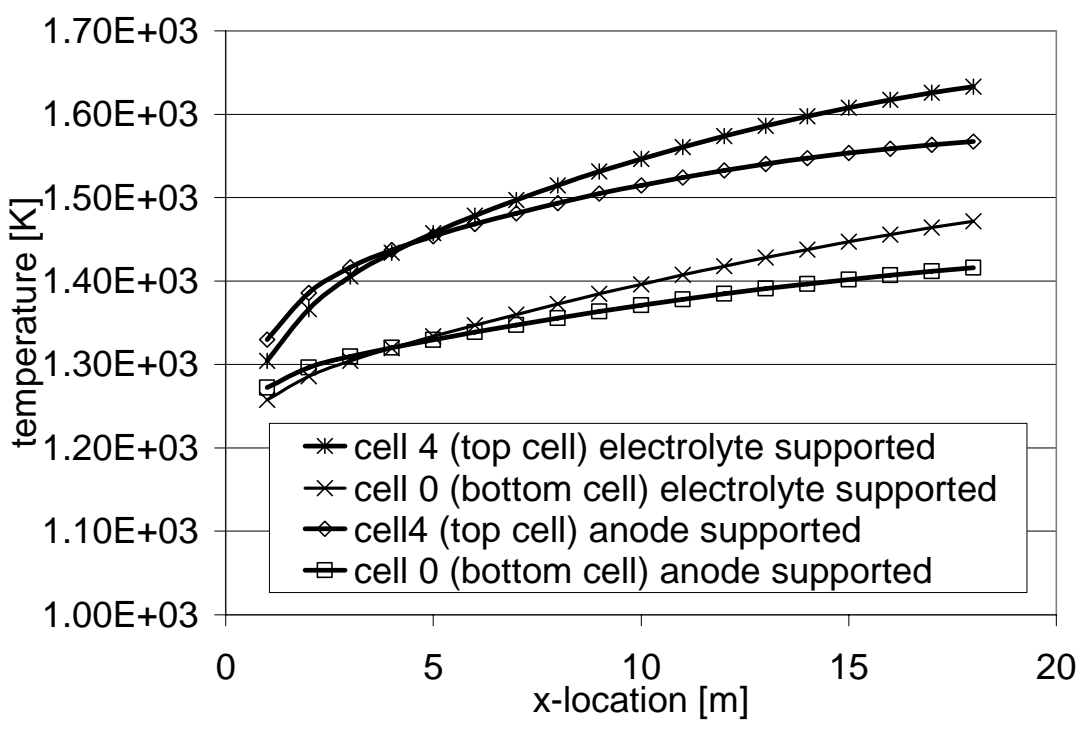

Figure 4.3.9. Electrolyte temperature for electrolyte and anode supported geometry

The temperatures observed in this case are unusually high and not typical for a

SOFC and are referenced here for their value as part of the present case study.

For the electrolyte supported case, the electrolyte temperature varied from $1258 \mathrm{~K}$ to 1633K (see Figure 4.3.9). By changing the model parameters (see Tables 4.2.1\&2) to simulate an anode supported fuel cell stack, the temperatures were reduced so that a maximum of $1567 \mathrm{~K}$ was obtained. This was the result of reduced ohmic heating in the anode supported geometry.

\subsection{Influence of Radiative Heat Transfer on Cell-to-Cell Performance}

The stack model was applied to the case of a 5 cell planar SOFC stack. Figure 4.4.1 depicts the physical geometry of a single cell (or unit cell) when visualized in a one- 
dimensional sense. The fuel and oxidizer are introduced to the cell in a coflow configuration. For illustration, in Figure 4.4.1 the stack has been divided in the xdirection into five computational nodes (denoted by $\mathrm{i}$, and used with finite volume analysis to descretize the governing equations) using dashed lines. The active area of the cell is modeled by the computational nodes 1,2 , and 3. In this study the cell was divided in the streamwise direction into 20 computational nodes. TTop and TBottom are extra storage arrays used for communication of temperature between neighboring cells in the stack. In the case of the top and bottom cells these arrays are also used to specify ambient temperatures useful for modeling heat transfer to the stack surroundings. In the current study the heat flux from the fuel cell stack to the surroundings is zero, representative of a perfectly insulated wall boundary condition on the top and bottom of the stack.

The physical geometry of the stack is defined by the length of the cell in the streamwise direction, and the thickness of each component. These dimensions are listed in Table 4.4.1. The PEN has a thickness defined by the sum of the thickness of anode electrode, electrolyte, and cathode electrode. In addition to the thickness of electrolyte plate the anode and cathode gas channel gap thicknesses must be specified. For the current study an electrolyte supported cell geometry was considered. 


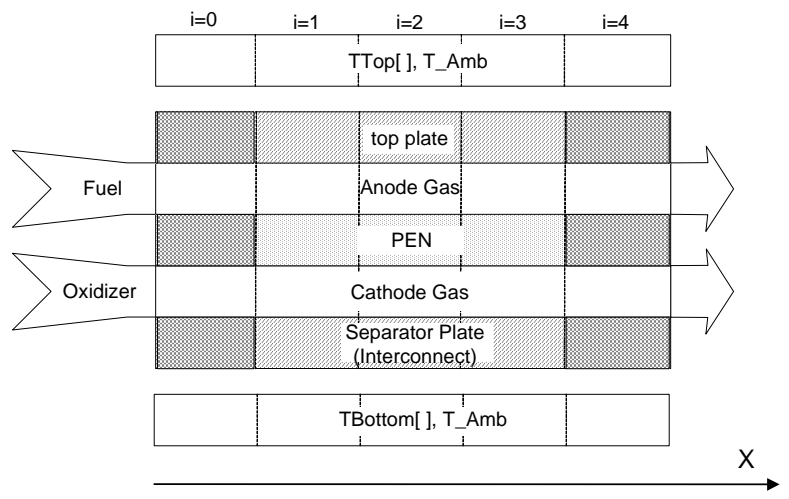

Figure 4.4.1. Physical geometry of a single cell

Table 4.4.1. Physical dimensions of single fuel cell with Electrolyte support (influence of radiative heat transfer)

\begin{tabular}{|c|c|}
\hline SOFC Component & [m] \\
\hline Cell Length & $1.0 \mathrm{E}-01$ \\
\hline Grid Length, $\Delta \mathrm{x}$ & $5.0 \mathrm{E}-2$ \\
\hline Cell Width, $\Delta \mathrm{z}$ & $1.0 \mathrm{E} 00$ \\
\hline Anode Gas Channel Gap, $\Delta \mathrm{y}$ & $1.0 \mathrm{E}-03$ \\
\hline Cathode Gas Channel Gap, $\Delta \mathrm{y}$ & $3.0 \mathrm{E}-03$ \\
\hline Electrolyte Thickness, $\Delta \mathrm{y}$ & $1.8 \mathrm{E}-04$ \\
\hline Anode Electrode Thickness, $\Delta \mathrm{y}$ & $5.0 \mathrm{E}-05$ \\
\hline Cathode Electrode Thickness, $\Delta \mathrm{y}$ & $5.0 \mathrm{E}-05$ \\
\hline Separator Thickness, $\Delta \mathrm{y}$ & $2.0 \mathrm{E}-03$ \\
\hline
\end{tabular}

Material properties and model parameters listed in Table 4.4.2 were taken from an earlier single cell model (Gemmen, et al., 2000). The stack is considered to be homogeneous with all the cells being constructed with the same physical dimensions and material properties. The inlet and outlet boundary conditions applied to the governing equations (continuity, energy conservation, species-mass conservation, and momentum equation) and electrochemistry model are specified as model parameters in Table 4.4.2. 
Table 4.4.2. Material properties and Model Parameters (influence of radiative heat transfer)

\begin{tabular}{|c|c|}
\hline Cell Heat Capacity $[\mathrm{J} / \mathrm{kg}-\mathrm{K}]$ & $8.00 \mathrm{E}+02$ \\
\hline Cell Density $\left[\mathrm{kg} / \mathrm{m}^{3}\right]$ & $1.50 \mathrm{E}+03$ \\
\hline Separator Heat Capacity $[\mathrm{J} / \mathrm{kg}-\mathrm{K}]$ & $4.00 \mathrm{E}+02$ \\
\hline Separator Density $\left[\mathrm{kg} / \mathrm{m}^{3}\right]$ & $8.00 \mathrm{E}+03$ \\
\hline No. Axial Nodes & 20 \\
\hline Anode Inlet Temperature [K] & $1.17 \mathrm{E}+03$ \\
\hline Anode Inlet Pressure [Pa] & $1.01 \mathrm{E}+05$ \\
\hline Anode Exit Pressure [Pa] & $1.01 \mathrm{E}+05$ \\
\hline $\mathrm{H}_{2}$ Anode Inlet Mole Fraction & $9.70 \mathrm{E}-01$ \\
\hline $\mathrm{H}_{2} \mathrm{O}$ Anode Inlet Mole Fraction & $3.00 \mathrm{E}-02$ \\
\hline Cathode Inlet Temperature [K] & $1.17 \mathrm{E}+03$ \\
\hline Cathode Inlet Pressure [Pa] & $1.01 \mathrm{E}+05$ \\
\hline Cathode Exit Pressure [Pa] & $1.01 \mathrm{E}+05$ \\
\hline $\mathrm{O}_{2}$ Cathode Inlet Mole Fraction & $2.10 \mathrm{E}-01$ \\
\hline $\mathrm{N}_{2}$ Cathode Inlet Mole Fraction & $7.90 \mathrm{E}-01$ \\
\hline
\end{tabular}

A numbering convention was used to identify the cells in a manner similar to levels in a building (with cell number increasing in the vertical direction). The inlet velocities prescribed are given in Table 4.4.3. For the non-uniform case the flow was redistributed from cell 0 to cell 1 . These inlet conditions were imposed for both cases with and without radiative heat transfer.

Table 4.4.3. Prescribed inlet velocity $[\mathrm{m} / \mathrm{s}]$

\begin{tabular}{|c|c|c|c|c|}
\hline & \multicolumn{2}{|c|}{ Uniform flow distribution } & \multicolumn{2}{c|}{ Non-uniform flow dist. } \\
\hline $\begin{array}{c}\text { Cell } \\
\text { number }\end{array}$ & anode & Cathode & anode & Cathode \\
\hline 4 & $4.07 \mathrm{E}-01$ & $1.21 \mathrm{E}+00$ & $4.07 \mathrm{E}-01$ & $1.21 \mathrm{E}+00$ \\
\hline 3 & $4.07 \mathrm{E}-01$ & $1.21 \mathrm{E}+00$ & $4.07 \mathrm{E}-01$ & $1.21 \mathrm{E}+00$ \\
\hline 2 & $4.07 \mathrm{E}-01$ & $1.21 \mathrm{E}+00$ & $4.07 \mathrm{E}-01$ & $1.21 \mathrm{E}+00$ \\
\hline 1 & $4.07 \mathrm{E}-01$ & $1.21 \mathrm{E}+00$ & $4.88 \mathrm{E}-01$ & $1.21 \mathrm{E}+00$ \\
\hline 0 & $4.07 \mathrm{E}-01$ & $1.21 \mathrm{E}+00$ & $3.26 \mathrm{E}-01$ & $1.21 \mathrm{E}+00$ \\
\hline
\end{tabular}

Fuel utilization is of major concern and therefore fuel mass flow rates are generally low to insure high $\mathrm{H}_{2}$ utilization. 
Variations in cell voltage are present as a result of asymmetries in stack geometry and flow rate. In this study steady state solutions are compared for a 5 cell planar SOFC stack providing a total current of $600 \mathrm{~A}$. Air was supplied to the cathode gas channel such that there was approximately $20 \%$ oxygen utilization (Table 4.4.3). The higher mass flow rate resulted in the cathode side of the cell being cooler than the anode side. This resulted in non-uniform temperature distributions throughout the stack (Figure 4.4.2a).

Figures 4.4.2a and 4.4.2b show that the addition of radiative heat transfer improved the uniformity of the temperature distribution within the stack (Figure 4.4.2b). Temperature is plotted as a function of layer and node. In the vertical direction the temperature is known for each layer (component) thus the sharp changes are and artifact of the coarseness of the grid. Also it should be noted that the layers actually have different heights but in the figure are present with a uniform height. 


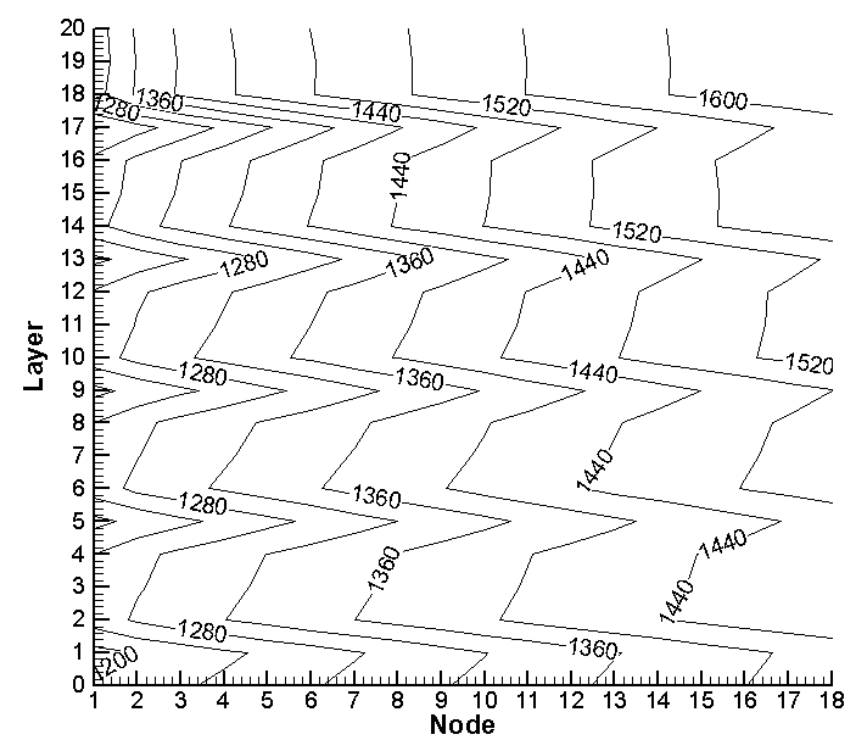

(a)

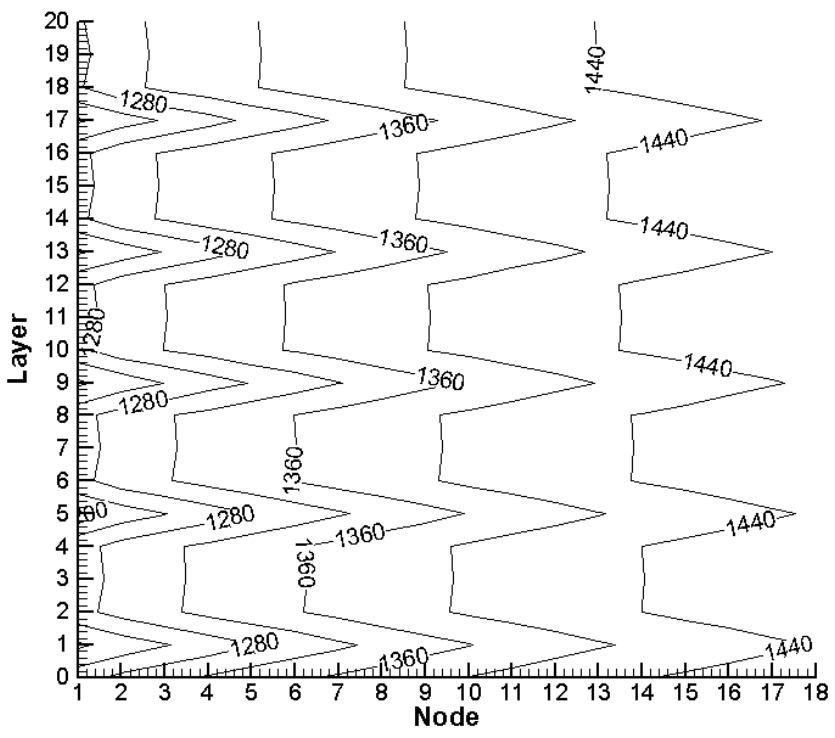

(b)

Figure 4.4.2. Temperature contours for uniform flow case (a) without radiative heat transfer (b) with radiative heat transfer

The open circuit (or Nernst) voltage and the Ohmic losses are functions of the temperature. Therefore variations in cell voltage are observed when there are 
temperature variations. When considering heat transfer only in a purely convective form even under uniform flow conditions noticeable variations in cell performance are observed (Burt, et al., 2003). Figure 4.4.3 shows that for the non-radiative case (purely convective heat transfer) a variation of $3.6 \%$ was obtained. When radiative heat transfer was included the same trend in voltage variation occurred but with a variation of only $0.4 \%$.

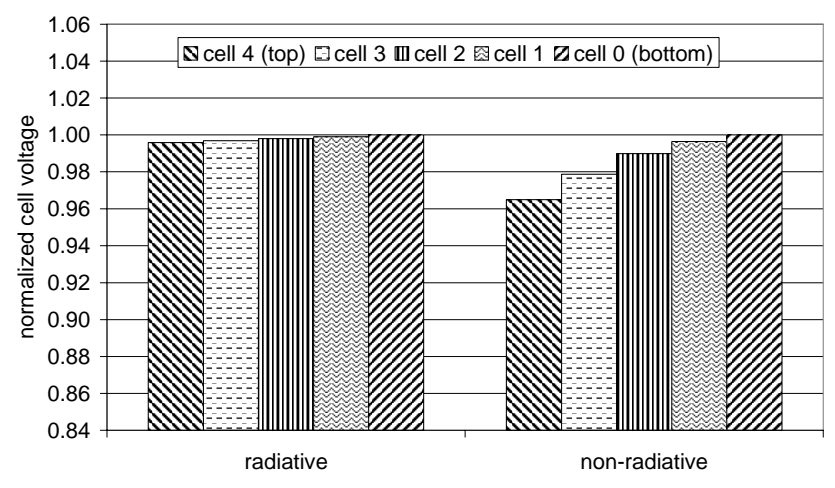

Figure 4.4.3. Variation in cell voltage for uniform flow distribution with and without radiative heat transfer; In each case the cell voltage is normalized with the highest cell voltage.

Even larger variations in cell voltage were observed while performing a parametric study on the impact of flow distribution. It was shown that the greatest voltage variation occurred when a $20 \%$ of the fuel flow in the bottom cell (cell 0) was directed to the neighboring cell (cell 1). Radiative heat transfer did not decrease the voltage variation caused by this non-uniform distribution. In both this study and the previous study it was found that a redistribution of the fuel mass flow rate resulted in up to $12.3 \%$ variation in 
cell voltage (Figure 4.4.4). This variation mostly results from the mole fraction of $\mathrm{H}_{2}$ in Nernst Equation (Eq. 3.1.10). However the voltage variations resulting from temperature distribution were much smaller when radiative heat transfer was included.

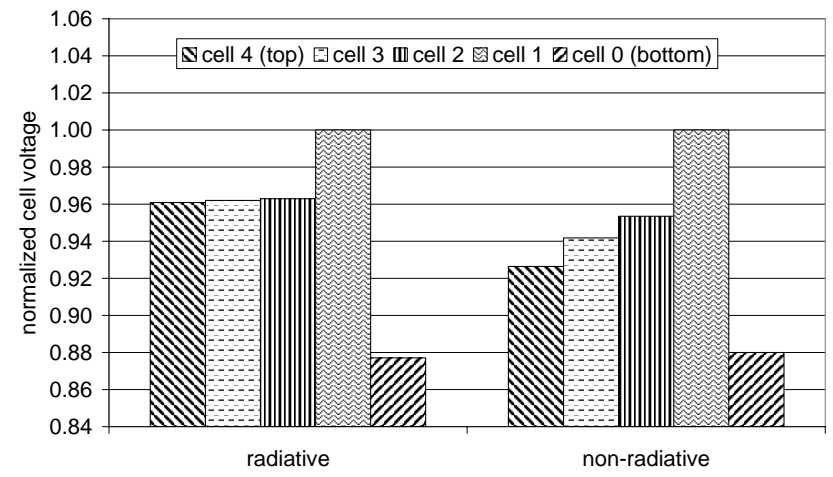

Figure 4.4.4. Variation in cell voltage for non-uniform flow distribution with and without radiative heat transfer; In each case the voltage is normalized with the highest voltage. 


\subsection{APPLICATIONS WITH REDUCED ORDER 3-D FC MODEL}

\subsection{Single Cell Solutions}

The Reduced Order 3-D Fuel Cell Model was successfully applied to the three common planar fuel cell configurations. The following sections present results from co-flow, counter-flow and cross-flow geometries. The case of most interest is the cross-flow configuration since this was not previously solvable with the Pseudo 2-D Fuel Cell Stack Model. Co-flow and counter-flow results are shown here to demonstrate that the new model is still applicable to the completed studies presented in the previous sections.

\subsubsection{Co-Flow Results}

The first configuration tested with the Reduced Order 3-D Fuel Cell Model was a co-flow "button" cell geometry where five fuel channels passed through the fuel cell parallel to five air channels. A similar study was previously shown for the Pseudo 2-D Fuel Cell Stack Model therefore for brevity only a few figures will be presented here to demonstrate the successful operation of the model.

Tables 5.1.1 and 5.1.2 give the dimensions and model parameters used for the co-flow case. The grid was uniform in the $\mathrm{x}$ - and $\mathrm{z}$ - directions, but non-uniform in the vertical $\mathrm{y}$ direction. As with the other studies there was a zero heat flux boundary condition applied 
at all external walls. The cell current was fixed at $0.7 \mathrm{~A}$ and the voltage and load resistance was solved by the electrochemistry model to be $0.475 \mathrm{~V}$ and $0.678 \mathrm{Ohms}$.

Table 5.1.1. Physical dimensions of "button" cell (co-flow cell)

\begin{tabular}{|c|c|}
\hline SOFC Component & [m] \\
\hline Cell Length & 0.011 \\
\hline Cell Width & 0.011 \\
\hline Grid Length, $\Delta \mathrm{x}$ & 0.001 \\
\hline Fuel Gas Channel Height, $\Delta \mathrm{y}$ & 0.001 \\
\hline Fuel Gas Channel Width, $\Delta \mathrm{z}$ & 0.001 \\
\hline Air Gas Channel Height, $\Delta \mathrm{y}$ & 0.001 \\
\hline Air Gas Channel Width, $\Delta \mathrm{z}$ & 0.001 \\
\hline Channel Wall Thickness, $\Delta \mathrm{z}$ & 0.001 \\
\hline Electrolyte Thickness, $\Delta \mathrm{y}$ & $5.0 \mathrm{E}-04$ \\
\hline Anode Electrode Thickness, $\Delta \mathrm{y}$ & $5.0 \mathrm{E}-04$ \\
\hline Cathode Electrode Thickness, $\Delta \mathrm{y}$ & $5.0 \mathrm{E}-04$ \\
\hline Separator Thickness, $\Delta \mathrm{y}$ & 0.001 \\
\hline
\end{tabular}

Table 5.1.2. Material properties and model parameters (co-flow cell)

\begin{tabular}{|c|c|}
\hline Cell Heat Capacity $[\mathrm{J} / \mathrm{kg}-\mathrm{K}]$ & $8.00 \mathrm{E}+02$ \\
\hline Cell Density $\left[\mathrm{kg} / \mathrm{m}^{3}\right]$ & $1.50 \mathrm{E}+03$ \\
\hline Separator Heat Capacity $[\mathrm{J} / \mathrm{kg}-\mathrm{K}]$ & $4.00 \mathrm{E}+02$ \\
\hline Separator Density $\left[\mathrm{kg} / \mathrm{m}^{3}\right]$ & $8.00 \mathrm{E}+03$ \\
\hline No. Axial Nodes & 11 \\
\hline Anode Inlet Temperature $[\mathrm{K}]$ & 1173 \\
\hline Anode Inlet Pressure $[\mathrm{Pa}]$ & $1.01 \mathrm{E}+05$ \\
\hline $\mathrm{H}_{2}$ Anode Inlet Mass Fraction & $9.0 \mathrm{E}-01$ \\
\hline $\mathrm{H}_{2}$ O Anode Inlet Mass Fraction & $1.0 \mathrm{E}-01$ \\
\hline Cathode Inlet Temperature $[\mathrm{K}]$ & 1150 \\
\hline Cathode Inlet Pressure $[\mathrm{Pa}]$ & $1.01 \mathrm{E}+05$ \\
\hline $\mathrm{O}_{2}$ Cathode Inlet Mole Fraction & 0.233 \\
\hline $\mathrm{N}_{2}$ Cathode Inlet Mole Fraction & 0.767 \\
\hline Contact + Separator Resistance $\left[\Omega / \mathrm{cm}^{2}\right]$ & $1.0 \mathrm{E}-01$ \\
\hline Limiting Current Density $\left[\mathrm{A} / \mathrm{m}^{2}\right]$ & $4.0 \mathrm{E}+03$ \\
\hline Exchange Current Density $\left[\mathrm{A} / \mathrm{m}^{2}\right]$ & $5.5 \mathrm{E}+03$ \\
\hline Heat Transfer Coefficient for Air Channel $\left[\mathrm{W} / \mathrm{m}^{2}-\mathrm{K}\right]$ & 268.8 \\
\hline Heat Transfer Coefficient for fuel Channel $\left[\mathrm{W} / \mathrm{m}^{2}-\mathrm{K}\right]$ & 1020.0 \\
\hline
\end{tabular}


Figure 5.1.1 depicts the current density in the PEN along the streamwise direction between the center air and fuel gas channels. The square symbols indicate the current density calculated using the Electrochemistry Model (ECM). The solid line represents the averaged current density used along the anode electrode. This case is different than what is later shown for the cross-flow configuration in that the grid which was used by the ECM is the same as the grid used by the rest of the fuel cell model. Therefore the current densities calculated by the ECM directly correlate to the anode. Whereas for the crossflow case a coarse grid was used for the ECM which required the current density be redistributed on the fine fuel cell grid. This is shown later in section 5.1.3.

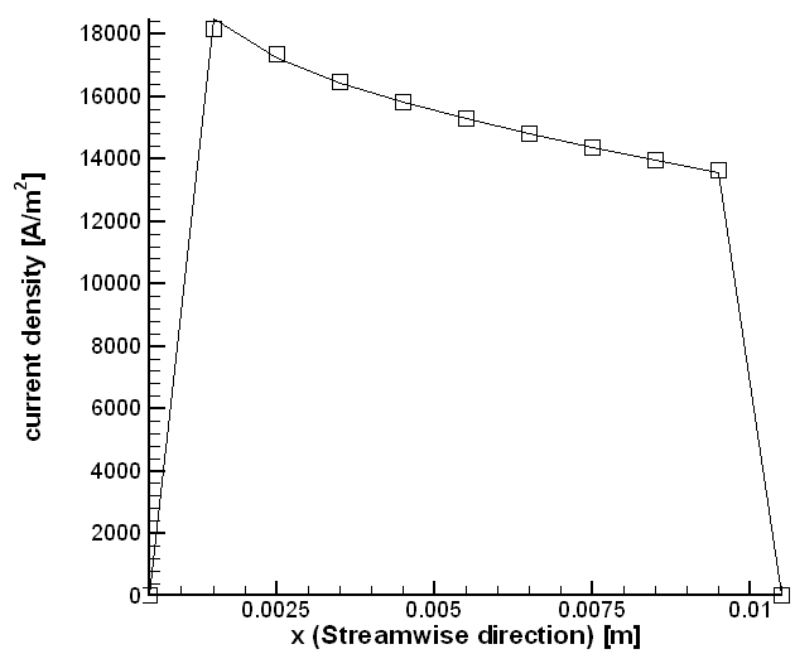

Figure 5.1.1. Current density versus streamwise direction calculated by ECM (square symbols) and distributed anode current (solid line)

Figure 5.1.2 shows the calculated temperature contours for the co-flow case. As expected the temperature increases relatively uniformly in the streamwise direction which is from left to right. The five regions of higher temperature are located between the air and fuel channels hence are the regions that correspond to higher thermal activity. 


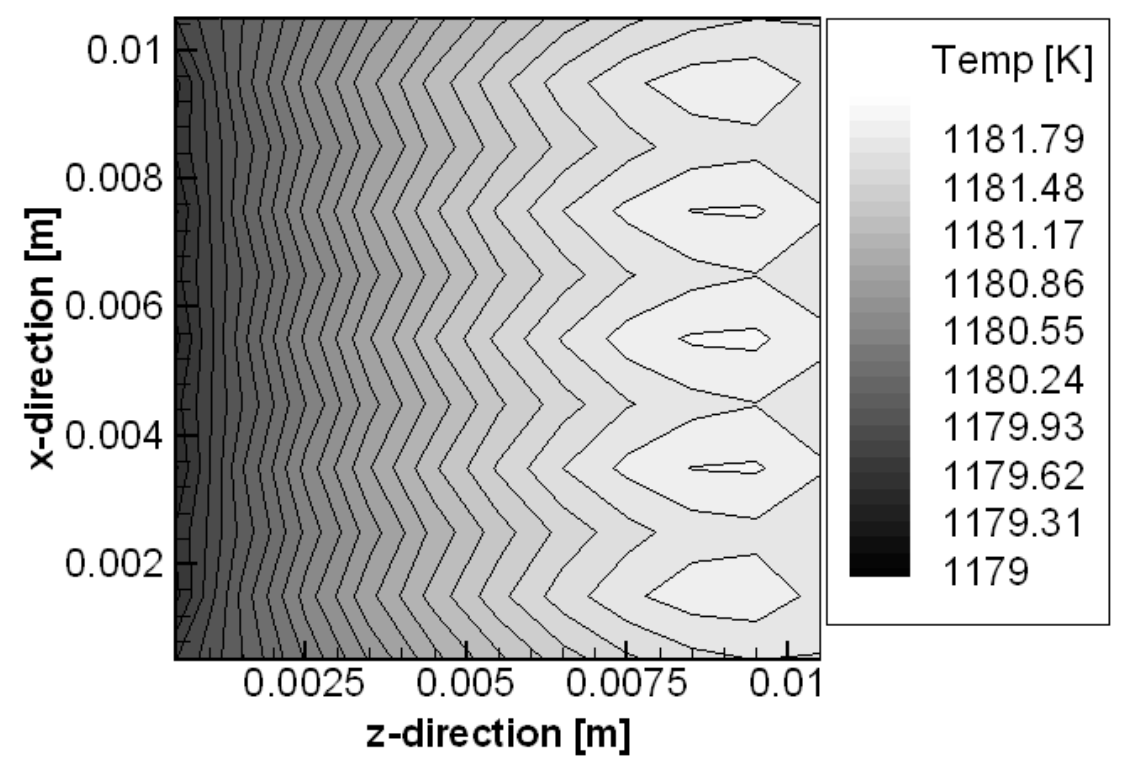

Figure 5.1.2. Steady-state temperature contours in PEN of 5 channel co-flow fuel cell (flow is from left to right)

\subsubsection{Counter-Flow Results}

In order to fully demonstrate the versatility of the Reduced Order 3-D Fuel Cell Model it is necessary to show a case where a counter-flow configuration is solved. The geometry is described in Table 5.1.3. It should be noted that this geometry is different from the coflow case in that the gas channels were $0.002 \mathrm{~m}$ by $0.002 \mathrm{~m}$. The cell itself was increased by $0.005 \mathrm{~m}$ to accommodate this increase in channel width. For this study the current was fixed at $0.512 \mathrm{~A}$ and the voltage and resistance was solved by the electrochemistry model to be $0.167 \mathrm{~V}$ and $0.326 \mathrm{Ohms}$. 
Table 5.1.3. Physical dimensions of "button" cell (counter-flow cell)

\begin{tabular}{|c|c|}
\hline SOFC Component & [m] \\
\hline Cell Length & 0.016 \\
\hline Cell Width & 0.016 \\
\hline Grid Length, $\Delta \mathrm{x}$ & 0.001 \\
\hline Fuel Gas Channel Height, $\Delta \mathrm{y}$ & 0.002 \\
\hline Fuel Gas Channel Width, $\Delta \mathrm{z}$ & 0.002 \\
\hline Air Gas Channel Height, $\Delta \mathrm{y}$ & 0.002 \\
\hline Air Gas Channel Width, $\Delta \mathrm{z}$ & 0.002 \\
\hline Channel Wall Thickness, $\Delta \mathrm{z}$ & 0.001 \\
\hline Electrolyte Thickness, $\Delta \mathrm{y}$ & $5.0 \mathrm{E}-04$ \\
\hline Anode Electrode Thickness, $\Delta \mathrm{y}$ & $5.0 \mathrm{E}-04$ \\
\hline Cathode Electrode Thickness, $\Delta \mathrm{y}$ & $5.0 \mathrm{E}-04$ \\
\hline Separator Thickness, $\Delta \mathrm{y}$ & 0.001 \\
\hline
\end{tabular}

Table 5.1.4. Material properties and model parameters (counter-flow cell)

\begin{tabular}{|c|c|}
\hline Cell Heat Capacity $[\mathrm{J} / \mathrm{kg}-\mathrm{K}]$ & $8.00 \mathrm{E}+02$ \\
\hline Cell Density $\left[\mathrm{kg} / \mathrm{m}^{3}\right]$ & $1.50 \mathrm{E}+03$ \\
\hline Separator Heat Capacity $[\mathrm{J} / \mathrm{kg}-\mathrm{K}]$ & $4.00 \mathrm{E}+02$ \\
\hline Separator Density $\left[\mathrm{kg} / \mathrm{m}^{3}\right]$ & $8.00 \mathrm{E}+03$ \\
\hline No. Axial Nodes & 11 \\
\hline Anode Inlet Temperature $[\mathrm{K}]$ & 1150 \\
\hline Anode Inlet Pressure $[\mathrm{Pa}]$ & $1.01 \mathrm{E}+05$ \\
\hline $\mathrm{H}_{2}$ Anode Inlet Mass Fraction & $9.0 \mathrm{E}-01$ \\
\hline $\mathrm{H}_{2}$ O Anode Inlet Mass Fraction & $1.0 \mathrm{E}-01$ \\
\hline Cathode Inlet Temperature $[\mathrm{K}]$ & 1150 \\
\hline Cathode Inlet Pressure $[\mathrm{Pa}]$ & $1.01 \mathrm{E}+05$ \\
\hline $\mathrm{O}_{2}$ Cathode Inlet Mole Fraction & 0.233 \\
\hline $\mathrm{N}_{2}$ Cathode Inlet Mole Fraction & 0.767 \\
\hline Contact + Separator Resistance $\left[\Omega / \mathrm{cm}^{2}\right]$ & $1.0 \mathrm{E}-01$ \\
\hline Limiting Current Density $\left[\mathrm{A} / \mathrm{m}^{2}\right]$ & $4.0 \mathrm{E}+03$ \\
\hline Exchange Current Density $\left[\mathrm{A} / \mathrm{m}^{2}\right]$ & $5.5 \mathrm{E}+03$ \\
\hline Heat Transfer Coefficient for Air Channel $\left[\mathrm{W} / \mathrm{m}^{2}-\mathrm{K}\right]$ & 268.8 \\
\hline Heat Transfer Coefficient for fuel Channel $\left[\mathrm{W} / \mathrm{m}^{2}-\mathrm{K}\right]$ & 1020.0 \\
\hline
\end{tabular}

Figure 5.1.3 depicts the current density in the electrolyte along the center channel of the 5 channel counter-flow SOFC. For the counter-flow the fuel flows from right to left unlike previously shown in the co-flow case. Thus it can be seen that the current density decreases in the flow direction from right to left. 


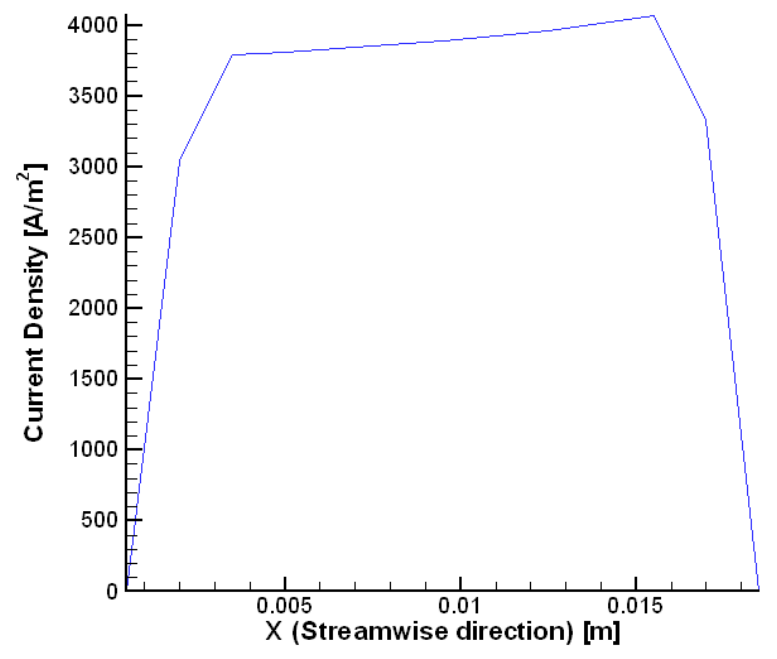

Figure 5.1.3. Current density versus streamwise direction for along center channel

\section{of counter-flow case (fuel flow is right to left).}

Figure 5.1.4 shows the variation of the mass fraction of the $\mathrm{H}_{2}$ and $\mathrm{H}_{2} \mathrm{O}$ species in the center fuel channel. The trend follows the typical behavior in that the mass of $\mathrm{H}_{2}$ is depleted and $\mathrm{H}_{2} \mathrm{O}$ produced along direction of flow.

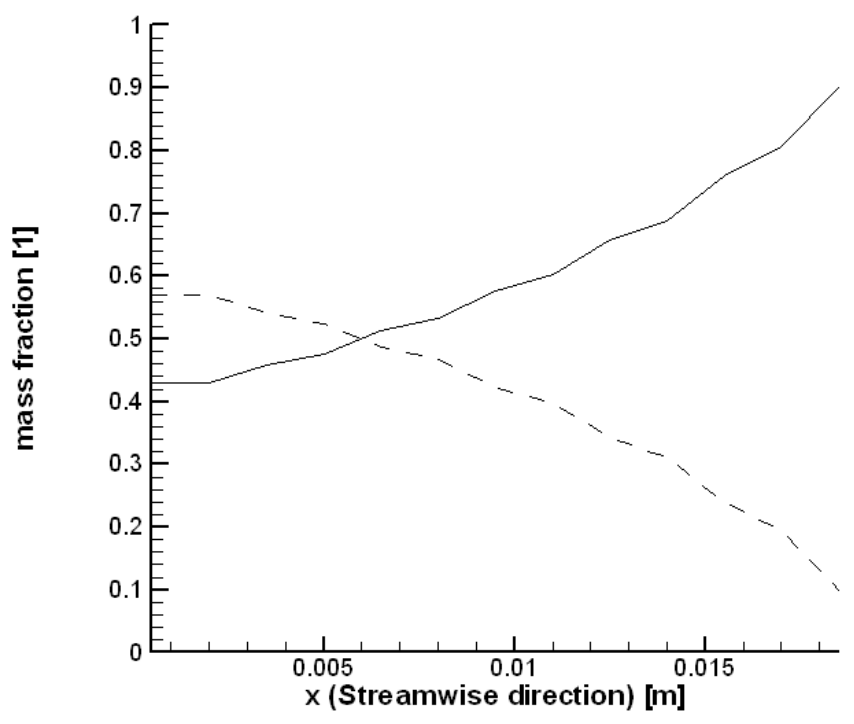

Figure 5.1.4. Variation of $\mathrm{H}_{2}$ (solid line) and $\mathrm{H}_{2} \mathrm{O}$ (dashed line) mass fraction along the center fuel channel for counter-flow case (Fuel flow is right to left) 
Figure 5.1.5 presents the temperature contours for the PEN in the counter-flow case. As expected there is a region of highest temperature located about $1 / 3$ of the way along the flow.

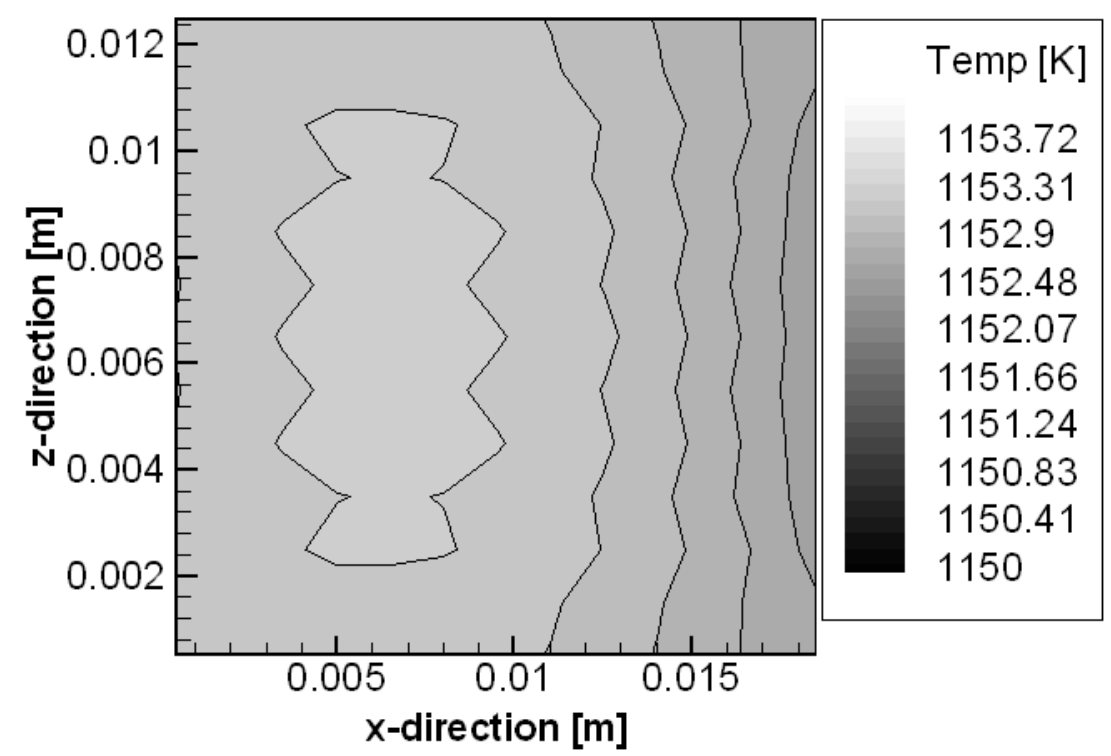

Figure 5.1.5. PEN temperature contours for counter-flow case (fuel flows right to left and air flows from left to right).

\subsubsection{Cross-Flow Results}

Although the inclusion of the radiative heat transfer reduces cell-to-cell voltage variations, significant variations are still present due to distribution of fuel and oxidizer resulting from flow within the cell or stack. Cross-flow configurations can be preferred for simplicity of the air and fuel manifolds. However cross-flow fuel cells exhibit complex temperature distributions due to the orientation of the channels and their affect on heat convection. 
The same geometry and model parameters were used for both a higher and lower utilization case. Table 5.1.5 gives the dimension of the cell. Note that the geometry was the same for the counter-flow case except the air channels were rotated 90 degrees. For the cross-flow, lower utilization case the load resistance was fixed at $0.5 \mathrm{Ohms}$ and the voltage and current was solved by the electrochemistry model to be $0.272 \mathrm{~V}$ and $0.544 \mathrm{~A}$. The higher utilization case had a fixed total current of $0.512 \mathrm{~A}$ and the voltage and load resistance were solved by the electrochemistry to be $0.251 \mathrm{~V}$ and $0.490 \mathrm{Ohms}$.

Table 5.1.5. Physical dimensions of "button" cell (cross-flow cell)

\begin{tabular}{|c|c|}
\hline SOFC Component & [m] \\
\hline Cell Length & 0.016 \\
\hline Cell Width & 0.016 \\
\hline Grid Length, $\Delta \mathrm{x}$ for fuel, $\Delta \mathrm{z}$ for air & 0.001 \\
\hline Fuel Gas Channel Height, $\Delta \mathrm{y}$ & 0.002 \\
\hline Fuel Gas Channel Width, $\Delta \mathrm{z}$ & 0.002 \\
\hline Air Gas Channel Height, $\Delta \mathrm{y}$ & 0.002 \\
\hline Air Gas Channel Width, $\Delta \mathrm{x}$ & 0.002 \\
\hline $\begin{array}{c}\text { Channel Wall Thickness, } \Delta \mathrm{z} \\
\text { between fuel, } \Delta \mathrm{z} \text { between air }\end{array}$ & 0.001 \\
\hline Electrolyte Thickness, $\Delta \mathrm{y}$ & $5.0 \mathrm{E}-04$ \\
\hline Anode Electrode Thickness, $\Delta \mathrm{y}$ & $5.0 \mathrm{E}-04$ \\
\hline Cathode Electrode Thickness, $\Delta \mathrm{y}$ & $5.0 \mathrm{E}-04$ \\
\hline Separator Thickness, $\Delta \mathrm{y}$ & 0.001 \\
\hline
\end{tabular}

Table 5.1.6 gives the material properties and model parameters used for the cross-flow cases. The lower utilization case used a total inlet mass flow rate of $1 \times 10-5 \mathrm{~kg} / \mathrm{s}$ for the air channels and $1 \times 10-7 \mathrm{~kg} / \mathrm{s}$ for the fuel channels. For the higher utilization case the inlet mass flow rates were reduced by $1 / 5$. 
Table 5.1.6. Material properties and model parameters (cross-flow cell)

\begin{tabular}{|c|c|}
\hline Cell Heat Capacity $[\mathrm{J} / \mathrm{kg}-\mathrm{K}]$ & $8.00 \mathrm{E}+02$ \\
\hline Cell Density $\left[\mathrm{kg} / \mathrm{m}^{3}\right]$ & $1.50 \mathrm{E}+03$ \\
\hline Separator Heat Capacity $[\mathrm{J} / \mathrm{kg}-\mathrm{K}]$ & $4.00 \mathrm{E}+02$ \\
\hline Separator Density $\left[\mathrm{kg} / \mathrm{m}^{3}\right]$ & $8.00 \mathrm{E}+03$ \\
\hline No. Axial Nodes & 11 \\
\hline Anode Inlet Temperature $[\mathrm{K}]$ & 1150 \\
\hline Anode Inlet Pressure $[\mathrm{Pa}]$ & $1.01 \mathrm{E}+05$ \\
\hline $\mathrm{H}_{2}$ Anode Inlet Mass Fraction & $9.0 \mathrm{E}-01$ \\
\hline $\mathrm{H}_{2}$ O Anode Inlet Mass Fraction & $1.0 \mathrm{E}-01$ \\
\hline Cathode Inlet Temperature $[\mathrm{K}]$ & 1150 \\
\hline Cathode Inlet Pressure $[\mathrm{Pa}]$ & $1.01 \mathrm{E}+05$ \\
\hline $\mathrm{O}_{2}$ Cathode Inlet Mole Fraction & 0.233 \\
\hline $\mathrm{N}_{2}$ Cathode Inlet Mole Fraction & 0.767 \\
\hline Contact + Separator Resistance $\left[\Omega / \mathrm{cm}^{2}\right]$ & $1.0 \mathrm{E}-01$ \\
\hline Limiting Current Density $\left[\mathrm{A} / \mathrm{m}^{2}\right]$ & $4.0 \mathrm{E}+03$ \\
\hline Exchange Current Density $\left[\mathrm{A} / \mathrm{m}^{2}\right]$ & $5.5 \mathrm{E}+03$ \\
\hline Heat Transfer Coefficient for Air Channel $\left[\mathrm{W} / \mathrm{m}^{2}-\mathrm{K}\right]$ & 268.8 \\
\hline Heat Transfer Coefficient for fuel Channel $\left[\mathrm{W} / \mathrm{m}^{2}-\mathrm{K}\right]$ & 1020.0 \\
\hline
\end{tabular}

\section{Case 1: Lower $\mathrm{H}_{2}$ Utilization}

The Reduced Order 3-D Fuel Cell Model was then applied to a 5 channel cross-flow electrolyte supported SOFC button cell. The steady state solution is presented in this section with discussion. Fuel gas was 0.9 mass fraction hydrogen and 0.1 mass fraction water and was introduced at a mass flow rate of $2.0 \times 10^{-8} \mathrm{~kg} / \mathrm{s}$ per channel. The air gas had an oxygen mass fraction of 0.233 with the remainder being nitrogen and was introduced at a mass flow rate of $2.0 \times 10^{-6} \mathrm{~kg} / \mathrm{s}$ per channel. The fuel and air inlet temperature was $1150.0 \mathrm{~K}$. The total current of $0.544 \mathrm{~A}$ resulted in a hydrogen utilization of $6.28 \%$. This is very low fuel utilization and resulted in only minor heating of the cell (temperatures at the center of the cell increased by $2.25 \mathrm{~K}$ ). 
Figures 5.1.6-14 show results obtained with the Modified Lump Model simulating a 5 channel cross-flow SOFC. The temperature contours observed are compared with temperature contours predicted by Achenbach (1994). Results are found to be consistent.

Figure 5.1.6 shows the convergence of the temperature to steady state by considering the variation of 3 points located in the center of the fuel cell with time. The three points are located in the fuel channel, PEN, and air channel at the center of the 5 cell cross-flow cell. The thermal response time of the cell is much longer then the response of other phenomena occurring in the cell thus it is used to identify whether the cell has reached steady state.

Temperature at cell center vs. time

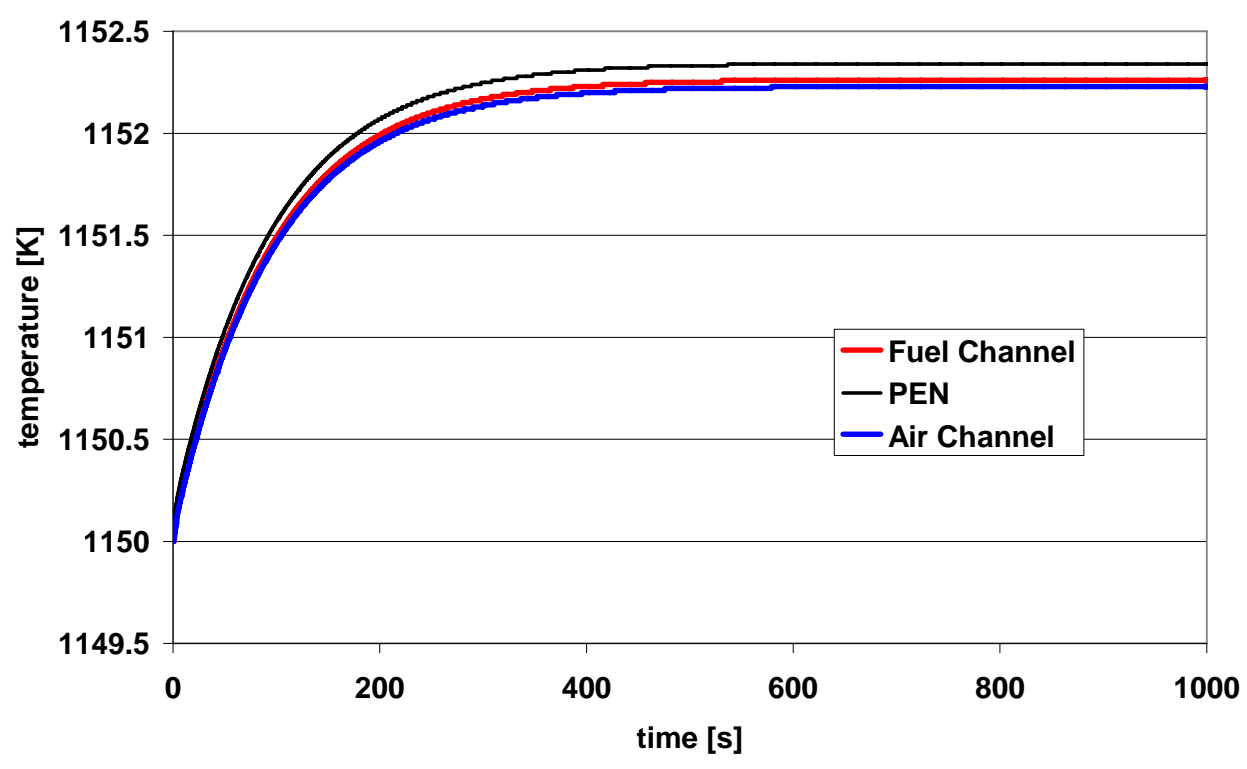

Figure 5.1.6. Temperature at 3 points along line passing through center of cell 
Figure 5.1.7 introduces the current density along the center fuel channel calculate by the Electrochemistry Model (ECM) as square symbols and the distributed anode current density as a solid line. The ECM was used to determine the electric potential and current density at locations where fuel and air channels cross. As expected the current density (square symbols) decreases in the streamwise direction attributed mostly to changes species concentration as hydrogen is depleted and water introduced. Due to diffusion of oxygen ions in the electrolyte and the porosity of the electrodes it is necessary to distribute the current along the fuel and air channels. The current density estimated by the ECM predicts the total flux of oxygen ions that pass from air to fuel channel across a coarse grid which encompasses more then just the PEN control volume located between the air and fuel channel. This flux (represented as a current) is therefore distributed based area ratios as explained in Section 3.8.3.

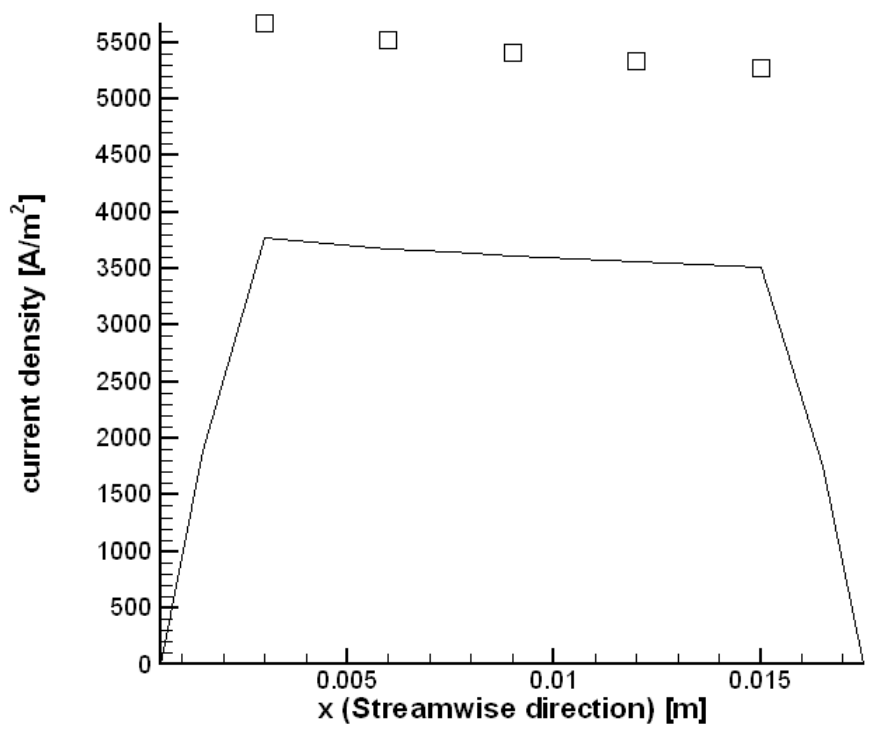

Figure 5.1.7. Current density calculated by ECM (square symbols) at points where channels cross and current density distributed along fuel channel (solid line). 
Figure 5.1.8 depicts the mass fractions of hydrogen and water in the streamwise direction. As a result of the current density predicted in Figure 5.1.7 the hydrogen is consumed and water is introduced to the fuel channel. Thus the mass fraction of hydrogen decreases in the streamwise direction while the water mass fraction increases. The sum of the mass fractions of the species in the fuel channel by definition is unity. This is indeed the case in the figure confirming that mass balance is achieved.

Figure 5.1.9 elucidates on the changes in density as a result of the increase in water (steam) mass in the fuel channel. It is reasonable given the difference in molecular weight of hydrogen versus water that with the introduction of water the density would significantly increase and this trend is observed in the figure.

Figure 5.1.10 shows the increase in temperature of the center fuel channel while traversing the cell in the direction of fuel flow and the temperature in the neighboring PEN. Due to temperature difference between fuel channel and neighboring solid regions the fluid temperature increases. This mass is transported by the flow in the channel downstream where more heat is added. This process results in the temperature profile observed in Figure 5.1.10. The temperature changes in the PEN show a stair case pattern as a result of the influence of the neighboring air channel which traverse the cross-flow cell perpendicular to the fuel channels. 


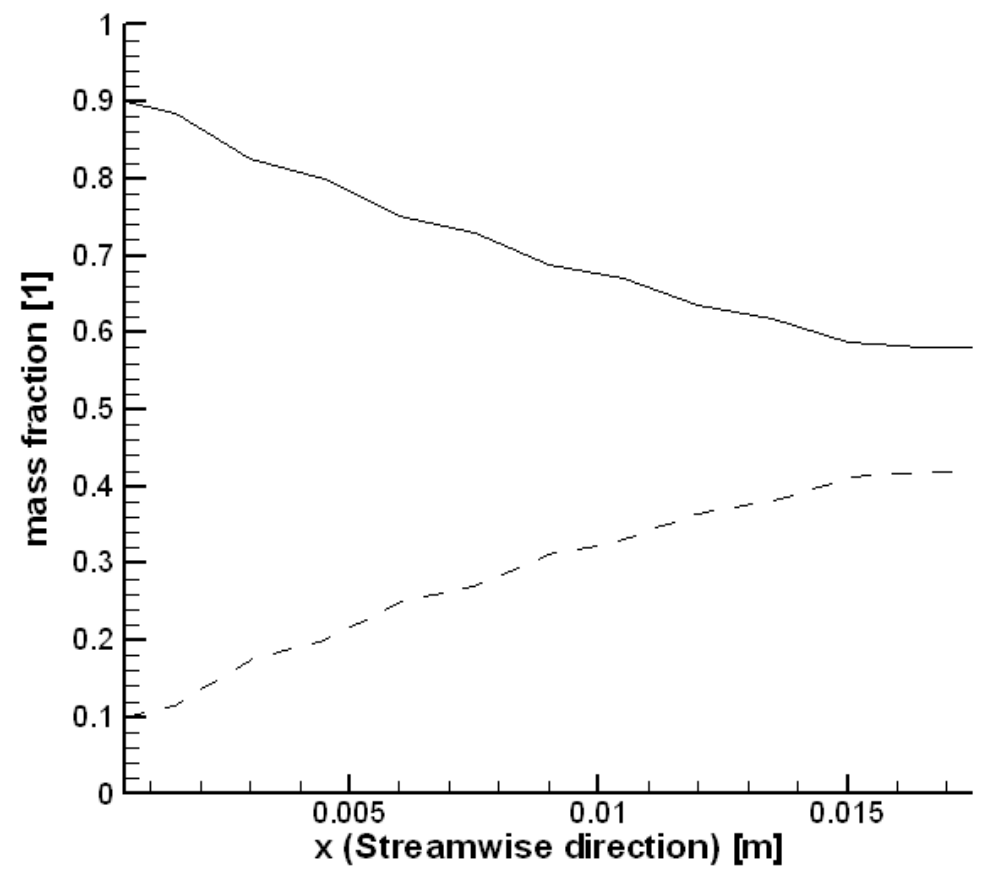

Figure 5.1.8. $\mathrm{H}_{2}$ (solid line) and $\mathrm{H}_{2} \mathrm{O}$ (dashed line) mass fraction along center fuel channel

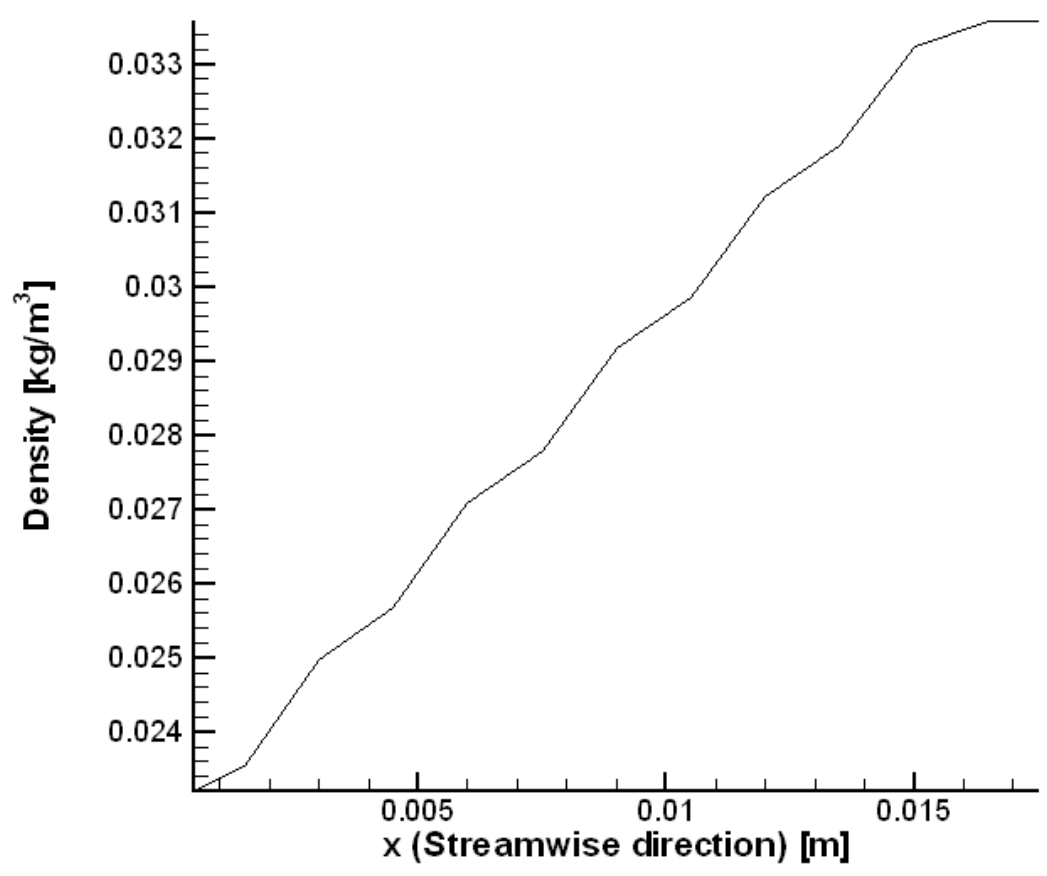

Figure 5.1.9. Density along center fuel channel 


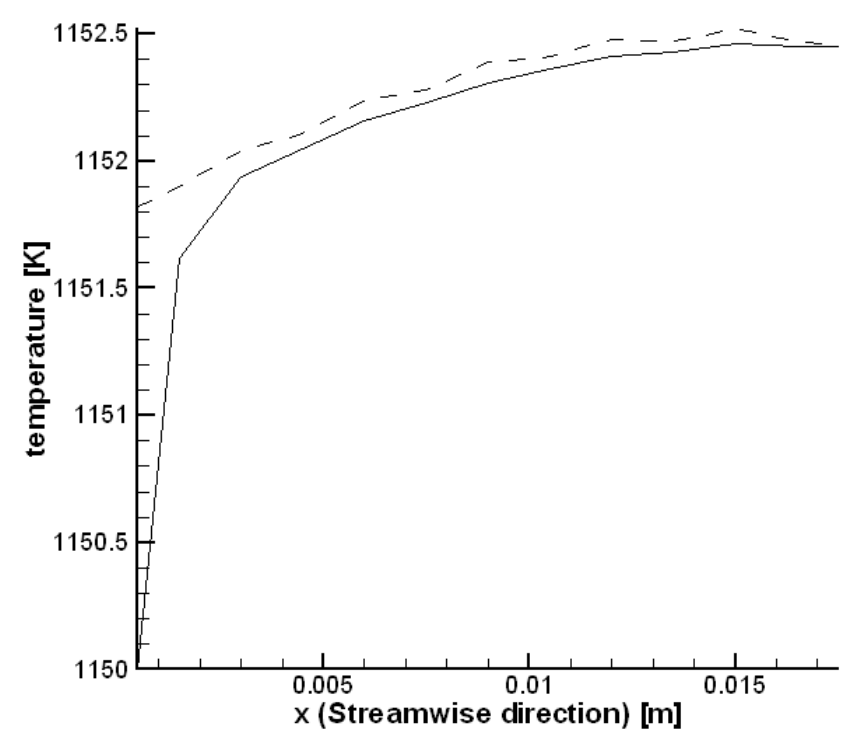

\section{Figure 5.1.10. Temperature profile along center fuel channel (solid line) with temperature of neighboring PEN (dashed line)}

Figures 5.1.11 and 5.1.12 show temperature contours for the PEN (Positive electrode Electrolyte Negative electrode) assembly obtained with the Modified Lump Model and presented by Achenbach (2004). Nonuniform temperature distributions are observed in the PEN due to influence of the air and fuel gas channels. The gas channels which flow from left to right (fuel) and bottom to top (air) result in thermal gradients where the greatest temperatures are observed to be near the outlet of the fuel gas channels. These trends have been observed in the literature (Stevenson et al., 2003, Zitney et al., 2004, and Cheng et al., 2004). Recknagle et al. (2003) showed that the region of highest temperature might appear near the anode inlet or outlet depending on whether a high or low fuel flow rate is prescribed. 


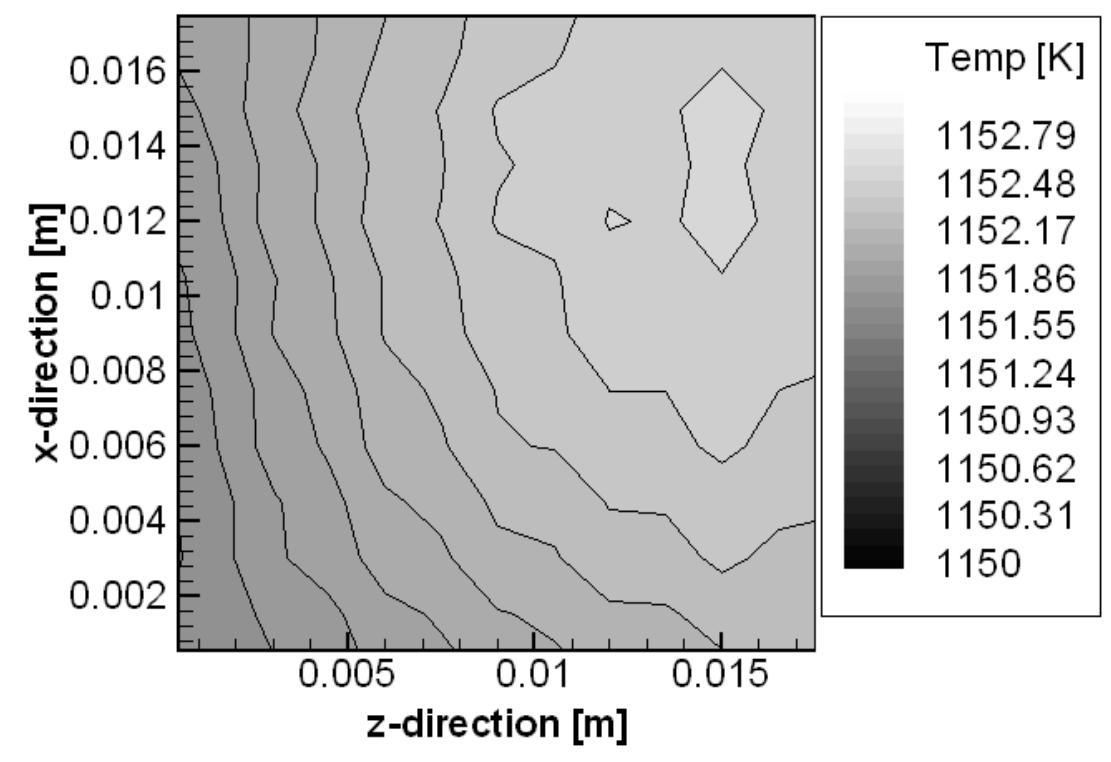

Figure 5.1.11. Temperature contours in the PEN (fuel flows from left to right and air flows from bottom to top)

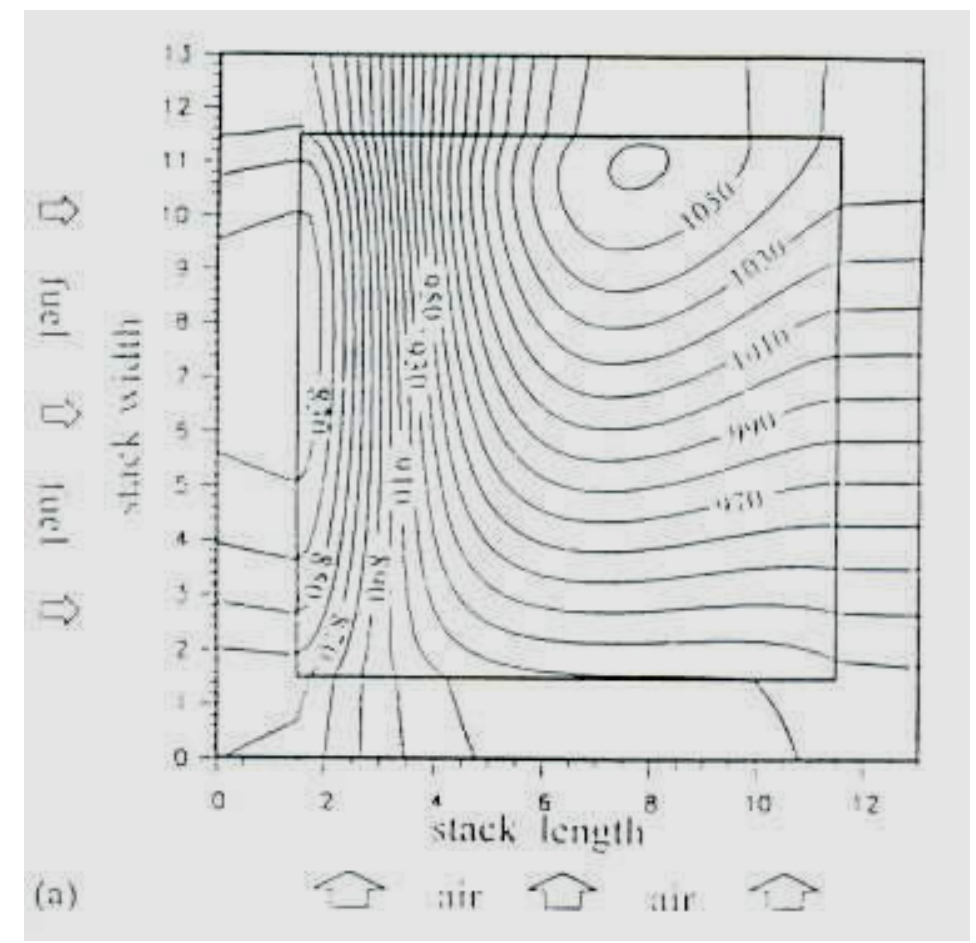

Figure 5.1.12. Temperature contours for cross-flow fuel cell with internal methane reforming (Achenbach, 1994) 
Figures 5.1.13 and 5.1.14 depict temperature contours in the air and fuel gas channels. The minimal temperature locations, shown as dark regions on the left or bottom of the figure, correspond to the air and fuel inlets. The contour lines show that the air channels to have a more significant impact on the cooling of the cell. This was expected since excess air is being used to cool the cell.

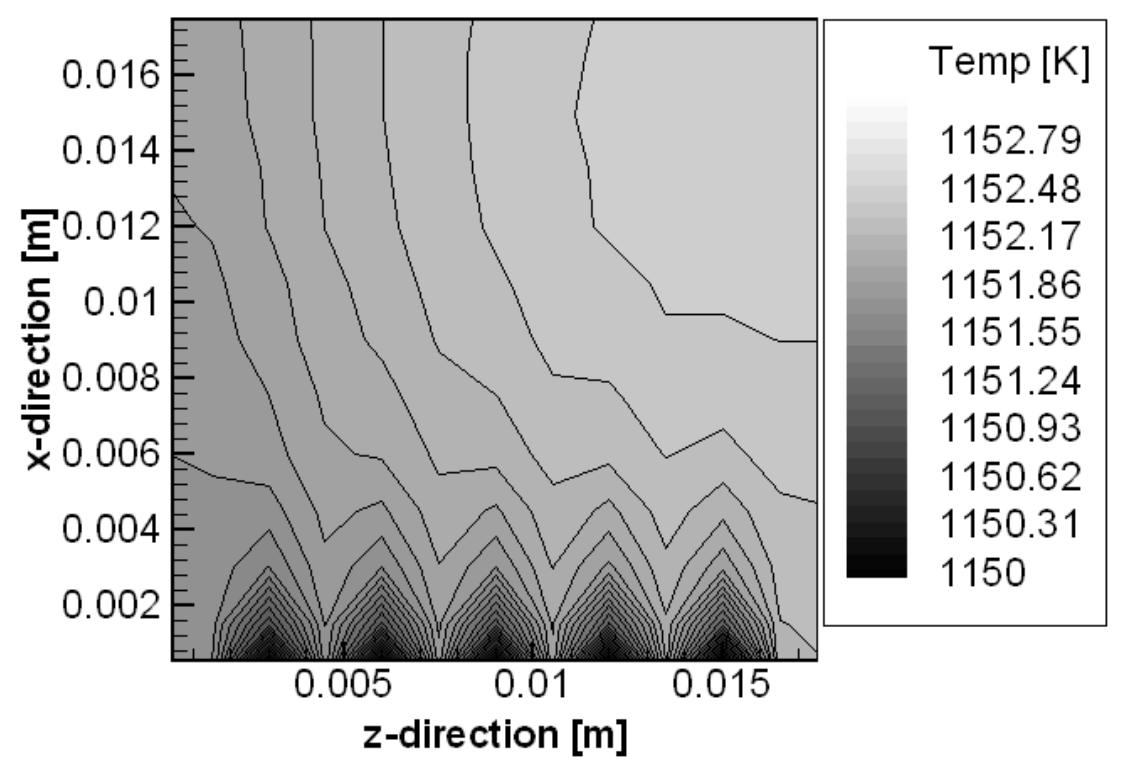

Figure 5.1.13. Temperature contours in a plane passing through the center of the air gas channels (air flow from bottom to top) 


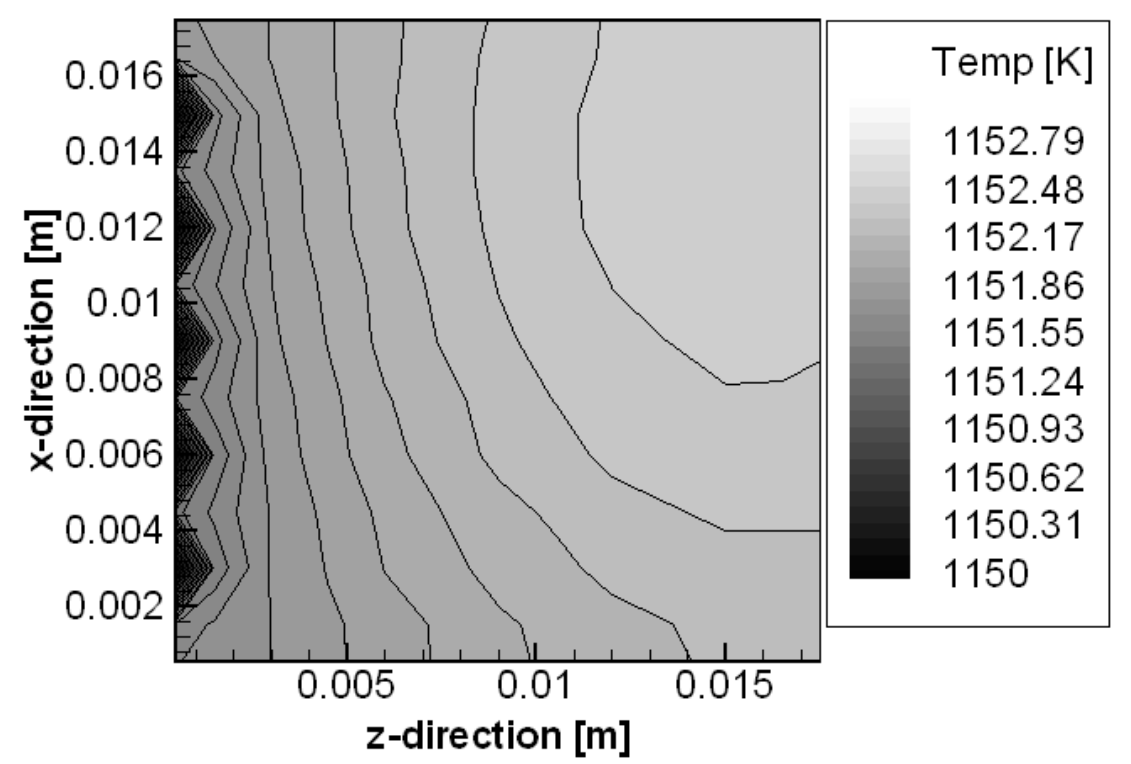

Figure 5.1.14. Temperature contours in a plane passing through the center of the fuel gas channels (fuel flow from left to right)

These results demonstrate that the Reduced Order 3-D Fuel Cell Model can successfully simulate cross-flow configurations. The predicted results are similar in trend to crossflow seen in the literature.

\section{Mass and Energy Balance}

Balance checks were performed on the single cell cross-flow case to insure conservation of mass and energy in the cell. The difference between the total mass flow rate into the cell and the total mass flow rate leaving the cell was found to be $1.67 \times 10^{-12} \mathrm{~kg} / \mathrm{s}$ which is close to machine accuracy. For the energy balance, because the outer walls of the cell are insulated (heat flux of zero) the difference between the total rate of energy entering the system and the total rate of energy leaving the system plus the electric work was found to 
be $3.39 \times 10^{-4} \mathrm{~kJ} / \mathrm{s}$. Although this is not as small as mass it represents an relative error in the total rate of energy leaving the system of about $3 \%$. This is a transient run and although the case is deemed to be close to steady state this could also represent the small change of total energy in the system.

\section{Case 2: Higher $\mathrm{H}_{2}$ Utilization}

To simulate a cross-flow cell operating at higher $\mathrm{H}_{2}$ utilization the flow rates used in the low utilization case were divided by 5 . For this case the total current was fixed at $0.512 \mathrm{~A}$ which resulted in $29.50 \% \mathrm{H}_{2}$ utilization. It should be noted that this is still a relatively low $\mathrm{H}_{2}$ utilization case.

Figure 5.1.15 shows the variation of the anode current density along the axial direction of the center fuel channel with the current density calculated by the ECM represented by square symbols. In this case the mass flow rate was decreased while maintaining the same total current and geometry as used in the lower utilization case. Therefore, the current density remains the same in Figures 5.1.15 and 5.1.17.

Figure 5.1.16 presents the variation of the mass fraction of $\mathrm{H}_{2}$ and $\mathrm{H}_{2} \mathrm{O}$ along the center fuel channel in the streamwise direction. It can be readily seen that the $\mathrm{H}_{2}$ is consumed and $\mathrm{H}_{2} \mathrm{O}$ is being produced. The mass fractions at the outlet are typical for a fuel cell operating under high $\mathrm{H}_{2}$ utilization. 


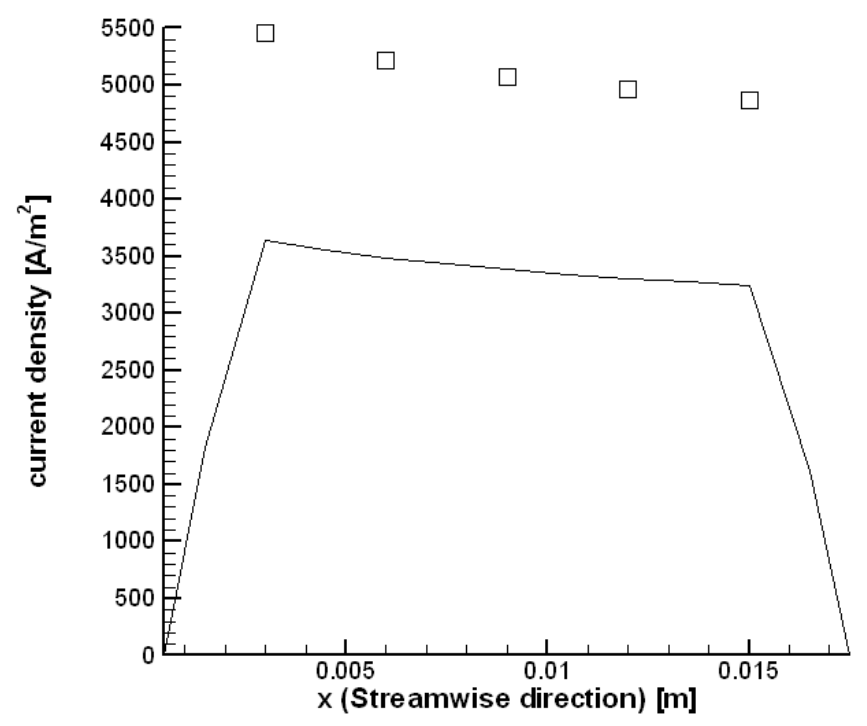

Figure 5.1.15. Current density calculated by ECM (square symbols at points where channels cross and current density distributed along fuel channel (solid line) for higher $\mathrm{H}_{2}$ utilization case.

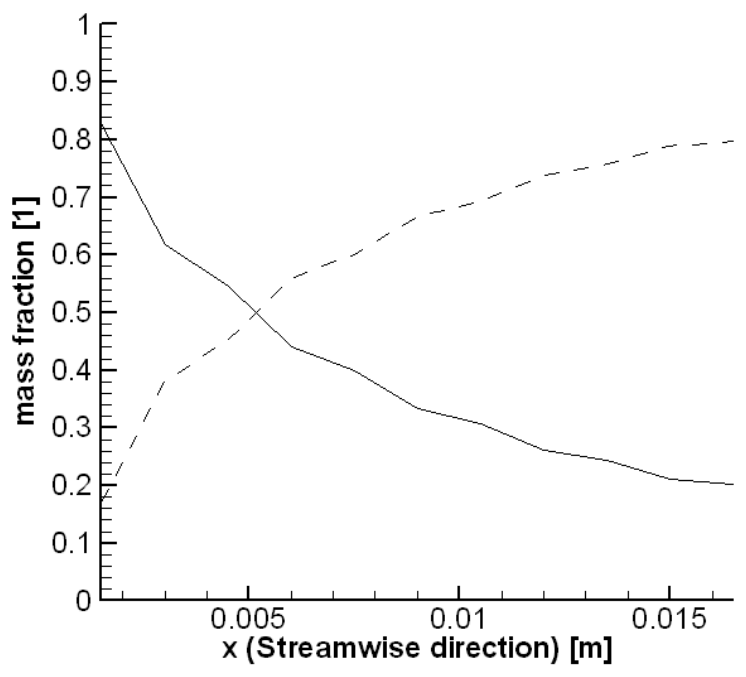

Figure 5.1.16. Variation of $\mathrm{H}_{2}$ (solid) and $\mathrm{H}_{2} \mathrm{O}$ (dashed) mass fraction along center fuel channel for higher utilization case. 
Figure 5.1.17 shows the temperature distribution in the PEN for the high utilization case. The previous case (Figure 5.1.11) showed that for low utilization (high fuel flow rate compared to fuel consumption) the region of highest temperature for the cross-flow configuration was located near the outlet of the fuel gas channel. A similar trend was observed here.

Recknagle et al. (2003) found that for the case of high utilization (slower fuel flow rate relative to fuel consumption) this high temperature region shifts closer to the fuel inlet. However in this study the higher utilization $(29.50 \%)$ was still too low to capture this trend. And the results were found to be similar to the lower $\mathrm{H}_{2}$ utilization case.

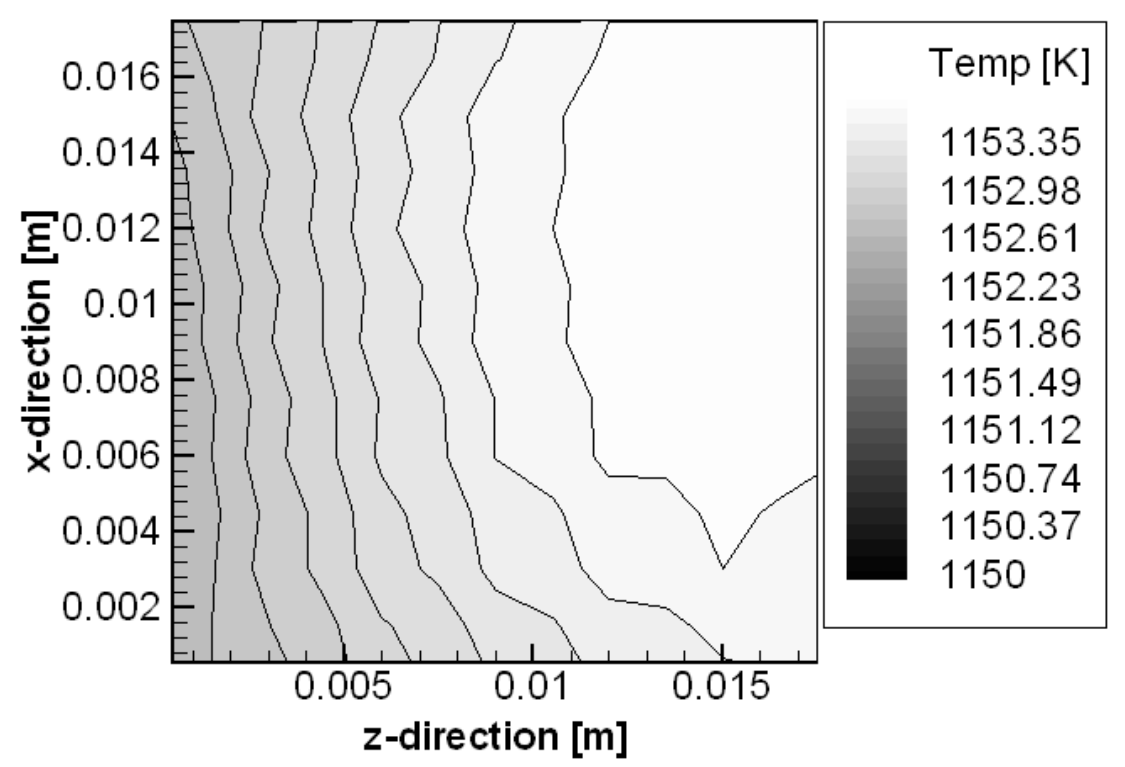

Figure 5.1.17. Temperature contours in the PEN (fuel flows from left to right and air flows from bottom to top) for higher utilization case. 
Comparison of Figures 5.1.18 and 5.1.19 with the same temperature contours observed for the lower utilization case show that for the higher utilization case the temperatures are higher. This is as expected due to the increased heat generation. All the trends appear to be the same.

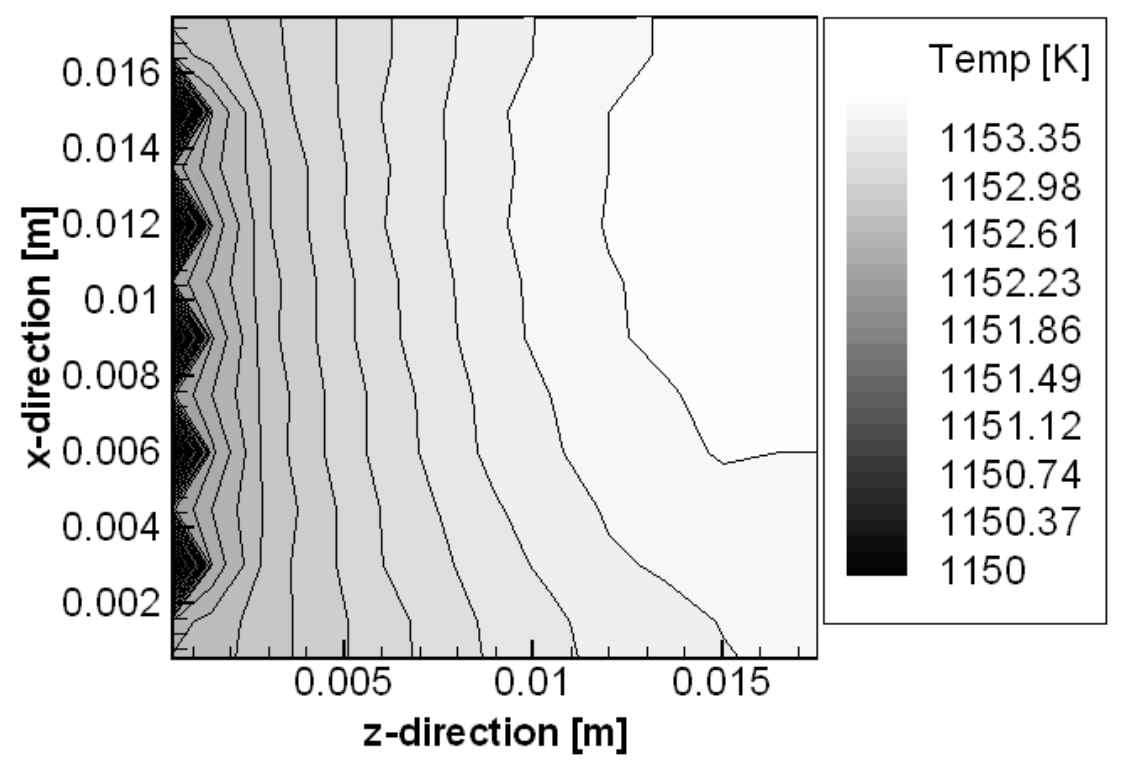

Figure 5.1.18. Temperature contours for fuel channels (fuel flow is left to right) for higher utilization case 


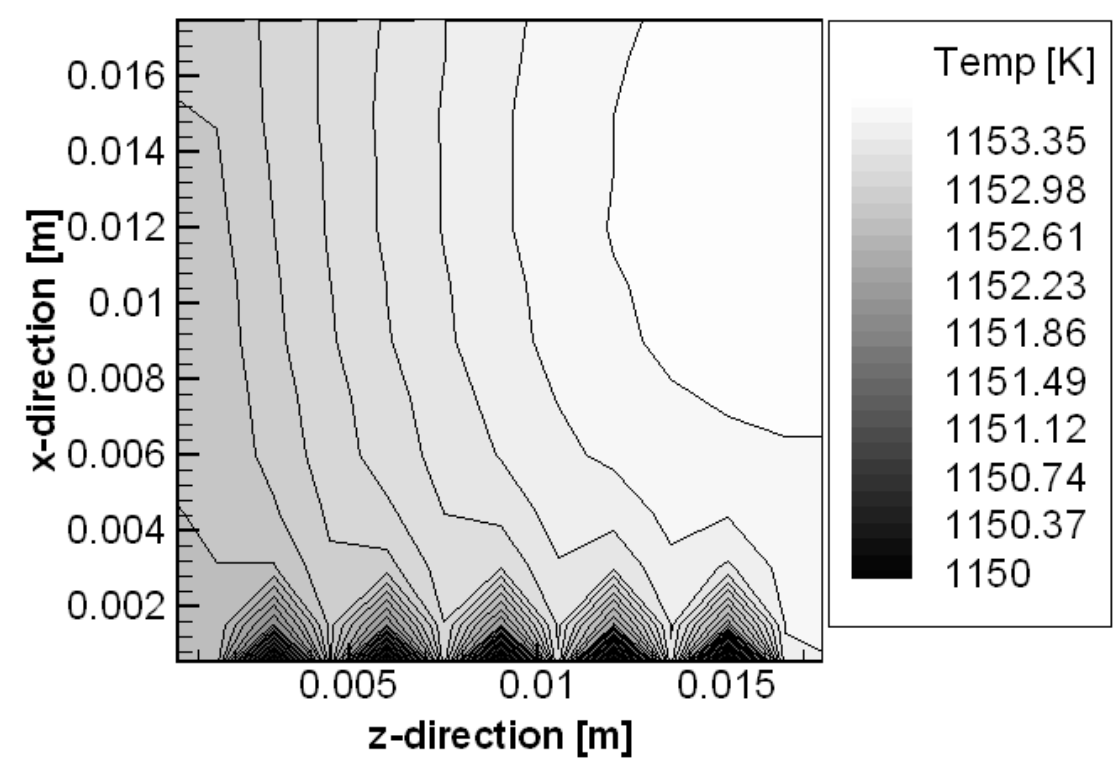

Figure 5.1.19. Temperature contours in air channel (air flow is bottom to top)

\section{Efficiency of Co-Flow, Counter-Flow, and Cross-Flow cells}

The co-flow, counter-flow, and cross-flow cases presented here were not chosen for direct comparison but to show that the Reduced Order 3-D Fuel Cell Model was capable of studying the common planar geometries. Due to differences in the selected cases direct comparison of the efficiencies should not be made.

The free-energy efficiencies were calculated in the same manner as described in Section 4.2 and found to be $41.97 \%, 10.75 \%$, and $53.88 \%$ for the co-flow, counter-flow, and cross-flow (low $\mathrm{H}_{2}$ utilization) cases, respectively. The cross-flow efficiency calculated was found to be within the range typical for SOFC efficiencies of 50\%-80\% (Blomen and Mugerwa, 1993). However for both the co-flow and counter-flow case the efficiency was found to be low. 
The low efficiency observed for the counter-flow case was the result of having a low cell voltage of $0.166826 \mathrm{~V}$ due to the large concentration overpotential. This resulted in a low power production relative to the power potential of the fuel consumed and a relatively bad efficiency.

\subsection{Four-Cell Stack simulation}

The Reduced Order 3-D Fuel Cell Stack Model was developed in order to study crossflow planar fuel cell stacks and in this section results from a 4 cell stack are presented. Previously cross-flow geometries were not solvable with the Psuedo 2-D Fuel Cell Stack Model due to the inherent 3-D nature of the cross-flow geometry. Section 5.1 presented some single cell solutions based on the "button" cell geometry. This same geometry is solved here as part of a 4 cell cross-flow button cell stack.

The exact same procedure was used to parallelize the Reduced Order 3-D Fuel Cell Model as was previously demonstrated with the Psuedo 2-D Fuel Cell Stack Model. Domain decomposition was used such that each cell was solved separately as an individual process. MPI communication was used to pass appropriate boundary conditions between cells. 
The parallel version require significantly more cpu time than the single cell model. Typically the single cell run would complete 1000s of simulation in approximately 5 days. The 4 cell stack required about 18 days to complete. This loss in speed is attributed to be due to both extra overhead and inter-process communication required to assign the communicated data correctly.

Table 5.2.1 gives the dimensions of the cross-flow geometry. Each cell in the stack was identical in geometry, material properties, and model parameters. The inlet mass flow rate for each air and fuel channel was $2 \times 10^{-6}$ and $2 \times 10^{-8} \mathrm{~kg} / \mathrm{s}$, respectively. This corresponds to the lower utilization cross-flow cell presented in the previous section.

Table 5.2.1. Physical dimensions of "button" cell (4 cell cross-flow stack)

\begin{tabular}{|c|c|}
\hline SOFC Component & [m] \\
\hline Cell Length & 0.016 \\
\hline Cell Width & 0.016 \\
\hline Grid Length, $\Delta \mathrm{x}$ for fuel, $\Delta \mathrm{z}$ for air & 0.001 \\
\hline Fuel Gas Channel Height, $\Delta \mathrm{y}$ & 0.002 \\
\hline Fuel Gas Channel Width, $\Delta \mathrm{z}$ & 0.002 \\
\hline Air Gas Channel Height, $\Delta \mathrm{y}$ & 0.002 \\
\hline Air Gas Channel Width, $\Delta \mathrm{x}$ & 0.002 \\
\hline $\begin{array}{c}\text { Channel Wall Thickness, } \Delta \mathrm{z} \\
\text { between fuel, } \Delta \mathrm{z} \text { between air }\end{array}$ & 0.001 \\
\hline Electrolyte Thickness, $\Delta \mathrm{y}$ & $5.0 \mathrm{E}-04$ \\
\hline Anode Electrode Thickness, $\Delta \mathrm{y}$ & $5.0 \mathrm{E}-04$ \\
\hline Cathode Electrode Thickness, $\Delta \mathrm{y}$ & $5.0 \mathrm{E}-04$ \\
\hline Separator Thickness, $\Delta \mathrm{y}$ & 0.001 \\
\hline
\end{tabular}


Table 5.2.2. Material properties and model parameters (4 cell cross-flow stack)

\begin{tabular}{|c|c|}
\hline Cell Heat Capacity $[\mathrm{J} / \mathrm{kg}-\mathrm{K}]$ & $8.00 \mathrm{E}+02$ \\
\hline Cell Density $\left[\mathrm{kg} / \mathrm{m}^{3}\right]$ & $1.50 \mathrm{E}+03$ \\
\hline Separator Heat Capacity $[\mathrm{J} / \mathrm{kg}-\mathrm{K}]$ & $4.00 \mathrm{E}+02$ \\
\hline Separator Density $\left[\mathrm{kg} / \mathrm{m}^{3}\right]$ & $8.00 \mathrm{E}+03$ \\
\hline No. Axial Nodes & 11 \\
\hline Anode Inlet Temperature $[\mathrm{K}]$ & 1150 \\
\hline Anode Inlet Pressure $[\mathrm{Pa}]$ & $1.01 \mathrm{E}+05$ \\
\hline $\mathrm{H}_{2}$ Anode Inlet Mass Fraction & $9.0 \mathrm{E}-01$ \\
\hline $\mathrm{H}_{2}$ O Anode Inlet Mass Fraction & $1.0 \mathrm{E}-01$ \\
\hline Cathode Inlet Temperature $[\mathrm{K}]$ & 1150 \\
\hline Cathode Inlet Pressure $[\mathrm{Pa}]$ & $1.01 \mathrm{E}+05$ \\
\hline $\mathrm{O}_{2}$ Cathode Inlet Mole Fraction & 0.233 \\
\hline $\mathrm{N}_{2}$ Cathode Inlet Mole Fraction & 0.767 \\
\hline Contact + Separator Resistance $\left[\Omega / \mathrm{cm}^{2}\right]$ & $1.0 \mathrm{E}-01$ \\
\hline Limiting Current Density $\left[\mathrm{A} / \mathrm{m}^{2}\right]$ & $4.0 \mathrm{E}+03$ \\
\hline Exchange Current Density $\left[\mathrm{A} / \mathrm{m}^{2}\right]$ & $5.5 \mathrm{E}+03$ \\
\hline Heat Transfer Coefficient for Air Channel $\left[\mathrm{W} / \mathrm{m}^{2}-\mathrm{K}\right]$ & 268.8 \\
\hline Heat Transfer Coefficient for fuel Channel $\left[\mathrm{W} / \mathrm{m}^{2}-\mathrm{K}\right]$ & 1020.0 \\
\hline
\end{tabular}

Table 5.2.3 shows the cell voltage and resistance calculated by the ECM for each cell in the 4 cell stack at steady state conditions. The total current was prescribed to be $0.512 \mathrm{~A}$. This is a requirement of all cells located in series in a stack and therefore was enforced here. From the table it can be seen that the under these conditions the model has the highest cell voltage in the bottom cell and the lowest cell voltage was found in the top cell. Although these differences in cell voltage are very small. A similar trend was observed in the Pseudo 2-D Fuel Cell Stack Model in the case with lower utilizations.

Table 5.2.3. Cell Voltage and Resistance for 4 cell stack at steady state.

\begin{tabular}{|c|c|c|}
\hline Cell number & Cell Voltage [V] & Resistance [Ohms] \\
\hline 3 & 0.319196 & 0.623429 \\
\hline 2 & 0.319242 & 0.623519 \\
\hline 1 & 0.319299 & 0.623631 \\
\hline 0 & 0.319356 & 0.623742 \\
\hline
\end{tabular}


Figure 5.2.1 shows the convergence of the temperature in the PEN of the top and bottom cell of the 4 cell stack. The temperature in all of the solid regions of the cell along the center line (perpendicular to the gas channels) was found to be approximately the same. Therefore the temperature is shown for just the top and bottom cells. The solid black and grey lines in Figure 5.2.1 represent the temperature of the top and bottom cells, respectively.

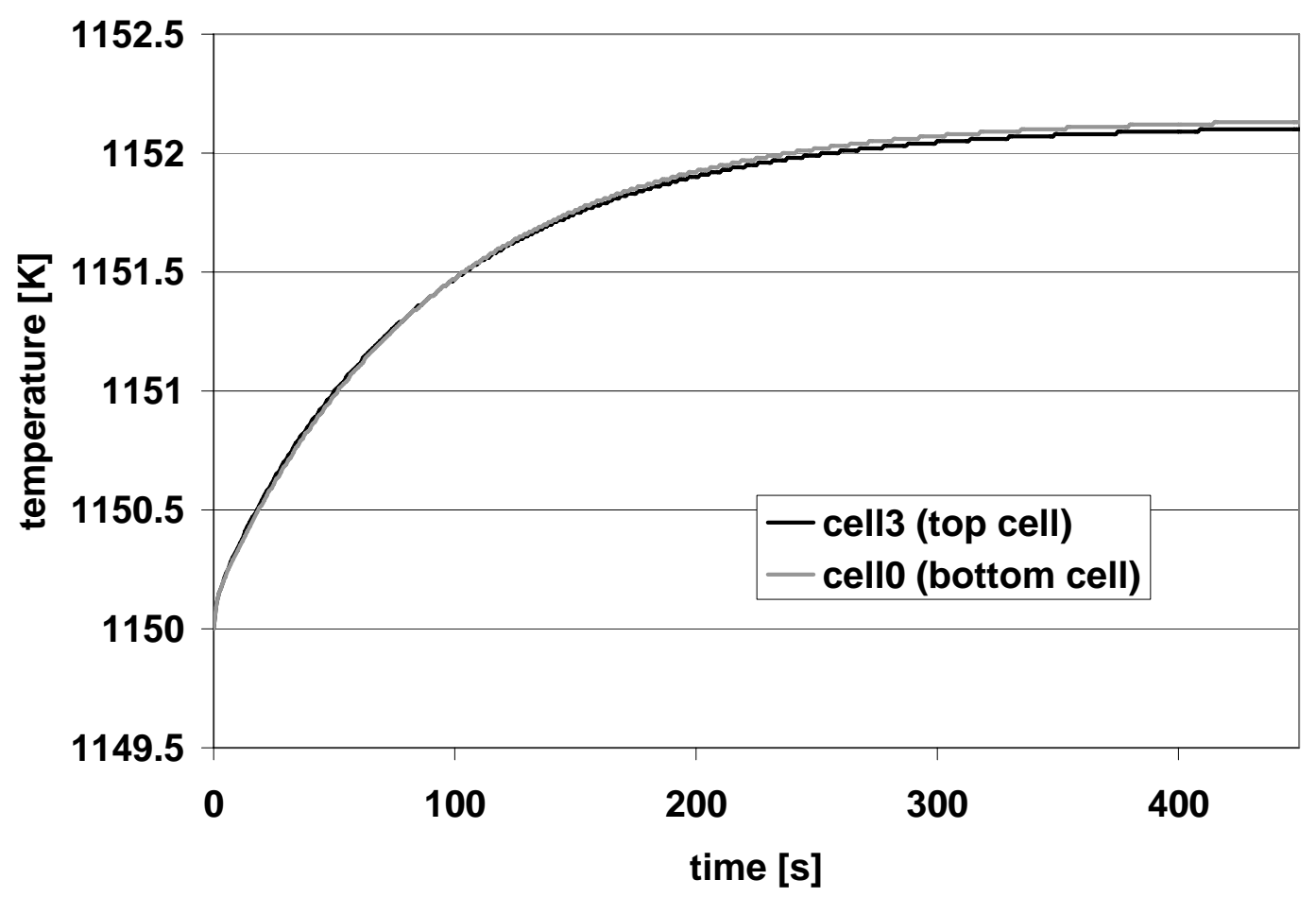

Figure 5.2.1. Temperature variation with time for center location of PEN in the top and bottom cell

Figure 5.2.2 shows the temperature profile along the vertical center line of the 4 cell cross-flow stack. From the figure it can be seen that the temperatures of the different 
components appear to be behaving approximately the same. This may be the result the conduction in the solids which surrounds the channels and radiation from the PEN and the sides of the channels to the interconnect which would all help the interconnect to reach a temperature closer to that of the PEN. In the previous co-flow stack results obtained with the Pseudo 2-D Fuel Cell Stack Model (see Figure 4.2.3a) the temperatures of the interconnect, PEN, and fuel gas channels where in relatively close agreement and the air channel temperatures had the lowest values. Also in that previous case there was an overall increase in cell temperature as you moved from the bottom to top cell. Of course these cases are significantly different in that in this case we are simulating a crossflow button cell operating at a much lower temperature (around $1152 \mathrm{~K}$ ) and lower power $(0.52 \mathrm{~W})$

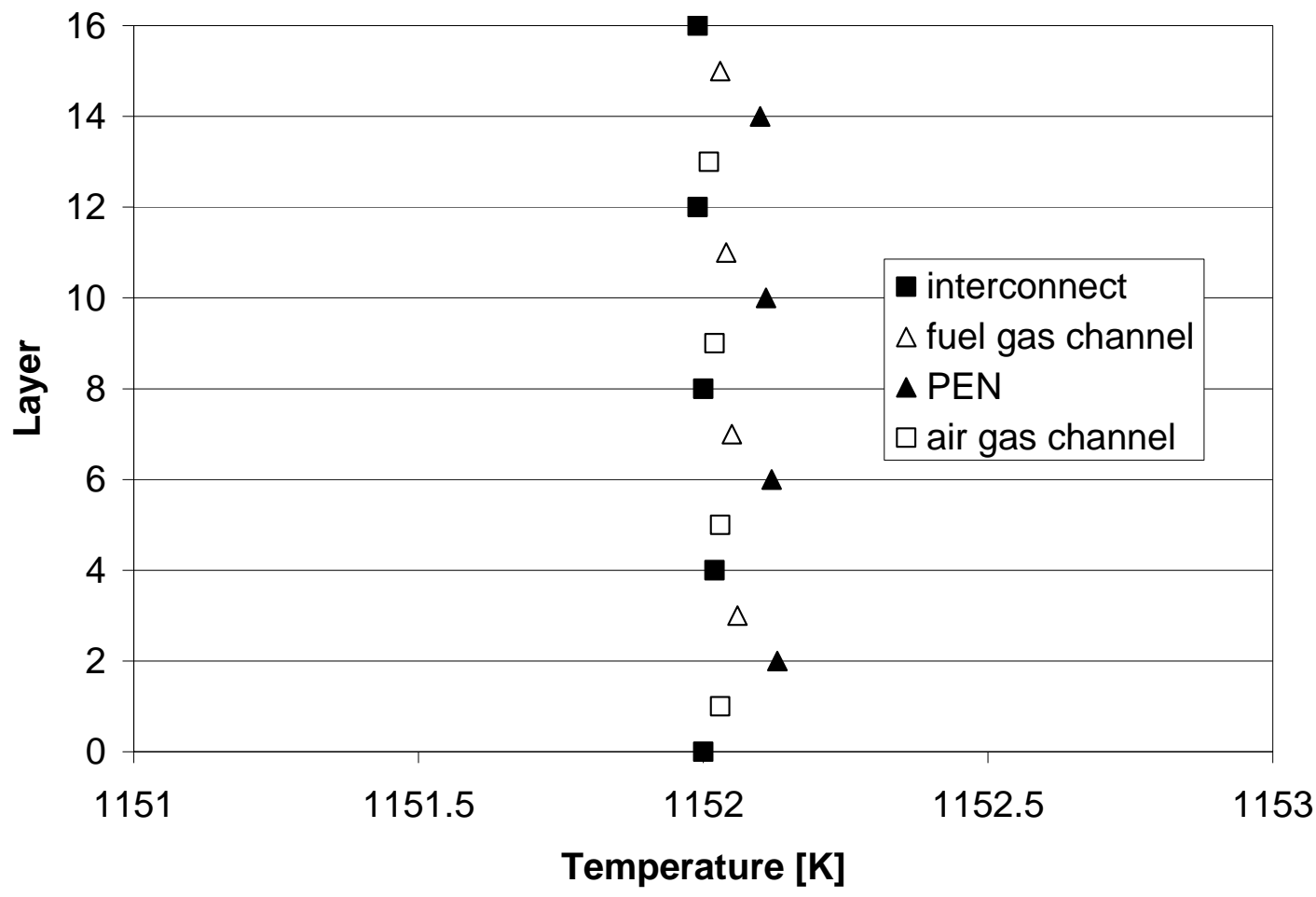

Figure 5.2.2. Temperature profile along the center of the 4 cell cross-flow stack 
Figure 5.2.3 shows the temperature contours of the PEN for each of the 4 cells in the cross-flow stack. It can be seen that there are minor differences in the temperature contours. In general there is a slight increase in the overall temperature from the top to the bottom cell. Most notable is the increase in area of the region of highest temperature located near the outlet of the air and fuel channels.
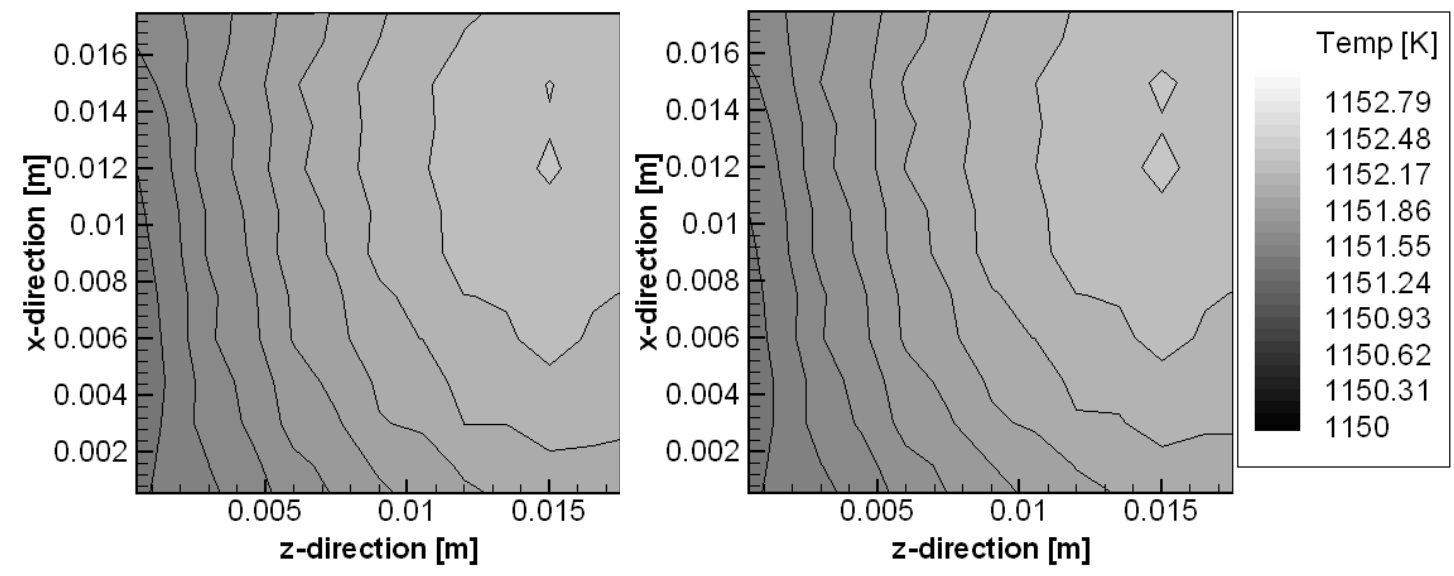

a) cell 3 (top cell)

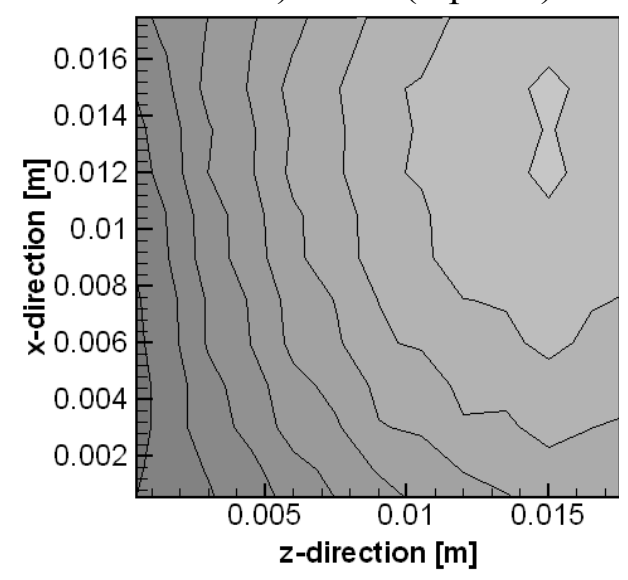

b) cell 2

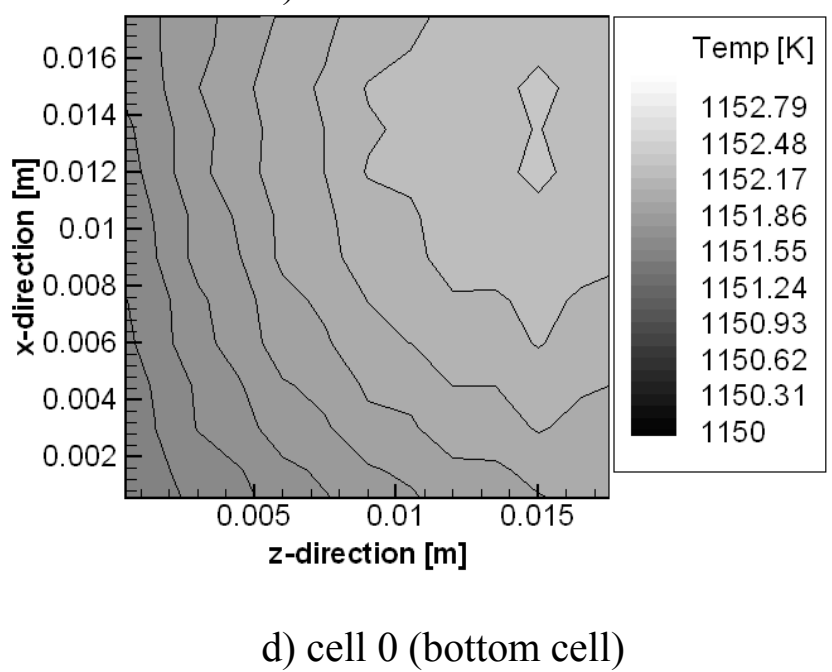

Figure 5.2.3. PEN Temperature counters for each cell in the 4 cell cross-flow stack (fuel flows left to right and air flows from bottom to top) 


\subsection{CONCLUSIONS AND FUTURE RECOMMENDATIONS}

\subsection{Conclusions}

Two reduced order models (ROMs), the Psuedo 2-D Stack Model and the Reduced Order 3-D Stack Model, were developed in order to study SOFC stacks containing the common planar configurations of co-flow, counter-flow, and cross-flow. The Psuedo 2-D Stack Model was developed by extending the basic 1-D single SOFC model of Gemmen et al. (2000). The Reduced Order 3-D Stack Model was developed to be a more general solver capable of handling the cross-flow geometries which the Psuedo 2-D Stack Model could not. Further, a parallelization paradigm was developed and implemented in both models which used domain decomposition to allow the solution of fuel cell stacks by simulating a single cell on an individual processor in a Beowulf computer cluster or multi-processor machine. Parallelization reduced the memory space and computational effort required by each processor to simulate large fuel-cell stacks.

The influence of stack size on individual cell performance for stacks as large as 40 cells was studied. This was the first study to model a 40 cell stack in a reasonable period of time (14 days of calculations on a 40 processor heavily shared cluster using a transient solver to model 1000 seconds of simulation to reach steady state). A similar sized stack would take significantly longer to solve using a full 3-D CFD solver. The FLUENT SOFC model takes approximately 3 hours to solve a 32 cell stack (almost a million nodes 
on a $2.8 \mathrm{GHz}$ Pentium 4) using a steady state solver (Prinkey, 2005). It is believed that a 1000s transient solution would take significantly longer than 14 days. It was observed that as stack size increased the temperature gradients in the stack changed from a linear to non-linear profile. This non-linear profile was first published by the author (Burt et al, 2004a and Burt et al., 2004b) during the process of this study and confirmed by Lin et al. (2003). It was found that for uniform flow distributions the cells in the center of the stack tend to operate at nearly the same temperatures.

The influence of non-uniform flow distribution on cell-to-cell performance variations within a stack was studied and found to be significant. No literature was found where non-uniform flow distribution within a fuel cell stack was studied. The stack models developed as part of this study allowed for the variation of fuel and air mass flow rates to be studied and the impact of mal-distribution determined. The highest cell-to-cell voltage variation was observed when fuel was redistributed between the bottom and neighboring cell.

As part of this work the influence of radiation between the solid parts of the fuel cell was also considered. The literature was unclear on the importance of including this mode of heat transfer. Some authors included radiation and others did not. This study was the first to include this radiation influence in a SOFC stack model. It was found that the temperature gradients at the top and bottom of the cell were reduced when radiation effects were included. Thus it is recommended that radiation not be neglected in SOFC models. 
Improved view factors were calculated to increase the accuracy of the existing radiation model used in the1-D single SOFC model of Gemmen et al. (2000) which the stack models of this study were based. The new view factors were calculated based on Hottel's "string rule" which was originally intended for 2-D geometries. These new view factors were included in the Reduced Order 3-D Fuel Cell Model.

A Multi-Component Multi-Physics (MCMP) paradigm and implementation was developed as part of this study and was not previously seen in the literature. Many engineering problems involve more than one component type in which different models must be solved. The MCMP scheme introduces a method/programming structure for linking multiple models/solvers to multiple components. This creates a generic platform which the user can use to create a domain composed of user defined components and solved by user defined models. In this study the Reduced Order 3-D Fuel Cell Model was developed based on the MCMP scheme.

The results obtained in this study for the co-flow, counter-flow, and cross-flow cases are difficult to validate with experiments. The electrochemistry model itself is based on empirical formulation from experiments. And with the lack of detailed measurements of the internal workings of an actual SOFC stack it is very difficult to determine the accuracy of these results using experimental results. Therefore the cases in this study were compared with other numerical results published in the literature and found to have 
the same trends. Further consistency checks were made to ensure that the overall mass and energy balances were satisfied.

\subsection{Recommendations}

The main incentive for developing ROM fuel cell stack models is to reduce computational turn around time while retaining reasonable accuracy. This study was based solely on $1^{\text {st }}$ order explicit numerical techniques. This resulted in very small time steps. For the Reduced Order 3-D Fuel Cell Model a time step of 5e-5s was used in order

to maintain stability. A future direction would be to solve the system of governing equations implicitly thus the solution would not be as sensitive to Courant number and could allow for larger time steps.

The Reduced Order 3-D Fuel Cell Model could be further improved to allow for the solution on finer grids. The current electrochemistry model was implemented to allow for gas channels and channel walls that are only one control volume high and wide with multiple control volumes along the direction of flow. Some improvements in the implementation can be made to allow for multiple solid control volumes between gas channels.

Most applications for fuel cells require repeated start-up and cycling of the fuel cell. However, this study focused on steady-state solutions. There are several studies that 
could be performed to consider transient behaviors. Especially interesting would be studies on material fatigue or failures resulting from mismatched thermal expansion coefficients. The time required for start-up is very important for design engineers which if too long can make SOFC not a viable solution for some applications. Generally, during start-up fuel cells are heated using a combustor and once sufficiently high temperatures are reached the electrolyte can begin to conduct ions and the normal operation of the fuel cell begins. In this study the fuel cell simulations started from a pre-heated state, but start-up simulations could be an interesting route of research.

The fuel cell models could be extended to allow for the simulation of more than hydrogen fuel. Many models in the literature consider methane and other hydrocarbon fuels. These were not considered in this study. The behavior of fuel cells under different types of fuel is of great interest to the fuel cell community. There is considerable literature on fuel cells with direct or indirect methane reforming. Coal syngas can be challenging due to the composition of the fuel which in general can be termed as "dirty." Impurities can result in material degradation and failure. Carbon deposition and sulfur poisoning are challenging problems that warrant further investigation. 


\section{BIBLIOGRAPHY}

1) Achenbach, E., (1994), “Three-dimensional and time-dependant simulation of a planar solid oxide fuel cell stack," Journal of Power Sources vol. 49, pp. 333-348

2) Aguiar, P., Chadwick, D., Kershenbaum, L., (2002), "Modelling of an indirect internal reforming solid oxide fuel cell," Chemical Engineering Science, vol 57, pp. 1665-1677.

3) Billingham, J., King, A.C., Copcutt, R.C., and Kendall, K., (2000), "Analysis of a Model for a Loaded, Planar, Solid Oxide Fuel Cell," Siam J. Appl. Math. Vol. 60, No. 2, pp. 574-601.

4) Blomen, L. and Mugerwa, M. (eds.) ( 1993) Fuel Cell Systems, Plenum Press, New York, NY.

5) Burt, A., Celik, I., Gemmen, R., and Smirnov, A., (2003a), "Cell-to-Cell Performance Variations within a Stack," ECS SOFC-VIII Proceedings Vol. 2003-07, pp 1487-1500, held April 27 - May 2, 2003 Paris, France.

6) Burt, A., Celik, I.,Gemmen, R. and Smirnov, A., (2003b), "Influence of Radiative Heat Transfer on Variation of Cell Voltage within a Stack" proceedings of First International Conference on Fuel Cell Science, Engineering and Technology held April 21-23, 2003 Rochester, NY 
7) Burt, A., Celik, I., Gemmen, R., and Smirnov, A., (2004a), “A Numerical Study of Cell-to-Cell Variations in a SOFC Stack," Journal of Power Sources vol. 126, pp. 76-87.

8) Burt, A. C., Celik, I. B., Gemmen, R. S., Smirnov, A. V., Rogers, W.A. (2004b) “Cellto-Cell Variations with Increasing SOFC Stack Size," proceedings of Second International Conference on Fuel Cell Science, Engineering and Technology held June 14-16, 2004 Rochester, NY, pp. 31-38.

9) Costamagna, P. and Honegger, K., (1998), "Modeling of solid oxide heat exchanger integrated stacks and simulation at high fuel utilization," J. Electrochem. Soc., Vol. 145, No. 11, pp. 3995-4007.

10) Costamagna, P., Arato, E., Achenbach, E., and Reus, U., (1994), "Fluid dynamic study of fuel cell devices: simulation and experimental validation," Journal of Power Sources vol. 52, pp. 243-249

11) EG\&G Technical Services, Inc. (2002), Fuel cells handbook, Sixth Ed., USDOE, NETL, Morgantown, WV.

12) Ferguson, J.R., Fiard, J.M., and Herbin, R., (1996), “Three-dimensional numerical simulation for various geometries of solid oxide fuel cells," Journal of Power Sources vol. 58, pp. 109-122 
13) Gemmen, R. S., Liese, E., Rivera, J., Jabbari, F. and Brouwer, J., (2000), "Development of Dynamic Modeling Tools for Solid Oxide and Molten Carbonate Hybrid Fuel Cell Gas Turbine Systems," International Gas Turbine Institute meeting of the ASME, May 8-12, 2000.

14) Gemmen, R., Rogers, W., and Prinkey, M., (2000), “Application of a Computational Fluid Dynamics Code to Fuel Cells-Integrated SOFC Fuel Cell and Post Oxidizer," American Flame Research Committee (AFRC) International Symposium, Newport Beach, CA, USA, September 2000.

15) Gubner, A., Froning, D., Haart, B., and Stolten, D., (2003), "Complete modeling of kW-range SOFC stacks," ECS proceedings Vol. 2003-17, pp. 1436-1441.

16) Hirata, H., and Hori, M., (1996), "Gas-flow uniformity and cell performance in a molten carbonate fuel cell stack," Journal of Power Sources, Vol. 63 pp. 115-120.

17) Koh, J, Seo, H., Yoo, Y., and Lim, H., (2002), "Consideration of numerical simulation parameters and heat transfer models for a molten carbonate fuel cell stack," Chemical Engineering Journal, Vol 87, pp. 367-379

18) Krotz, D., (2003), Almost there: a commercially viable fuel cell, http://enews.lbl.gov/Science-Articles/Archive/MSD -fuel-cells.html. 
19) Larminie, J. and Dicks, A. (2003) Fuel Cell Systems Explained, $2^{\text {nd }}$ Edition, Wiley, West Sussex, England.

20) Lin, Z., Khaleel, M., Surdoval, W., and Collins, D. (2003) "Finite Element Analysis of Solid Oxide Fuel Cells: Coupled Electrochemistry, Thermal and Flow Analysis in MARC," proceedings of SECA Modeling and Simulation Training Session held August 29, 2003 Morgantown, WV.

21) Ma, Z., 2000, A combined differential and integral model for high temperature fuel cells, Ph.D. Thesis Georgia Institute of Technology.

22) Maggio, G., Recupero, V., and Mantegazza, C., (1996), "Modelling of temperature distribution in a solid polymer electrolyte fuel cell stack," Journal of Power Sources Vol 62, pp. $167-174$

23) Mills, A., (1995), Basic Heat and Mass Transfer, Irwin, Chicago.

24) Murthy, S. and Fedorov, A. (2003), "Radiation Heat Transfer Analysis of the Monolith Type Solid Oxide Fuel Cell,” Journal of Power Sources Vol 124, pp. 453-458.

25) Pakalapati, S. R. (2003) A numerical study of current distribution inside the cathode and electrolyte of a solid oxide fuel cell, MS Thesis, West Virginia University, Morgantown, WV. 
26) Prinkey, M. (2005) Private communication on July 26, 2005 at WVU, Morgantown, WV

27) Recknagle, K.P., Williford, R.E., Chick, L.A., Rector, D.R., and Khaleel, M.A. (2003) "Three-Dimensional Thermo-Fluid-Electrochemical Modeling of Planar SOFC Stacks Using the STAR-CD Commercial CFD Code," proceedings of SECA Modeling and Simulation Training Session held August 29, 2003 Morgantown, WV.

28) Siegel, R. and J. Howell, (1972), Thermal Radiation Heat Transfer, McGraw-Hill, New York.

29) Strakey, J. (2002) "SECA Program Overview," proceedings of $3^{\text {rd }}$ Annual Solid State Energy Conversion Alliance (SECA), March 21-22, 2002.

30) Surdoval, W. (2002) “SECA Core Technology Program," proceedings of $3^{\text {rd }}$ Annual Solid State Energy Conversion Alliance (SECA), March 21-22, 2002.

31) Valluru, S. (2005). Steady state thermal stress analyses of two-dimensional and threedimensional solid oxide fuel cells, Master's Thesis, West Virginia University, WV.

32) VanderSteen, J., and Pharoah, J. (2004), "The Role of Radiative Heat Transfer with Participating Gases on the Temperature Distribution in Solid Oxide Fuel Cells," Fuel Cell Science, Engineering, and Technology, June 14-16, 2004 Rochester, NY, pp. 483-490. 
33) Virkar, A., (2001), Introduction to Solid Oxide Fuel Cells (SOFC): Science and Technology, short course offered July 10-11, 2001 at West Virginia University

34) Virkar, A., Chen, J., Tanner, C., and Kim, J., (2000), "The role of electrode microstructure on activation and concentration polarizations in solid oxide fuel cells," Solid State Ionics, Vol. 131 pp. 189-198.

35) Wójtowicz, M., Katianeni, S., and Privette, R., (2002), "The 2001 symposium on recent advances in fuel cells," Fuel, Vol. 81 pp. 2147-2149.

36) Yakabe, H., Hishinuma, M., Uratani, M., Matsuzaki, Y., and Yasuda, I., (2000), "Evaluation and modeling of performance of anode-supported solid oxide fuel cell," Journal of Power Sources, Vol. 86 pp. 423-431.

37) Yuan, J., Rokni, M., and Sundén, B., (2003), “Three-dimensional computational analysis of gas and heat transport phenomena in ducts relevant for anode-supported solid oxide fuel cells," International Journal of Heat and Mass Transfer, Vol. 46 pp. 809-821.

38) Zhu, W., and Deevi, S., (2003), "Opportunity of metallic interconnects for solid oxide fuel cells: a study on contact resistance," Material Research Bulletin 38, pp. 957-972. 


\section{APPENDIX A: Counter-flow single-cell results}

Figures A.1 and A.2 depict some results obtained from the single cell counter-flow model. These results were obtained using a coarse grid of 5 computational volumes. Nodes 1-3 depict the active area of the fuel cell. These figures are for $\mathrm{t}=2 \mathrm{~s}$ and are not considered to be a steady state solution. For the fuel gas channel (Figure 3.7.1) the gas

flow is from left to right. The mass flowrate of $\mathrm{H}_{2}$ in this case was relatively small with respect to the specified total current, therefore the $\mathrm{H}_{2}$ utilization is approximately $100 \%$ and the $\mathrm{H}_{2}$ fuel is immediately consumed as it enters the active region of the fuel cell. Figure A.2 shows the concentration of $\mathrm{O}_{2}$ in the cathode gas channel where the flow is from right to left. Here it can be seen that the concentration of $\mathrm{O}_{2}$ remains constant until reaching the control volume corresponding to the first volume in the anode gas channel. At this point $\mathrm{O}_{2}$ is consumed corresponding to the consumption of $\mathrm{H}_{2}$ in the anode gas channel. This simple case is therefore physically reasonable for the counter-flow geometry. 


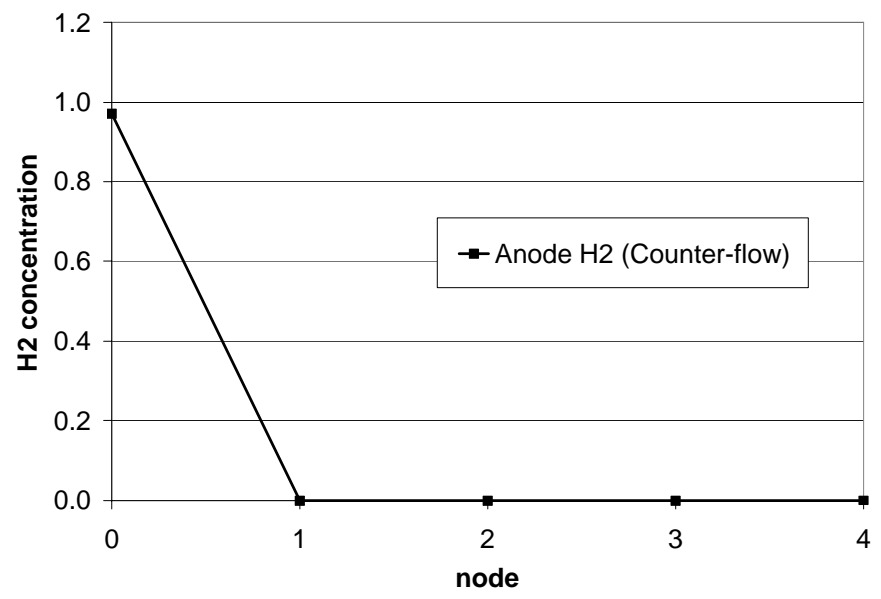

Figure A.1. Concentration of $\mathrm{H}_{2}$ in the anode gas channel vs. location for single counter-flow cell descritized with 5 computational volumes.

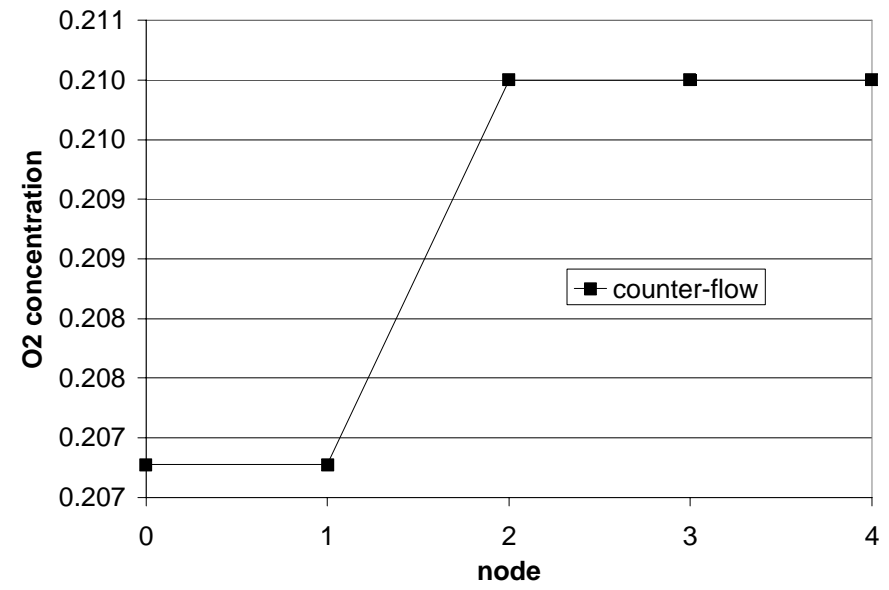

Figure A.2. Concentration of $\mathrm{O}_{2}$ in the cathode gas channel vs. location for single counter-flow cell descritized with 5 computational volumes. 
Figure A.3 and A.4 depict concentrations of $\mathrm{H}_{2}$ and $\mathrm{O}_{2}$ obtained from the counter-flow model for a case where the $\mathrm{H}_{2}$ utilization is $87 \%$. It can be seen in Figure A. 3 that the $\mathrm{H}_{2}$ concentration decreases over the entire active region of the fuel cell from computational node 1-3 as the gas flows from left to right. The $\mathrm{O}_{2}$ in Figure A.4 follows a similar trend as the gas flows from right to left. $\mathrm{H}_{2}$ and $\mathrm{O}_{2}$ concentrations remain constant outside of the active region where there is no chemical reaction or transport of $\mathrm{O}^{--}$from the cathode gas channel. Again these results are at $\mathrm{t}=2 \mathrm{~s}$ and do not necessarily depict the steady state solution for this case.

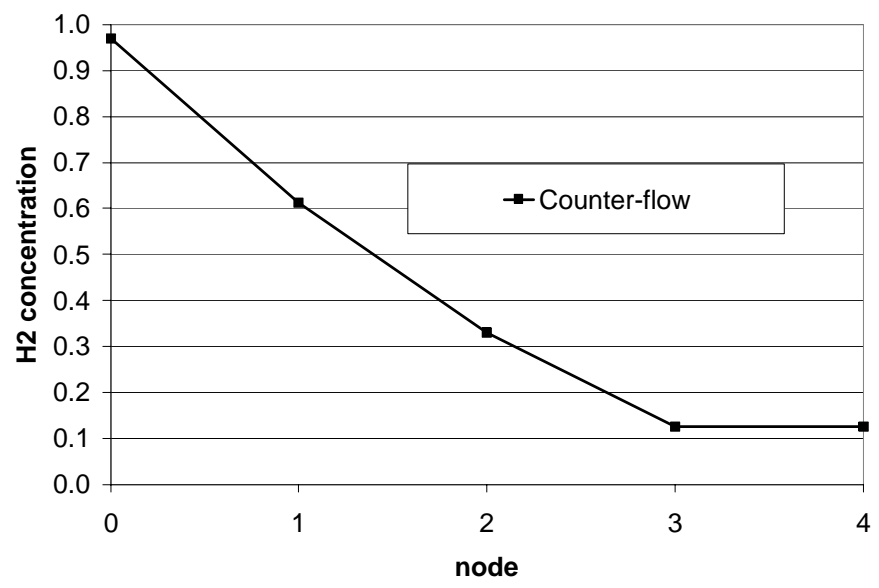

Figure A.3. Concentration of $\mathbf{H}_{2}$ in the anode gas channel vs. location for single counter-flow cell descritized with 5 computational volumes. 


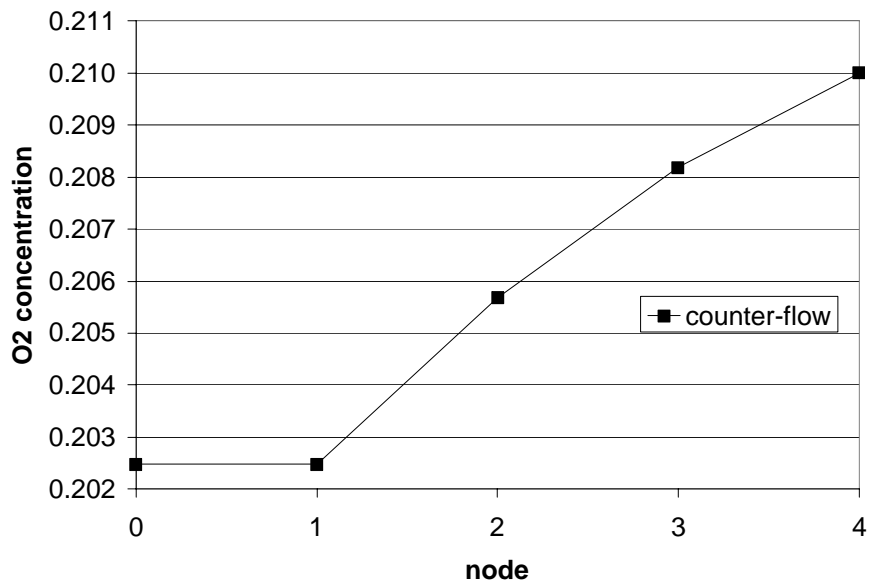

Figure A.4. Concentration of $\mathrm{O}_{2}$ in the cathode gas channel vs. location for single counter-flow cell descritized with 5 computational volumes.

These results predicted concentration profiles that are consistent for a counter-flow SOFC. 


\section{APPENDIX B: Numerical Method used for the Reduced Order 3-D Fuel Cell Model}

The total internal energy can be found from the energy equation

$e_{t o t, i}^{n+1}=\frac{e_{t o t, i}^{n} \rho_{i}^{n}}{\rho_{i}^{n}}-\frac{\Delta t}{\rho_{i}^{n} \forall_{i}} \sum_{k=1}^{n f f a c e s} e_{t o t, k}^{n} \rho_{k}^{n}\left(\vec{V}_{k}^{n} \cdot \hat{n}_{k}\right) A_{k}+\frac{\Delta t}{\rho_{i}^{n} \forall_{i}} \dot{Q}_{\text {net }, i}^{n}$

where, after neglecting potential energy, the total internal energy can be found from the absolute enthalpy

$e_{t o t, i}=e_{i}+\frac{P}{\rho_{i}}+\frac{\vec{V}^{2}}{2}=h_{i}+\frac{\vec{V}^{2}}{2}$

The enthalpy can be found from

$h(T)=\left.h^{o}\right|_{T_{r e f}}+\int_{T_{r e f}}^{T} C_{p} d T$

The net heat flux in can be found from a summation of the different fluxes calculated for each mode of heat transfer (conduction, convection, etc.).

$\dot{Q}_{\substack{n e t, i \\ \text { in }}}^{n}=\dot{Q}_{\text {cond }, i}^{n}+\dot{Q}_{c o n v, i}^{n}+\dot{Q}_{\text {wall }, i}^{n}+\dot{Q}_{m a s s, i}^{n}+\dot{Q}_{s, i}^{n}$

$\dot{Q}_{\text {cond }}=\sum_{i=0}^{\text {nfaces }} \frac{2 k * k_{i}}{\left(k+k_{i}\right)} \frac{A_{i}\left(T_{i}-T\right)}{\Delta x_{i}}$

$\dot{Q}_{\text {conv }, i}=\sum_{k=1}^{n f a c e s}\left(\left.\dot{m}_{k} e_{t o t, i}\right|_{\dot{m}_{i} \leq 0}+\left.\dot{m}_{k} e_{t o t, k}\right|_{\dot{m}_{i}>0}\right)$ 


$$
\begin{aligned}
& \dot{Q}_{\text {wall }, i}=\sum_{k=1}^{n \text { ffaces }} h_{c} A_{k}\left(T_{k}-T\right) \\
& Q_{\text {mass }, i}^{n}=\dot{m}_{\text {wall }, i}^{n} e_{\text {tot }, i}^{n}
\end{aligned}
$$

Mass fraction for species $\mathrm{s}=1$..ns- 1 can be found from species transport equation

$$
\begin{aligned}
& Y_{s, i}^{n+1}=\frac{Y_{s, i}^{n} \rho_{i}^{n} \forall_{i}}{\rho_{i}^{n} \forall_{i}}-\frac{\Delta t}{\rho_{i}^{n} \forall_{i}} \sum_{k=1}^{\text {nfaces }} Y_{s, k}^{n} \rho_{k}^{n}\left(\vec{V}_{k}^{n} \cdot \hat{n}_{k}\right) A_{k}+\frac{\Delta t}{\rho_{i}^{n} \forall_{i}} \sum_{k=1}^{\text {nfaces }} \dot{q}_{D s, i, k}^{n} A_{k}-\frac{\Delta t}{\rho_{i}^{n} \forall_{i}} \dot{\omega}_{s, i}^{n} A_{\text {wall }, i} M W_{s} \\
& \dot{\omega}_{s, i}^{n}=\frac{-i_{\text {den }, i}^{n}}{z F} \\
& \dot{q}_{D s, i, k}^{n}=-\rho D_{s} \frac{Y_{s, k}^{n}-Y_{s, i}^{n}}{\Delta x}
\end{aligned}
$$

the mass fraction for species ns can be found from definition of mass fraction

$$
Y_{n s, i}^{n+1}=1-\sum_{s=1}^{n s-1} Y_{s, i}^{n+1}
$$

The molecular weight of the mixture can then be found from

$$
M W_{i}^{n+1}=\frac{1}{\sum_{s=1}^{n s} \frac{Y_{s, i}^{n+1}}{M W_{s}}}
$$

The molar species concentration, $\mathrm{X}$, can be found from

$$
X_{s, i}^{n+1}=Y_{s, i}^{n+1} \frac{M W_{i}^{n+1}}{M W_{s}}
$$

The partial pressures for each species can then be found from the mole fraction and total pressure 
$P_{s, i}^{n+1}=\frac{X_{s, i}^{n+1}}{P_{i}^{n+1}}$

The gas constant for the mixture can be found from

$R_{i}^{n+1}=\frac{R_{u}}{M W_{i}^{n+1}}$

The mixture density can be found from the Ideal Gas Law

$\rho_{i}^{n+1}=\frac{P_{i}^{n+1}}{R_{i}^{n+1} T_{i}^{n+1}}$

The exit velocity can be found from Mass Conservation Equation

$$
\begin{aligned}
v_{\text {exit }, i}^{n+1} & =\frac{1}{A_{\text {exi }, i} \rho_{i}^{n+1}} \frac{\rho_{i}^{n+1} \forall_{i}-\rho_{i}^{n} \forall_{i}}{\Delta t}+\frac{1}{A_{\text {exit }, i} \rho_{i}^{n+1}} \sum_{k=1}^{n f a c e s} \rho_{k}^{n}\left(\vec{V}_{k}^{n} \cdot \hat{n}_{k}\right) A_{k}-\frac{1}{A_{\text {exit }, i} \rho_{i}^{n+1}} \dot{m}_{\text {wall }, i}^{n} \\
m_{\text {wall }, i}^{n+1} & =\sum_{s=1}^{n s} \dot{\omega}_{s, i}^{n} A_{\text {wall }, i} M W_{s}
\end{aligned}
$$

The pressure drop can be calculated from the Conservation of Momentum Equation

$$
\frac{\Delta P}{\Delta x}=-\frac{v_{i}^{n+1} \rho_{i}^{n+1} \forall_{i}-\rho_{i}^{n} v_{i}^{n} \forall_{i}}{\Delta t}-\sum_{k=1}^{n f a c e s} v_{k}^{n} \rho_{k}^{n}\left(V_{k}^{n} \cdot \hat{n}_{k}\right) A_{k}+C_{f} \frac{1}{2} \rho\left(v_{i}^{n}\right)^{2}
$$

where the friction coefficient is

$$
\begin{aligned}
& C_{f}=f(\mathrm{Re}) \\
& \mathrm{Re}=\frac{\rho v d}{\mu}
\end{aligned}
$$




\section{APPENDIX C: Cross-Flow Implementation based on MCMP scheme}

To accomplish the solution of the cross-flow problem, it's been decided to implement the so-called Multi-Component Multi-Physics (MCMP) scheme. In this approach the domain is split into control-volumes of variable sizes. Each control volume can implement it's own balance equation. This is done by introducing multiple components and associated physical models and assigning a model-tag for every control volume. The components are implemented in a Component-class, and its sub-classes, where each sub-class implements a particular component with a particular model. It is similar to the approach used in MulPhys simulation system (see mulphys.com).

\section{Geometry definition}

A volume pixel (voxel) approach was used whereby a pixel is used to represent a discrete volume and has a specific component type. These voxel are also known as elements. The collection of the control volumes (CVs) is contained inside geometry class Geom, which in a simplified form can be implemented as:

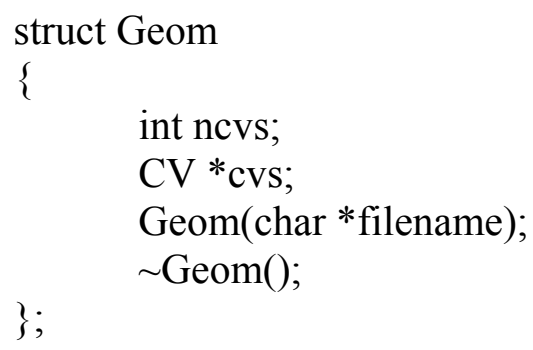


Where ncvs is the number of CVs and cvs is the array of all the control volumes retrieved from the underlying voxel-grid supplied by the GUI. Each control volume contains the information on its type, number of faces, array of area vectors for all faces, array of all local variables relevant to the model of this type, array of pointers to neighbor control volumes, and methods within its class:

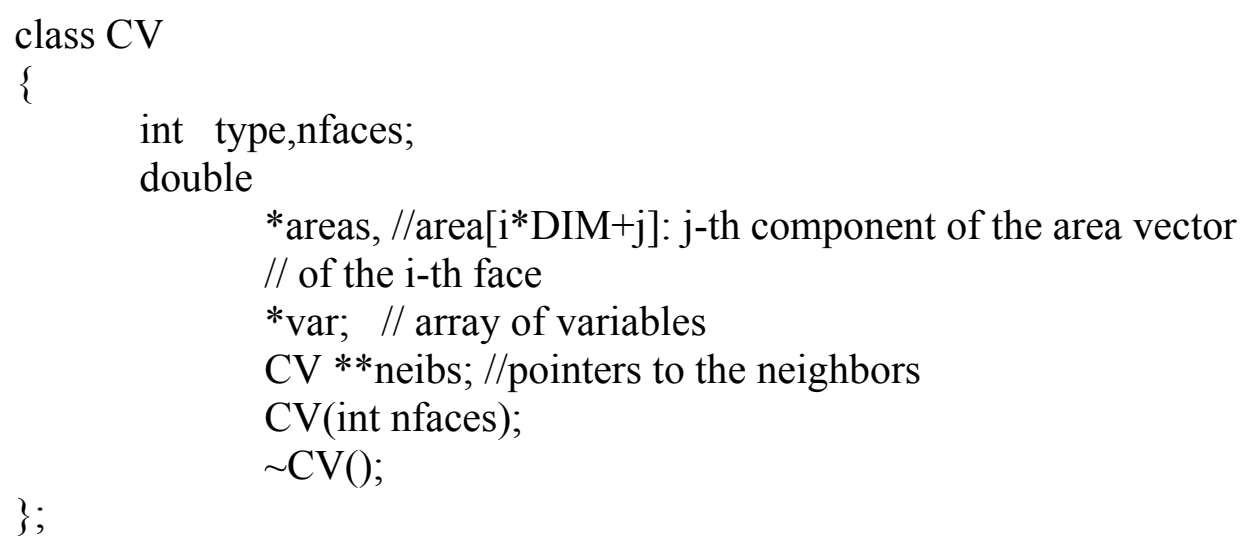

In an alternative implementation the area vectors can be retrieved from the separately stored list of all faces, in which case the Face-class and pointers to the faces should be introduced into the CV class.

The extraction of control-volumes from the voxel grid is realized through a special CVsegmentation algorithm. 


\section{Model definition}

Model is a combination of variables and methods (algorithms) to update them. Each component can have its own set of variables and methods, and is realized as a separate sub-class of Component-class. For example, for a planar fuel-cell design, the list of components can be given in terms of enumerative variable names:

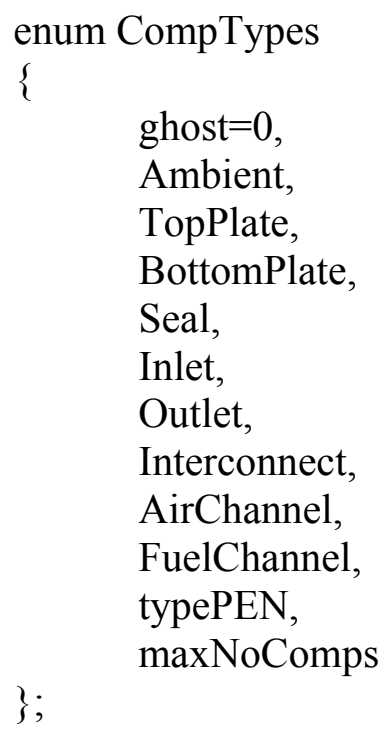

The component class contains specification of component type, number of control volumes ncvs, which belong to this component, and the array of pointers pointing to the respective control-volumes, cvs:

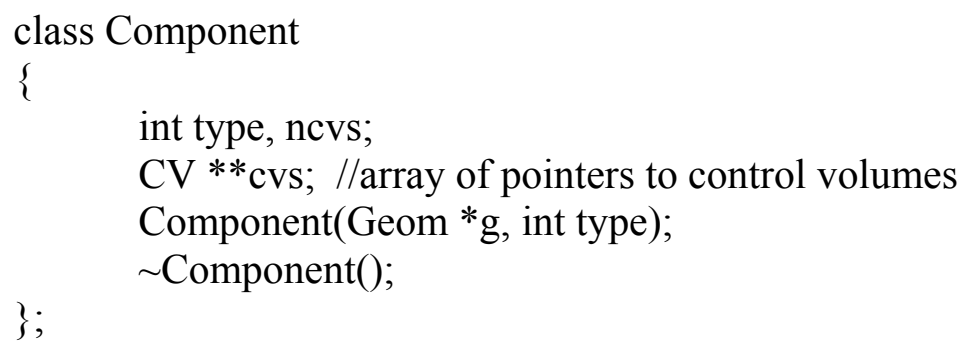


The constructor of the class requires access to geometry, which is supplied by the GUI in form of a control-volume grid. It performs a scan of the CV-grid and constructs the pointer array to the control volumes which belong to its type.

Since components, like PEN or air-channel can be represented by different models, each particular component is implemented as a child of the Component class, with variable names related to its model encapsulated inside the class:

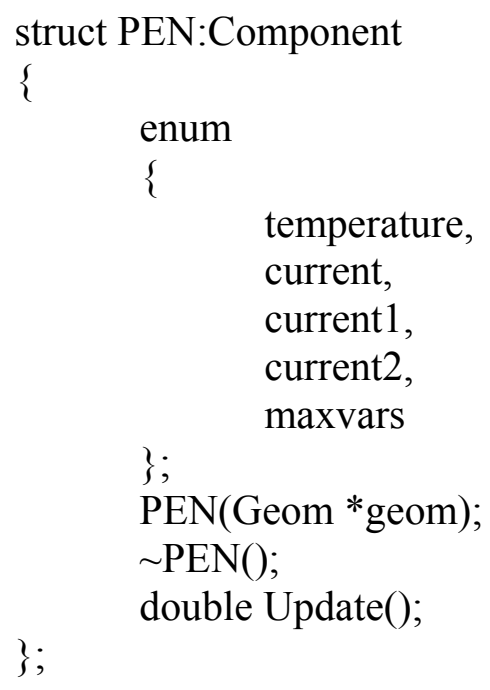




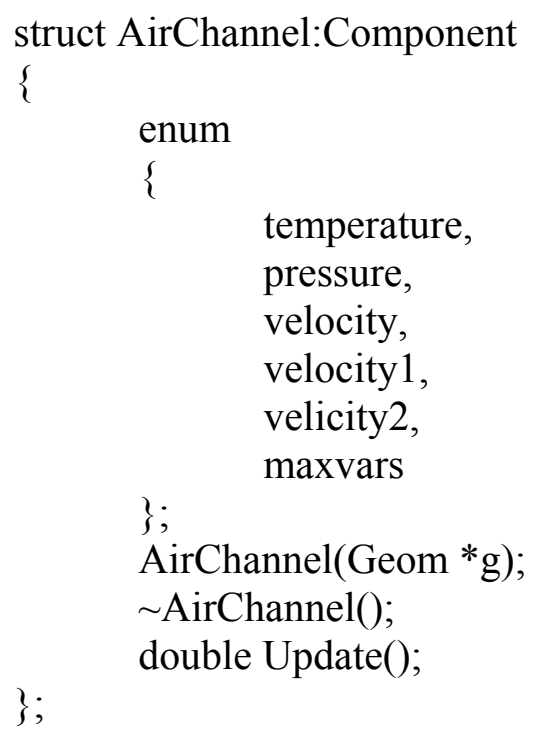

The Update function realizes the solution procedure, whereby fluxes through the CV faces are computed for specific variables and then the balance equation is solved. The Update function returns a residual, or the miss-balance, which then can be used in a global solution loop.

Here is a simple example of geometry loading, component initializing and solving sequence for two components: PEN and AirChannel:

Geom geom("geom.dat");

PEN pen(\&geom);

AirChannel air(\&geom); double error $=0.0$;

do

\{ error=pen.Update()+air.Update(); \} while (error>minerror);

This approach will enable to run a multi-dimensional control-volume based simulation using different physical models in different parts of space. For instance, computation 
procedures for solving fuel cell electro-chemistry in the PEN region will be adopted from the NETL code, while the procedures for solving heat and current transport in the interconnect region and flow in air/fuel channels can be solved using simple Poisson solvers or channel flow approximations.

A double reference system allows for association of models and components from a global and local perspective. Each component (Interconnect, Gas Channel, PEN, etc.) and model (Momentum, Pressure, Energy, etc.) is associated through two pointer arrays. The local model array allows for each component to reference the relevant models using an component specific index. The global model array was developed to allow the local model index to be determined from the global model "id" without requiring excessive looping during execution. Each local and global model "id" is now cross-referenced to decrease the computational effort required. This approach allows for significant performance improvements with a small increase in memory requirements.

\section{Psuedo Code of Overall Program Flow}

Initialize

Setup::Init();

Setup Components

Setup Geometry

Initialize Components

Initialize Models

Set initial variable values

Read restart if restarting

Determine number of iterations from time, endtime, and dt.

\section{Begin main loop}

Call Update function for each model passing time argument 
Solve energy equation for temperature

Solve momentum equation (mass continuity equation) for velocity

If print condition is true then print selected variable values

Increment time by $\mathrm{dt}$

End main loop

Save variable data

Delete components

End Program

\section{Psuedo Code for Energy Equation Update Function}

Newtime passed as argument

Assign static Boolean flags for each CV

bSolveCV[MAXCELLS],

bGasCV[MAXCELLS],

bGasNeibCV[MAXCELLS][MAXNEIGHBRS]

Begin loop for time $<$ newtime increment by model dt

Initialize normalized residual to 0.0

Begin looping through $\mathrm{CV}$

If bSolveCV is false skip to next $\mathrm{CV}$

Retrieve current Temperature, Cp, density, conductivity, CV center location, volume, and velocity vector.

Initialize total heat flux to 0.0

Begin looping through faces

Determine type of neighbor

Determine area of face

If neighbor is "Ghost" cell and current cell is air or fuel gas outlet Add convection to total heat flux

Retrieve current variable data for neighbor

Determine heat flux due to conduction and add it to total heat flux

If $\mathrm{CV}$ is gas and neighbor $\mathrm{CV}$ is gas then

Determine convection and add it to total heat flux

If $\mathrm{CV}$ is solid and neighbor $\mathrm{CV}$ is gas then

Determine wall heat flux based on heat transfer coefficient

Add wall heat flux to total heat flux

If $\mathrm{CV}$ is gas and neighbor $\mathrm{CV}$ is solid then

Determine wall heat flux and add it to total heat flux

End looping over faces

If Interconnect or PEN add appropriate heat source to total heat flux

Determine new temperature from current temperature and total heat flux

Calculate normalized temperature change and save largest as normalized residual

End looping over CV 
End looping for time

Psuedo Code for Momentum Equation Update Function

Newtime passed as argument

Assign static Boolean flags for each CV

bSolveCV[MAXCELLS],

bGasCV[MAXCELLS],

bGasNeibCV[MAXCELLS][MAXNEIGHBRS]

Begin loop for time $<$ newtime increment by model dt

Begin looping over $\mathrm{CV}$

Retrieve current density, velocity vector

Initialize total mass flow out to 0.0

Begin looping over faces

Determine area of face

Determine velocity magnitude

If bGasNeibCV true

Retrieve neighbor variable data

Determine mass flow rate out of the $\mathrm{CV}$ and add to total

If air or fuel channel and neighbor is PEN

Determine appropriate mass source or sink

End looping over faces

Set new velocity vector

End looping over CV

End looping for time

\section{Calculation of Temperature}

The overall heat rate is found from

$\dot{Q}=\dot{Q}_{\text {cond }}+\dot{Q}_{\text {conv }}+\dot{Q}_{\text {wall }}+\dot{Q}_{\text {mass }}+\dot{Q}_{s}$

where $\dot{Q}_{\text {cond }}$ is the net heat flux due to conduction, $\dot{Q}_{\text {conv }}$ is the net heat flux due to convection, $\dot{Q}_{\text {wall }}$ is the wall heat flux, $\dot{Q}_{\text {mass }}$ is the heat flux associated with mass 
transported through the wall, and $\dot{Q}_{s}$ is the heat source term. These net heat fluxes are found from the following relations.

$\dot{Q}_{\text {cond }}=\sum_{i=0}^{\text {nneibs }} \frac{2 k * k_{i}}{\left(k+k_{i}\right)} \frac{A_{i}\left(T_{i}-T\right)}{\Delta x_{i}}$

$\dot{Q}_{\text {conv }}=\sum_{i=1}^{\text {nneibs }}\left(\left.\dot{m}_{i} c_{p} T\right|_{\dot{m}_{i} \leq 0}+\left.\dot{m}_{i} c_{p} T_{i}\right|_{\dot{m}_{i}>0}\right)$

where the mass flow rate is calculated from the velocity and area vectors

$$
\begin{aligned}
& \dot{m}_{i}=\frac{\left(\vec{V} \cdot \vec{A}_{i}\right)}{\left|\vec{A}_{i}\right|} A_{i} \rho \\
& \dot{Q}_{\text {wall }}=\sum_{i=1}^{\text {nneibs }} h_{c} A_{i}\left(T_{i}-T\right)
\end{aligned}
$$

The temperature at the next time level $(j+1)$ is found from

$$
T^{j+1}=T^{j}+\frac{\dot{Q} d t}{C_{p} \rho \forall}
$$




\section{Calculation of Velocity}

Assuming incompressible steady state flow the velocity can be calculated from the mass continuity equation. The flow rate of mass leaving through the wall was derived given a constant wall velocity.

$\dot{m}_{\text {wall }}=V_{\text {wall }} A_{\text {wall }} \rho$

where $\mathrm{V}_{\text {wall }}$ is the velocity of gases leaving the $\mathrm{CV}$.

The mass flow rate of gas leaving the volume is equal to the sum of the mass flow rate into the volume (found by looping through the neighbors) minus the mass lost through the wall. The normal vector for each surface of the control volume can be found from the area vector, $\vec{A}_{i}$.

$\hat{n}_{i}=\frac{\vec{A}_{i}}{\left|\vec{A}_{i}\right|}$

$\dot{m}_{\text {out }}=\sum_{i=1}^{\text {nneibs }} \rho_{i}\left(\vec{V}_{i} \cdot \hat{n}_{i}\right) A_{i}-\dot{m}_{\text {wall }}$

$V_{\text {exit }}=\frac{\dot{m}_{\text {out }}}{\rho A_{\text {exit }}}$ 


\section{APPENDIX D: User Guide for Reduced Order 3-D Fuel Cell Model}

\section{Outline}

D.1 Introduction

D.1.2 Overview of file contents

D.2 Modifying the Code

D.2.1 Changing model parameters

D.2.2 Defining new components

D.2.3 Adding new models

D.3 Running the model

D.4 Post-Processing

\section{D.1 Introduction}

This guide is provided for the benefit of those who may need to use or modify the Reduced Order 3-D Fuel Cell Model for future studies or research. It is anticipated that this resource will be used as part of an appendix but for generality will be presented as a stand-alone document. For any theoretical or application questions however the user is directed to the dissertation by Burt (2005). The Reduced Order 3-D Fuel Cell Model implements a novel paradigm presented as the Multi-Component Multi-Physics (MCMP) Scheme and was written in $\mathrm{C}++$. Therefore it is assumed that the user has a basic operating knowledge of $\mathrm{C}++$.

A brief history of what led to the development of the model is as follows. Originally a single cell 1-D fuel cell model was developed at NETL by Dr. Randall Gemmen. The code was 1-D and saved computational effort by resolving variable variations in the 
stream-wise direction. The geometry was defined by four components; interconnect, air gas channel, fuel gas channel, and PEN (Positive electrode, Electrolyte, and Negative electrode) assembly. All electrochemical reactions were treated as occurring in the PEN thus heat generation term resulting from the total change in entropy was added to the PEN control volume and not divided and added to each electrode separately. Ohmic heating was introduced as a source term in the energy equation for solid components like the PEN and interconnects. Conduction however was neglected. This was based on the assumption that the heat convection in the gas dominates the solid conduction and therefore conduction could be neglected. Individual species equations were solved for the mass fraction of hydrogen, oxygen, water, and nitrogen in air and fuel gas channels. The governing equations are presented in Gemmen et al. (2000).

The single cell 1-D model was expanded to solve stacks of planar SOFC. The resulting code was referred to as the Pseudo 2-D Fuel Stack Model. This was accomplished using domain decomposition where each fuel cell unit was solved separately as an individual process. Appropriate boundary conditions were passed from process to process to allow for coupling of the solutions. This model was considered to be pseudo 2-D because although the solution provides some idea of variations that occur within the stack the detail is very coarse. Each component represented by a single control volume as the stack is traversed. Like the single cell 1-D fuel cell model specific detail is only resolved along the stream-wise direction. Each cell in the stack was assumed to have no variation in the third axial direction. This proved to be the limitation that required the development of a new model. 
Figure D.1.1 depicts the three common planar fuel cell configurations; which are co-flow, counter-flow, and cross-flow. Channels were etched into each interconnect to facilitate the flow of fuel and oxidizer to the porous anode and cathode electrodes. These channels allowed for the development of three basic configurations. These configurations are given names commonly used for heat exchangers. It can be seen in the figure that for the coflow case the fuel and air channels flow parallel to each other and in the same direction. For the counter-flow case the channels are again parallel to each other but the flow is in opposite directions. The cross-flow configuration has fuel and air channels crossing perpendicular to one another. The pseudo 2-D stack model was expanded to solve both co-flow and counter-flow configurations but lacked the required three dimensionality needed to solve a cross-flow geometry. Thus there was a need to develop a Reduced Order 3-D Fuel Cell Model to study all three configurations.

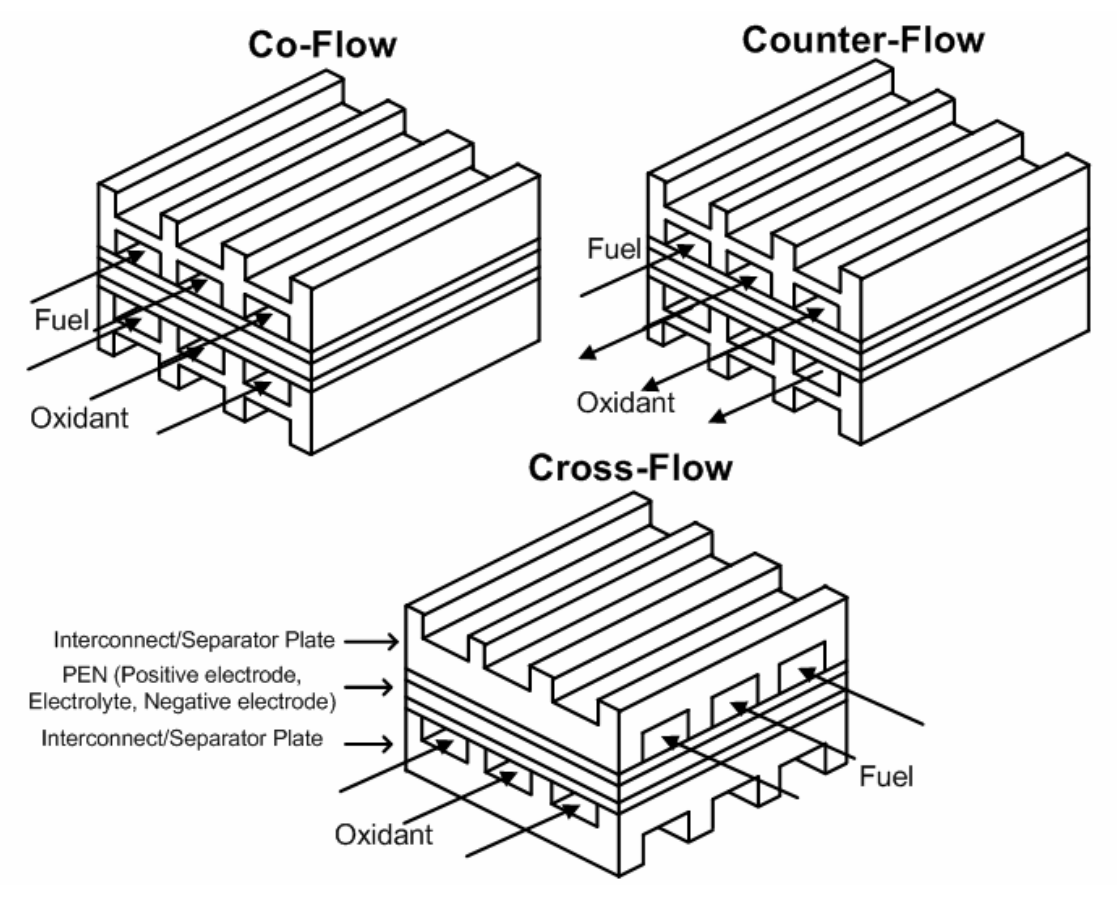

Figure D.1.1. Three common planar fuel cell configurations. 
The Reduced Order 3-D Fuel Cell Model solves the same governing equations that were previously used in the Pseudo 2-D stack Model. A Multi-Component Multi-Physics (MCMP) scheme was used whereby the user is able to easily introduce new components and physical models without the need to make many changes. New components can easily take advantage of existing models by including them in their constructor.

The energy equation is solved in 3-D and takes into account fluxes through all faces of each control volume. Species transport and channel flow is solved using simplified 1-D models. Like the previous models, all the electrochemistry is accounted for in the PEN. This reduces model accuracy by not accurately solving the details of the porous anode and cathode.

\section{D.1.2 Overview of file contents}

Table D.1.2.1. files composing the Reduced Order 3-D Fuel Cell Model.

\begin{tabular}{|c|c|}
\hline Makefile & Organizes the compilation and linking process \\
\hline Comm.h and Comm.cc & Contains the MPI communication functions \\
\hline comp.h and comp.cc & Contains the component definitions \\
\hline ECM.h and ECM.cc & Contains the electrochemistry model \\
\hline geom.h and geom.cc & Contains the geometry \\
\hline main.h and main.cc & Contains the setup and main execution loop \\
\hline math.h and math.cc & Contains useful math functions \\
\hline model.h and model.cc & Contains all models except the electrochemistry \\
\hline setup.h and setup.cc & Contains some initialization functions \\
\hline inpasc.geo & Geometry input file \\
\hline
\end{tabular}




\section{D.2 Modifying the Code}

The following sections will discuss three common changes that future users might want to make, these are: (1) changing model parameters, (2) Defining new components, and (3) adding new models.

\section{D.2.1 Changing model parameters}

There are many variables and parameters that users may be interested in changing. The following tables, organized by file, list where the user can find some common variables.

Table D.2.1.1. lists of variables initialized in main.cc

\begin{tabular}{|c|c|}
\hline $\mathrm{nx}, \mathrm{ny}, \mathrm{nz}$ & $\begin{array}{c}\text { Number of nodes in each direction. These are used by } \\
\text { Geom() to create generic geometry. The inpasc.geo file } \\
\text { eliminates the need for the user to define these variables } \\
\text { here. [1] }\end{array}$ \\
\hline O2massfrac, H2massfrac & $\begin{array}{c}\text { Mass fractions of } \mathrm{O} 2 \text { and } \mathrm{H} 2 \text { at the air and fuel gas channel } \\
\text { inlet. [1] }\end{array}$ \\
\hline airtemp, fueltemp & Air and fuel inlet temperature $[\mathrm{K}]$ \\
\hline $\begin{array}{l}\text { MWO2, MWN2, MWH2, } \\
\text { MWH2O }\end{array}$ & Molecular weight of various species. [kg/kmole] \\
\hline hcAir, hcFuel & $\begin{array}{l}\text { Convection heat transfer coefficient for air and fuel gas } \\
\text { channel. }[\mathrm{J} / \mathrm{m} 2-\mathrm{K}-\mathrm{s}]\end{array}$ \\
\hline CpAir, CpFuel & Specific heat of air and fuel. $[\mathrm{kJ} / \mathrm{kg}-\mathrm{K}]$ \\
\hline kAir, kFuel & Conductivity of air and fuel. $[\mathrm{J} / \mathrm{m}-\mathrm{K}-\mathrm{s}]$ \\
\hline $\begin{array}{l}\text { airv0, airv1, airv2, fuelv0, } \\
\text { fuelv1, fuelv2 }\end{array}$ & $\begin{array}{l}\text { Air and fuel channel inlet velocity vector components. [m/s] } \\
\text { This can also be specified using total mass flowrate using } \\
\text { massflowrate/(density*Area*number of channels) }\end{array}$ \\
\hline
\end{tabular}




\section{D.2.2 Defining new components}

This is a slightly tricky procedure but definitely not impossible. Use the following six steps and the existing components as a guideline for inserting a new one.

1) Add an entry to enum Components in main.h.

2) Add structure for component in comp.h. The structure should have the constructor and destructor functions for the component.

3) Add constructor and destructor to comp.cc. This is where you select the models to be solved in the component.

4) Create an instance in main() located in main.cc

5) Make sure you unallocated memory by including delete at end of main() in main.cc

6) Use setVar() to initialize appropriate model variables in main.cc

\section{D.2.3 Adding new models}

Follow a similar procedure to adding a component.

1) Add the model to enum Models in main.h.

2) Add an instance to main() in main.cc.

3) Add structure for model in model.h. Structure should include constructor and destructor and necessary function headers.

4) Add model constructor and destructor with Update() in model.cc

5) If appropriate add Update() to main() inside main while loop in main.cc.

6) Use set $\operatorname{Var}()$ to initialize model variables in main.cc

\section{D.3 Running the model}

Compile using makefile. Start the run using the executable. Use mpirun - np $<$ number of

processors $><$ executable name $>$ or the mpirun GUI to start a parallel run on a single computer to solve a stack of cells. To start a parallel run on a computer cluster will require submitting a batch job to the queue system. This procedure is normally explained by the system administrator. 


\section{D.4 Post-Processing}

Total current, voltage, and load resistance for each cell along with other selected information is displayed to the standard output interface. Generally it is necessary to capture these outputs using the $>$ operator in linux. For example "mpirun $-\mathrm{np} 4$ xfs.exe $>$ run.dat" will dump the output messages to a data file named run.dat. A successful run of the stack model may result in several data files. These can be variable matrix data or point data for monitoring a specific variable and location. These are described below.

Variable data can be written in a matrix format readable by TECPLOT using SaveVarMatrix() in main.cc. The third argument contains a user defined identifier string. This usually refers to variable being written in that file. After execution this function will produce a file with the mat- prefix for matrix and the dat suffix to denote that it is a data file.

Monitoring points can be defined in model.cc. Future development of the code may include the construction of a more permanent function for achieving this goal. Until this is accomplished the user may upon identifying the appropriate cell open a file and write the data. This is currently being done near the end of the EnergyEqu.Update() to monitor the changes in temperature at various points along the center of the cell/stack. This data is being stored in a file with the prefix mon- to denote that it is monitor data that varies with time. The data is concatenated to the output file in data pairs containing the time and variable value. These monitor data files can be easily read in Microsoft Excel. 